\title{
Development Of A Supercritical Carbon Dioxide Brayton Cycle: Improving VHTR Efficiency And Testing Material Compatibility
}

Final Report

Chang $\mathrm{H}$. Oh Thomas Lillo William Windes Terry Totemeier Bradley Ward Richard Moore Robert Barner

March 2006

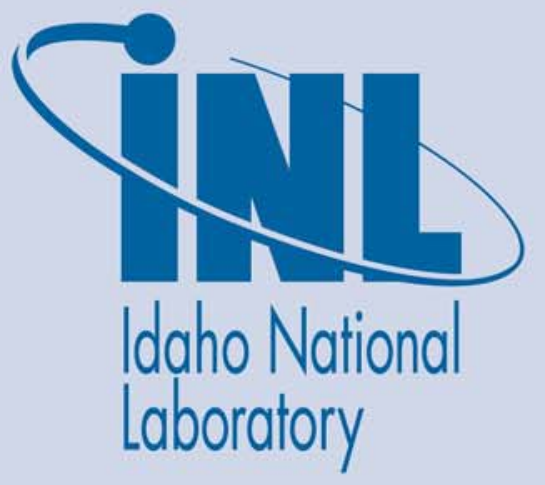

The INL is a U.S. Department of Energy National Laboratory operated by Battelle Energy Alliance 



\title{
Development of a Supercritical Carbon Dioxide Brayton Cycle: Improving VHTR Efficiency and Testing Material Compatibility
}

\author{
Chang H. Oh \\ Thomas Lillo \\ William Windes \\ Terry Totemeier \\ Bradley Ward \\ Richard Moore \\ Robert Barner
}

March 2006

Idaho National Laboratory Idaho Falls, Idaho 83415 



\section{NUCLEAR ENERGY RESEARCH INITIATIVE}

\section{Development of a Supercritical Carbon Dioxide Brayton Cycle: Improving VHTR Efficiency and Testing Material Compatibility}

PI:

Collaborators:

Project Start Date: $\quad$ September 2002

Projected End Date: December 2005 Robert Barner
Chang H. Oh, Idaho National Laboratory (INL)

Thomas Lillo, William Windes, Terry Totemeier, Bradley Ward, Richard Moore,

Project Number: $02-190$

\section{EXECUTIVE SUMMARY}

Generation IV reactors will need to be intrinsically safe, having a proliferation-resistant fuel cycle and several advantages relative to existing light water reactor (LWR). They, however, must still overcome certain technical issues and the cost barrier before it can be built in the U.S. The establishment of a nuclear power cost goal of 3.3 cents $/ \mathrm{kWh}$ is desirable in order to compete with fossil combined-cycle, gas turbine power generation. This goal requires approximately a 30 percent reduction in power cost for stateof-the-art nuclear plants. It has been demonstrated that this large cost differential can be overcome only by technology improvements that lead to a combination of better efficiency and more compatible reactor materials.

The objectives of this research are (1) to develop a supercritical carbon dioxide Brayton cycle in the secondary power conversion side that can be applied to the Very-High-Temperature Gas-Cooled Reactor (VHTR), (2) to improve the plant net efficiency by using the carbon dioxide Brayton cycle, and (3) to test material compatibility at high temperatures and pressures. The reduced volumetric flow rate of carbon dioxide due to higher density compared to helium will reduce compression work, which eventually increase plant net efficiency.

\section{Research Objectives}

The project has two major objectives: The first objective is to develop a supercritical carbon dioxide $\left(\mathrm{S}-\mathrm{CO}_{2}\right)$ Brayton cycle and to improve the VHTR plant efficiency by using supercritical $\mathrm{CO}_{2}$. The target of the improved cycle efficiency is close to a 50\% that includes the hydrogen plant coupled to the VHTR and power conversion unit through the intermediate heat transfer loop. The second objective is to test material compatibility. The current VHTR reference design has a recommended core outlet temperature of $900^{\circ} \mathrm{C}$, based on a 600 -megawatt thermal. Because of the high temperature in the reactor and an intermediate heat exchanger, a material compatibility could be a technical concern. In order to resolve this concern, we need to investigate the material compatibility by high-temperature exposure to supercritical carbon dioxide. In this study, we propose to characterize the creep deformation of Inconel MA 754, 758, and Inconel 617 over a range of temperatures of 850 to $1050^{\circ} \mathrm{C}$ and stresses within the power law creep regime. We also propose to investigate the interaction of MA 754, 758, and Inconel 617 in supercritical $\mathrm{CO}_{2}$ using thermogravimetric analysis combined with surface analysis to examine the 
possible chemical interaction mechanism(s), e.g., breakdown of the passivating chromium $(\mathrm{Cr})$ oxide or carburization, at temperatures and pressures of interest.

\section{Report Content and Organization}

This final report highlights key accomplishments from this project. Section 1 provides introductory information about the project. Detailed information about the objectives and accomplishments may be found in Sections 2 through 4. Section 5 highlights results and conclusions that can be drawn from results obtained from each task. This executive summary is provided to highlight accomplishments from this research project.

\section{Key Program Accomplishments}

Key accomplishments from this three year program are highlighted in this section. This project consisted of threes- tasks for the VHTR. These tasks are to: 1) develop a S-CO2 Brayton cycle, 2) improve VHTR cycle efficiency, and 3) test candidate materials for corrosion and creep resistance. The primary activities and key accomplishments for each task are summarized below.

Note that these accomplishments include items required to meet task objectives outlined in the original proposal for this project and items that meet overall NERI objectives. As indicated below, this project not only advanced the state-of-art in research pertaining to the VHTR, but also helped prepare graduate students to join the nuclear engineering workforce.

Advanced gas reactor technology has been identified as one of the best passively safe, thermally efficient, proliferation resistant, modular reactor systems capable of electricity and hydrogen production as well as efficient burning of spent fuel. Internationally, the VHTR concept has become the top priority for implementation because of its inherent safety and near-term implementation feasibility. The U.S. Department of Energy (DOE) indicates that the Next Generation Nuclear Plant (NGNP), VHTR, will be built at the INL site by 2017. In order to resolve any first of a kind technical issue, this project consists of three major tasks with a number of subtasks under the major ones. All tasks have been performed on schedule and budget. The technical accomplishments from each task are summarized below:

Development of $\mathrm{S}-\mathrm{CO}_{2}$ Brayton Cycle: The $\mathrm{S}^{-\mathrm{CO}_{2}}$ Brayton cycle deals with high pressures and temperatures. At these conditions, an ideal gas law, using isentropic compression and expansion cannot be applied because of real gas effects associated with non-ideal compression and expansion processes. Therefore, there was a need to develop analytical equations for polytropic expansion and compression through a sequence of turbines and compressors, respectively. The developed set of equations is used for scoping analyses aimed at investigating the effect of the overall plant efficiency. For the detailed computation of the balance of plant (BOP) efficiency calculations, a $\mathrm{CO}_{2}$ database is required to make accurate calculations. We compared a number of equations of state and $\mathrm{CO}_{2}$ databases and determined that the NIST $\mathrm{CO}_{2}$ database is the most accurate and the properties are consistent with those referenced in Perry's Handbook.

In order to compare the plant efficiency depending on the power conversion configuration, the initial reference design is depicted in Figure ES-1. 


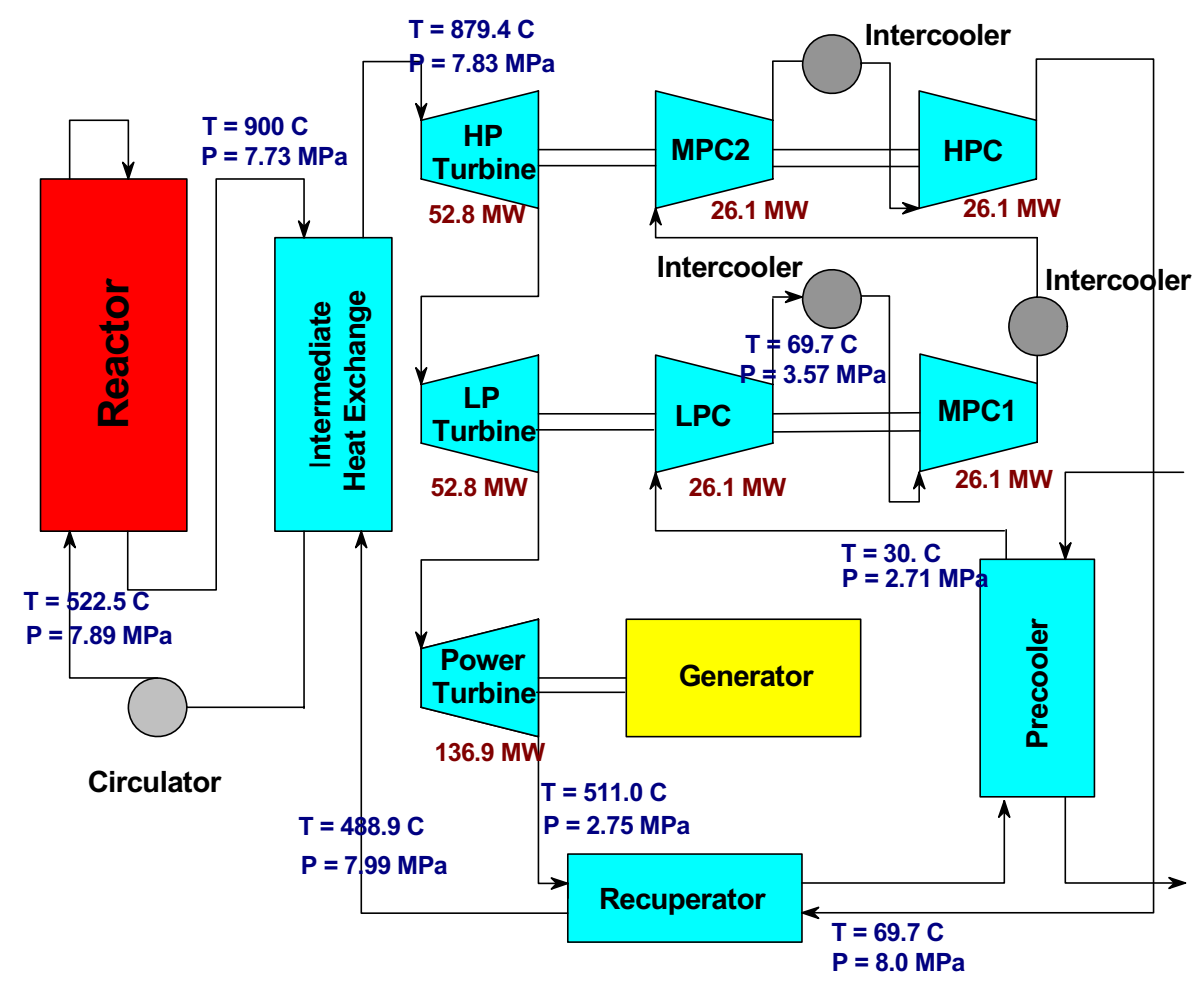

Figure ES-1. Three-shaft reference design.

We also investigated and compared Aspen Plus and HYSYS for BOP process optimization. Both codes agree well with conditions defined in a simple reference design. The deviation in results was less than $0.5 \%$. However, Aspen Plus is limited to isentropic expansion processes without multiple turbine performance curve capabilities. Therefore we decided to use the HYSYS code for our BOP calculations.

We also used a numerical model that was originally developed at Massachusetts Institute of Technology (MIT) using the Visual Basic computer language. This numerical model was revised by INL by implementing the NIST $\mathrm{CO}_{2}$ database and adding a reactor core pressure drop equation to the numerical model. The results from HYSYS were compared with those from the Visual-Basic (V-B) model. The results produced by both models agreed very well for the 3 -shaft baseline case. The HYSYS $\mathrm{CO}_{2}$ Brayton cycle model gives a $51 \%$ plant efficiency, which is an improvement over the $47 \%$ for the helium Brayton cycle using the same BOP layout. The improvement in efficiency is attributed to the reduced volumetric flow of $\mathrm{CO}_{2}$ over that of helium, which results in less compression work.

Improvement of VHTR Net efficiency: The objective of this task is to determine the overall plant cycle efficiency by the integration and optimization of each of the components used in the power conversion side. In order to perform this task in an efficient manner, our original reference design with a three-shaft turbo-machinery arrangement was used in a parametric study and optimization with helium as working fluid using HYSYS. In parallel to the use of HYSYS, the V-B model was used with an implementation of an appropriate friction pressure drop equation for a pebble bed reactor. This term is importance in determining the net power plant efficiency and is not directly calculated by the HYSYS model. A similar pressure drop equation can be input for a prismatic core of NGNP. After the helium Brayton Cycle loop was optimized a number of HYSYS simulations with $\mathrm{S}_{-} \mathrm{CO}_{2}$ were completed. 
A number of important parameters were investigated for this study. The parameters investigated are: various temperature differences across the reactor, reactor inlet temperatures, inlet cooling temperatures to compressors, effectiveness factor of the IHX and recuperator, efficiencies of the compressors, turbines, and other components. Results corresponding to various temperature differences across the reactor for a three-shaft $250 \mathrm{MW}$ thermal helium Brayton cycle using a $92 \%$ effectiveness factor for the intermediate heat exchange and $90 \%$ polytropic efficiency for the turbines and compressors, indicate that at a relatively low reactor outlet temperature $\left(850^{\circ} \mathrm{C}\right)$, the maximum cycle efficiency peaks at $45 \%$, which corresponds to a reactor inlet temperature of $520^{\circ} \mathrm{C}$. As the reactor outlet temperature is allowed to increase, the maximum efficiency increases to $51.5 \%$ at an outlet temperature of $1000^{\circ} \mathrm{C}$. For intermediate outlet temperature between $850^{\circ} \mathrm{C}$ and $1000^{\circ} \mathrm{C}$, the cycle efficiency increases from $45 \%$ to $51.5 \%$ with the corresponding reactor inlet temperature increasing from $520^{\circ} \mathrm{C}$ to $640^{\circ} \mathrm{C}$. The effect of compressor efficiency on the overall Brayton cycle efficiency was determined by varying the compressor efficiency from 90 to $94 \%$ using a constant reactor inlet and outlet temperature of 5000C and $900^{\circ} \mathrm{C}$, respectively. The results showed that the cycle efficiency increases from $48.2 \%$ for a compressor polytropic efficiency of $90 \%$ to $50.2 \%$ for a polytropic efficiency of $94 \%$. A practical way of reducing the compressor work is to keep the specific volume of the gas as small as possible during the polytropic compression. This can be achieved by maintaining the gas temperature as low as possible because specific volume is proportional to temperature. By dividing the compression process into stages and cooling the gas between stages, the total work done during the compression process is reduced. By reducing the compressor inlet temperature by $5^{\circ} \mathrm{C}$, the overall cycle efficiency increases by $0.65 \%$. We also investigated the sensitivity of the effectiveness of the intermediate heat exchanger (IHX) on the overall cycle efficiency. If the effectiveness of the IHX is improved from $90 \%$ to $92 \%$ at a core outlet temperature of $9500 \mathrm{C}$ and a core inlet temperature of $400^{\circ} \mathrm{C}$, for example, there is an initial improvement of the overall Brayton efficiency by $0.65 \%$. The IHX effectiveness has less impact on the efficiency compared to the compressor efficiency.

In order to validate the HYSYS and V-B models, a simple one-shaft Brayton cycle layout and reference design of the GTHTR300 was used. GTHTR300 is a direct cycle plant that consists of three subsystem modules including a reactor with a prismatic core, a gas turbine generator module with one turbine, one compressor, and a generator on a single shaft in a horizontal arrangement, and a heat exchanger module with one recuperator and one precooler as shown in Figure ES-2.

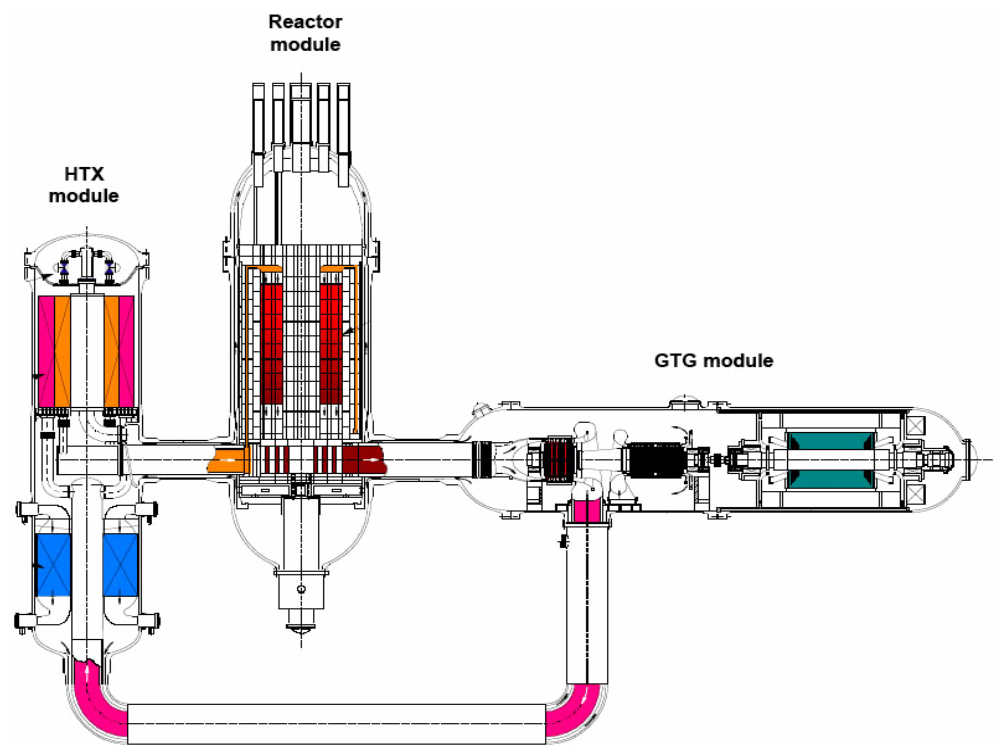

Figure ES-2. GTHTR300 Layout. 
Assumed values of turbine polytropic efficiency (92.8\%), compressor polytropic efficiency $(90.5 \%)$, recuperator effectiveness $(95 \%)$, and inlet compressor temperature $\left(28^{\circ} \mathrm{C}\right)$ were used along with same conditions of other parameters in both the V-B and HYSYS models. The V-B model gives lower net cycle efficiencies than those of HYSYS except at the maximum efficiency point. The one difference between the HYSYS and V-B models lies in the uses of different helium property database. The V-B model uses the NIST database while HYSYS uses an equation of state to define the helium properties. Then in order to check the accuracy of HYSYS simulation using $\mathrm{CO}_{2}, \mathrm{a} \mathrm{CO}_{2}$ pressure-enthalpy diagram was used. The results calculated by HYSYS agree very well with those calculated using the $\mathrm{CO}_{2}$ pressureenthalpy diagram.

A parametric investigation was made with supercritical $\mathrm{CO}_{2}$ cycle using a $250 \mathrm{MW}$ three-shaft reference design. Three different $\mathrm{CO}_{2}$ secondary system pressures of $6.3 \mathrm{MPa}, 13 \mathrm{MPa}$, and $20 \mathrm{MPa}$, give cycle efficiency of $48 \%, 49.3 \%$, and $50.3 \%$, respectively, which are not significantly different from each other.

Working fluids of helium for both direct and indirect cycle, nitrogen for indirect cycle, and CO2 for indirect cycle were investigated. The difference between the helium direct cycle and the indirect cycle was $50.9 \%$ vs. $48.7 \%$ respectively. Nitrogen gave a cycle efficiency of $45.5 \%$ while $\mathrm{CO}_{2}$ gave a cycle efficiency of $50.7 \%$. Total area ratio (total heat transfer area of working fluid / total heat transfer area of helium indirect cycle) gives, 0.65 for helium direct cycle, unity for helium indirect cycle, 1.32 for nitrogen indirect cycle, and 1.18 for $\mathrm{CO}_{2}$ indirect cycle at $20 \mathrm{MPa}$. Conclusions from the investigation are (1) among the three working fluids studied, $\mathrm{CO}_{2}$ has the highest cycle efficiency due to less compression. $\mathrm{CO}_{2}$ cycle also results in the smallest turbomachinery, and (2) helium direct cycle eliminates the IHX and consequently requires the smallest heat transfer area due to the higher heat capacity and thermal conductivity than those of the other fluids considered.

Theoretically a combination of reheat and intercooling increases the cycle efficiency in a closed loop. Preliminary multiple reheat with a number of intercooling were investigated using a molten salt (Flibe) in the primary side and helium in the power conversion loop.

This configuration yields a 56\% cycle efficiency. Further investigation using Flibe- $\mathrm{CO}_{2}$ is being considered.

The power conversion unit coupled with the hydrogen plant through an intermediate heat transfer loop is very important in VHTR. Therefore, we performed this extra task and included results in this report. The schematic of the combined cycle we investigated is depicted in Figure ES-3.

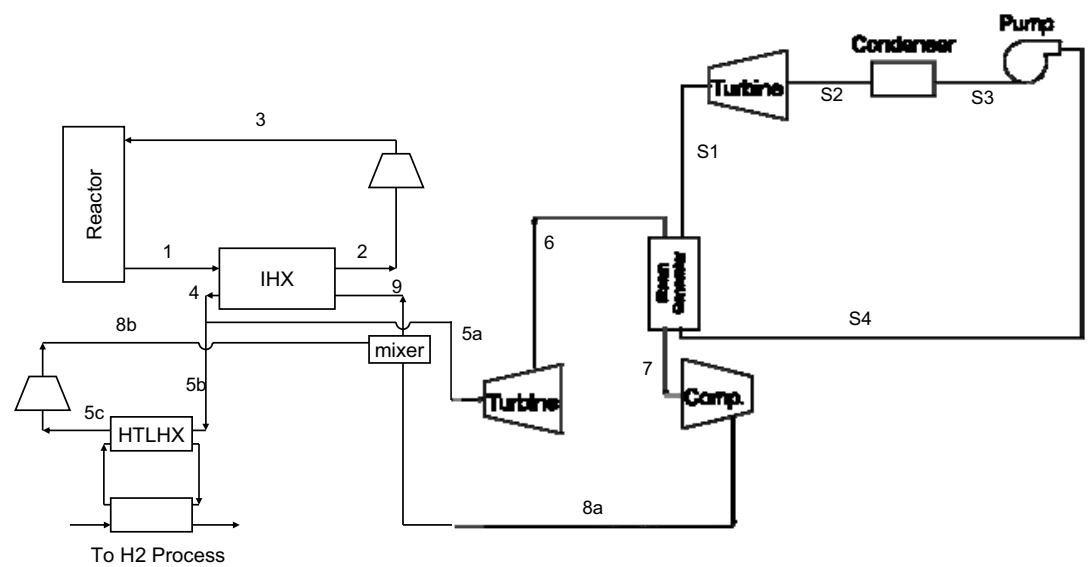

Figure ES-3. Schematic of the combined cycle. 
The primary side of the loop consists of a high temperature nuclear reactor, intermediate heat exchanger (IHX), and a circulator. The PCU configuration, illustrated in Figure ES-3, consists of; (1) a primary loop (2) an intermediate heat transport loop (HTL) in parallel with (3) the PCU with a Brayton top cycle consisting of a gas turbine, compressor and coupled to a Rankine bottoming cycle through a steam generator. The Rankine cycle consists of a steam turbine, condenser and a pump. This cycle was simulated using helium as the working fluid in the primary and intermediate heat transport loop. Helium, $\mathrm{CO}_{2}$ and the $\mathrm{N}_{2}$-He mixture were simulated in the PCU while water was used in Rankine cycle. The results indicate that (1) $\mathrm{CO}_{2}$ proved to be the best working fluid in terms of efficiency, with an efficiency of $48.76 \%$. Helium had an efficiency of $47.76 \%$ and the nitrogen-helium mixture had an efficiency of $47.24 \%$, (2) The turbomachinery work using $\mathrm{CO}_{2}$ was approximately $8.5 \%$ lower than the work when using helium and the mixture. $\mathrm{CO}_{2}$ also produced the smallest total heat exchanger volume which was $10 \%$ lower than the volume when using the nitrogen-helium mixture and $11 \%$ lower than the volume when using helium, and (3) Parametric studies demonstrated that the working fluids were equally affected by the working conditions within the cycle, except helium was less affected by pressure. The pressure study also highlighted that the combined cycle was not greatly effected by the pressure. Therefore, lower pressures could be used in the system to decrease component sizes with a small decrease in efficiency. The cycle was also the least affected as compared to the three-shaft and reheated cycles.

Materials Compatibility: Experimental studies were carried out on the high temperature mechanical properties, including the creep behavior, and the corrosion behavior of MA 754, an oxide dispersion strengthened nickel-base alloy with high creep resistance. Fabrication of this material is accomplished by consolidation of mechanically alloyed powder of yttrium oxide and a nickel/chrome alloy. Material in this work was consolidated via elevated temperature extrusion that resulted in microstructural variation within the extruded bar. Creep studies were carried out to elucidate the minimum creep rate/ applied stress relationship as well as the stress/rupture time relationship in direction parallel and perpendicular to the extrusion direction. Creep properties were significantly diminished in the direction perpendicular to the extrusion direction (referred to as the transverse direction). However, at $1000^{\circ} \mathrm{C}$, the creep properties in the transverse direction were still better than other high temperature alloys, such as I-617, I-800H and Nimonic 105. The stress for a given rupture time for the transverse direction of coarse-grained MA 754 was more than a factor 4 greater than the other high temperature alloys. The main deficiency with MA 754 are the very low creep strains at failure, especially in the transverse direction where creep strains at failure did not exceed 5\%. Creep failure was essentially brittle in nature - highly undesirable considering the target application is in a high pressure $\mathrm{CO}_{2}$ system. Fine grained MA 754 was also evaluated in an effort to increase the creep strain at failure without a large sacrifice in creep strength. The creep rates for the fine-grained MA 754 were significantly higher than the coarse-grained variety and were on the order of other high temperature alloys. Also, the creep strains at failure were still quite low and the strain resulted from cavitation. It was concluded that fine-grained MA 754 offered no advantage over the coarse-grained variety. In conclusion, this work showed that although MA 754 offers advantages through higher creep strength significant obstacles remain to be solved, e.g. alignment of elongated grains that give MA 754 its creep resistance with the primary loading direction of a component and improvement of defect tolerance/ductility.

Two supercritical $\mathrm{CO}_{2}$ corrosion systems were also designed, built and operated to evaluate the corrosion behavior of MA 754 at temperatures up to $1000^{\circ} \mathrm{C}$. One system allowed the testing of a large number of samples with different surface preparations as well as three different materials simultaneously without significant cross contamination. The other system used a specimen geometry resembling a pipe with supercritical $\mathrm{CO}_{2}$ flowing through the center and significant gradients in temperature and stress along and through the pipe, respectively, to provide a "real world" evaluation of the material response to operating conditions. 
Exposure of MA 754 to supercritical $\mathrm{CO}_{2}$ resulted in the formation of chromium oxide, the only thermodynamically stable compound at $1000^{\circ} \mathrm{C}$ in the presence of $\mathrm{CO}_{2}$. The growing corrosion layer appeared to reduce the corrosion rate to a value of $0.2 \mathrm{~mm} /$ year after 500 hours of exposure. However, exposure times were too short to determine the minimum corrosion rate for either coarse- or fine-grained MA 754. Near surface porosity developed, presumably from the diffusion of chromium out of the base metal, leaving behind porosity. No evidence of spalling of the corrosion layer or metal dusting was observed in this study, however, exposure times were relatively short. Although no evidence was obtained in this study to suggest that MA 754 is unsuitable for use in a supercritical $\mathrm{CO}_{2}$ Brayton cycle, longer term exposure tests are warranted to ensure breakaway corrosion processes, such as spalling or metal dusting, do not be come active prior to the end of the intended life cycle.

The commercial high temperature alloy, I-617, was also included in the supercritical $\mathrm{CO}_{2}$ corrosion study. Only one relatively short (175 hours) experiment was completed during the project. The corrosion rate was approximately $25 \%$ of the value for MA 754 for the same exposure time. The corrosion rate found in this study is thought to represent transient behavior, i.e. the steady state corrosion rate was not obtained. Significant intergranular corrosion was found in I-617 whereas MA 754 exhibited relatively uniform surface corrosion. As with MA 754, the main corrosion product was the formation of chromium oxide. Again, longer term experiments/exposures are needed to fully characterize the long term corrosion behavior and the possibility of break away corrosion processes, such as spalling and dusting. 


\section{CONTENTS}

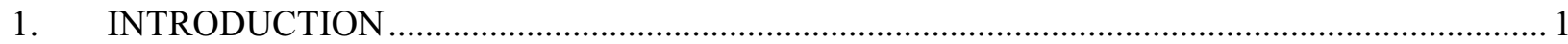

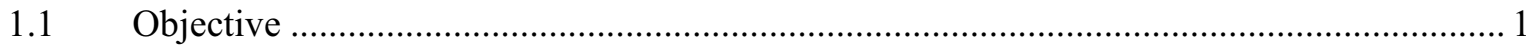

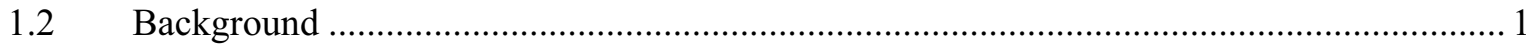

2. TASK 1: DEVELOPMENT OF $\mathrm{CO}_{2}$ BRAYTON CYCLE ..................................................... 3

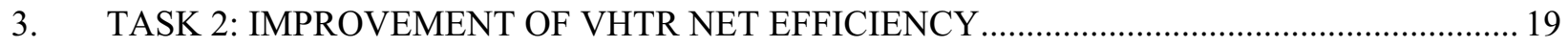

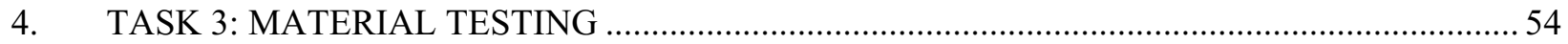

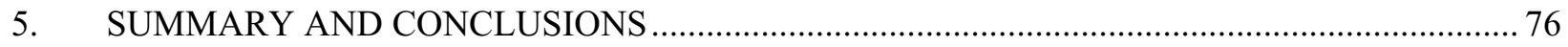

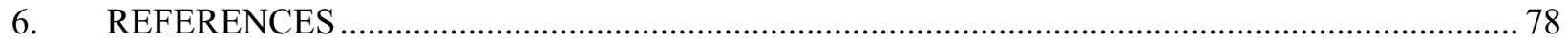

\section{FIGURES}

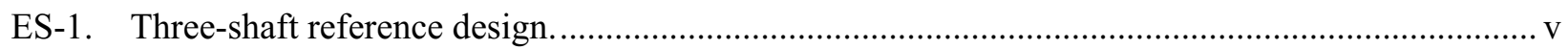

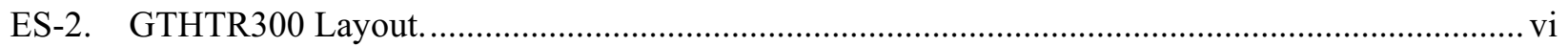

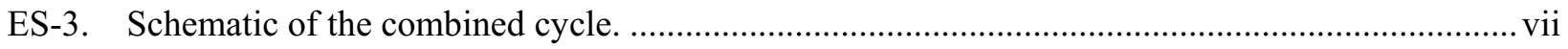

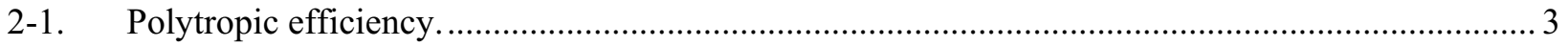

2-2. T-S diagram for the VHTR reference design in the power conversion side................................ 5

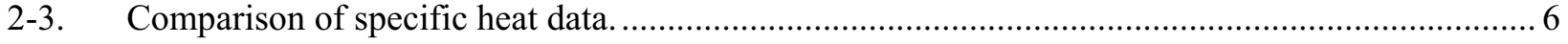

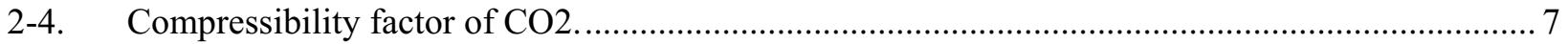

2-5. A comparison of calculated and reported fluid densities...................................................... 7

2-6. A comparison of calculated and reported specific enthalpies................................................. 8

2-7. HYSYS results for the baseline case with helium. ............................................................. 9

2-8. ASPEN PLUS results for the baseline case with helium...................................................... 9

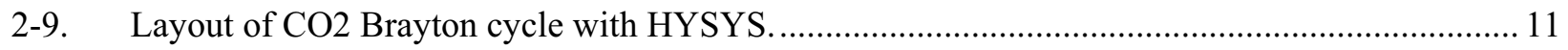

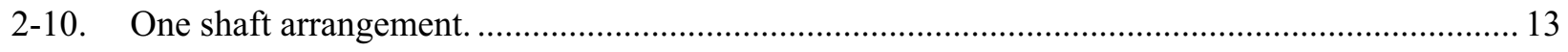

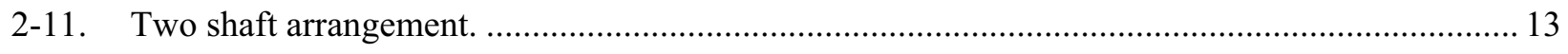

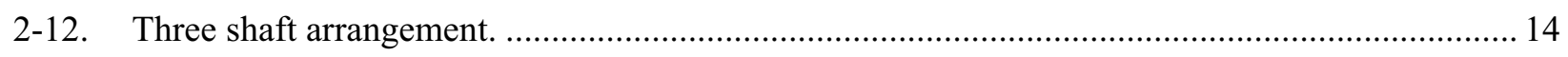




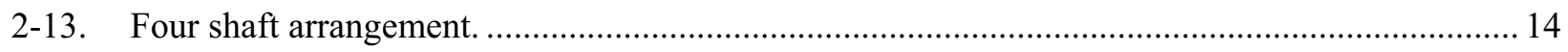

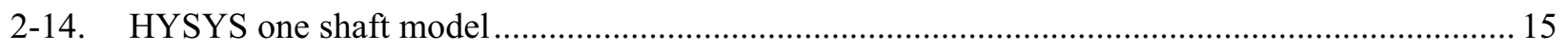

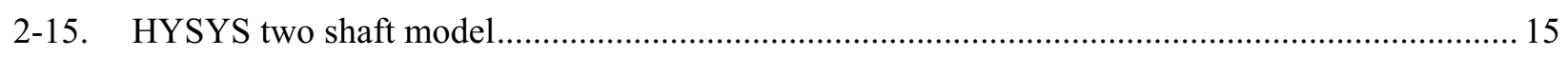

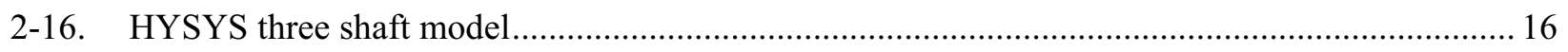

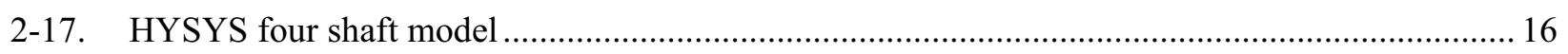

3-1. Cycle efficiency as a function of IHX primary outlet temperature for different reactor

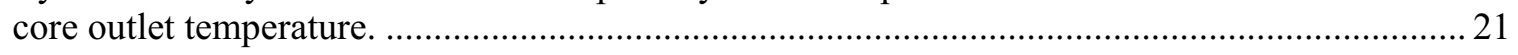

3-2. Cycle pressure ratio as a function of IHX primary outlet temperature for different reactor

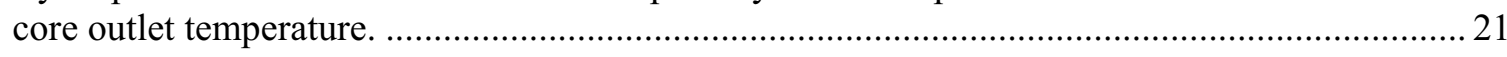

3-3. Busbar efficiency as a function of temperature difference across the reactor. ........................... 23

3-4. Busbar efficiency as a function of compressor efficiencies and reactor inlet temperatures. ......... 23

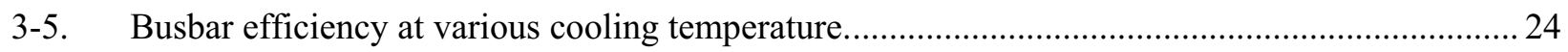

3-6. Busbar efficiency as a function of IHX efficiencies and reactor inlet temperatures..................... 24

3-7. Power turbine inlet temperature as a function of temperature drop across the reactor................. 25

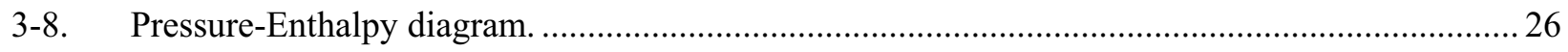

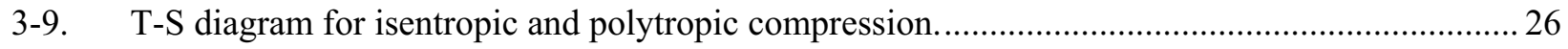

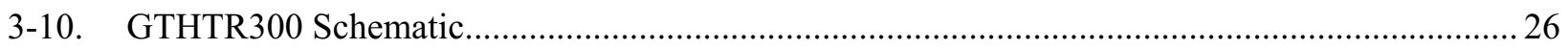

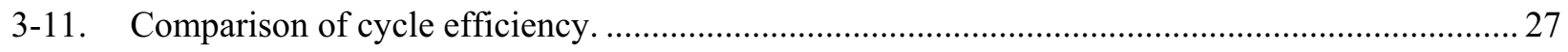

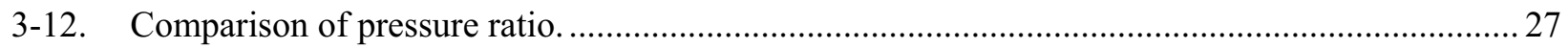

3-13. Stream property of the inlet and outlet of the high-pressure compressor from HYSYS

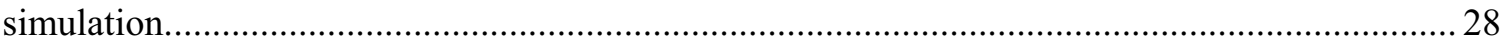

3-14. CO2 pressure-enthalpy diagram and paths to obtain the HPC exit temperature of $1130 \mathrm{C} \ldots \ldots \ldots \ldots . .28$

3-15. HYSYS Schematic for a supercritical CO2 cycle with $49.3 \%$ efficiency. ................................. 29

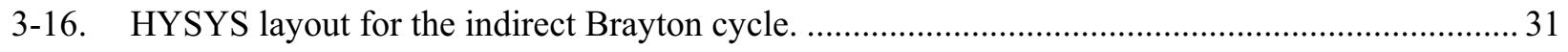

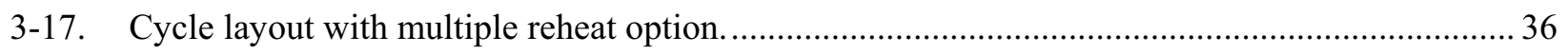

3-18. Snapshot of HYSYS model of the combined cycle with N2/He. ............................................ 40

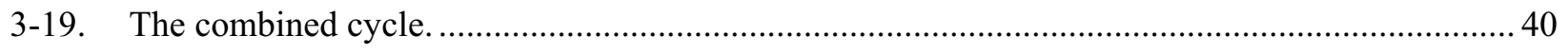

3-20. Reheat Cycle with $\mathrm{CO} 2$ fluid in the power conversion unit. .................................................. 42 
3-21. Schematic of the combined cycle.

3-22. HYSYS diagram of Brayton top cycle with $\mathrm{CO} 2$ working fluid.

3-23. T-S diagram of Brayton top cycle with $\mathrm{CO} 2$ working fluid.

3-24. Parametric study of the effects of reactor outlet temperature on combined cycle efficiency.

3-25. Parametric study of the effects of secondary mass flow rate on combined cycle efficiency.........52

3-26. Parametric study of the effects of working pressure on combined cycle efficiency.....................53

4-1. Initial microstructures of a) coarse, elongated-grained and b) fine, equiaxed-grained MA 754.

4-2. Low magnification micrograph of the coarse, elongated microstructure of MA 754 in the as-received condition.

4-3. Elevated temperature mechanical properties, a) yield and ultimate stress and b) ductility and reduction in area, of coarse-grained MA 754.

4-4. Tensile fracture surfaces of MA 754 samples oriented parallel to (left) and perpendicular to (right) the extrusion direction, longitudinal and transverse, respectively.

4-5. Comparison of the stress rupture data for MA 754 with other high temperature alloys

4-6. Elevated temperature yield and ultimate strength (left) and ductility and reduction in area (right) for fine-grained MA 754. Dashed curves show the elevated temperature properties of coarse-grained MA 754 (Recrystallized).

4-7. Minimum creep rates for fine-grained MA 754 as function of temperature. Lines representing coarse-grained data (Recrystallized) are shown for comparison

4-8. Stress-rupture behavior of fine-grained MA 754 as a function of temperature. Lines representing coarse-grained data (Recrystallized) are shown for comparison.

4-9. Metallographic cross-sections of creep specimens: (a) specimen F-T-19 tested at $1000^{\circ} \mathrm{C}$ and $10 \mathrm{MPa}$, elongation $24 \%$ (prior to failure); (b) specimen F-T-14 tested at $900^{\circ} \mathrm{C}$ and $25 \mathrm{MPa}$, failure elongation $2.4 \%$.

4-10. Schematic of the multi-sample supercritical CO2 corrosion testing system.

4-11. Schematic of second CO2 corrosion system utilizing the sample in a form of a pipe. The sample acted as the pressure boundary.

4-12. Corrosion rates of coarse-grained MA 754 in supercritical CO2 at $1000 \mathrm{oC}$ and $10 \mathrm{MPa}$ as a function of exposure time. The corrosion rate for fine grained MA 754 is shown as a blue triangle. 
4-13. SEM photographs of each section of the tube sample after 500 hours of exposure.

Samples were taken from the a) 0-25 mm, b)25-50 mm and c) 50-75 $\mathrm{mm}$ sections of the tube......

4-14. (BSE) Corrosion (dark) in the 50-75 mm length (i.e. the pipe center) showing EDS analysis locations.

4-15. Elemental analysis by EDS showing the corrosion product at the outermost \#2 location (Figure 4-14 in blue circle) is almost exclusively chromium oxide. (The unidentified peaks are from a conductive gold coating applied after exposure.).

4-16. The intrusion of corrosion into the base metal, a), may be due to corrosion along the grain boundaries of the fine grain material near the inner surface of the sample, b).

4-17. Cross section through samples, a) I-617 and b) MA 754, exposed to supercritical CO2 at $1000 \mathrm{oC}$ for 175 hours. I-617 shows intergranular attack which is absent from the MA 754 sample.

4-18. The corrosion product at spot 1 (blue circle in a)) that forms on I-617 in supercritical $\mathrm{CO} 2$ at $1000 \mathrm{oC}$ is composed mainly of chromium oxide as shown by the EDS spectra in b). (The unidentified peaks are from a conductive gold coating applied after exposure.).

\section{TABLES}

2-1. Temperature and pressure comparisons from the reference design, ASPEN PLUS and HYSIS models.

2-2. Temperature and pressure comparisons from the reference design, ASPEN PLUS and HYSYS models.

2-3. Comparisons of one-shaft vs. multiple-shafts.

3-1. Parametric study as a function of the turbine inlet temperature.

3-2. Comparison between HYSIS simulation and Visual-Basic based model.......

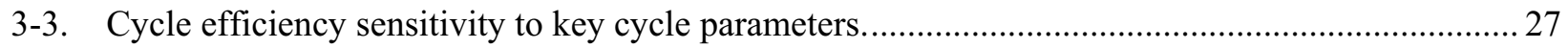

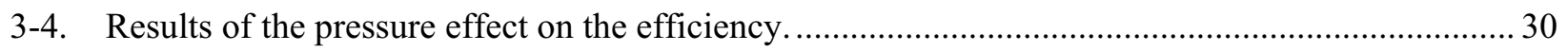

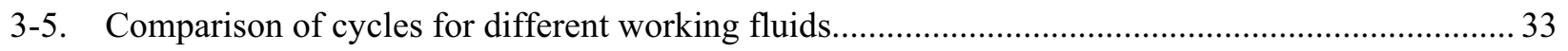

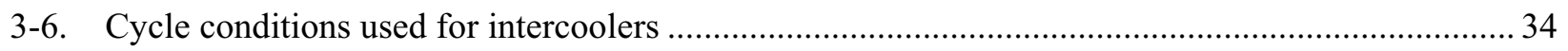

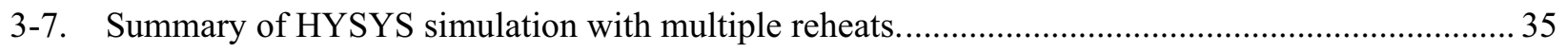

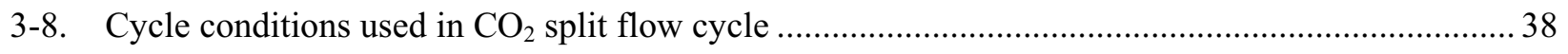

3-9. Comparison of cycle implication due to various cycle layouts and intermediate cooling................ 39 
3-10. Comparison of the combined $\mathrm{N}_{2} / \mathrm{He}$ and combined with $\mathrm{CO}_{2}$ cycle........

3-11. Summary of Primary working conditions for three-shaft and combined cycles.

3-12. Summary of Primary working conditions for reheated cycle.

3-13. Working conditions in the intermediate heat transport loop.

3-14. Summary of Primary working conditions for the combined cycle. .46

3-15. Cycle conditions for three-shaft configuration. .47

3-16. Cycle conditions for combined configuration. .48

3-17. Cycle conditions for the reheated configuration. .48

3-18. Component sizing data fro combined cycle with helium working fluid. 49

3-19. State points for Brayton top cycle with $\mathrm{CO}_{2}$ working fluid. .50

3-20. Component sizing data for combined cycle with $\mathrm{CO}_{2}$ working fluid. .51

3-21. Component sizing data for combined cycle with a nitrogen-helium mixture. .51

3-22. Parametric study of the effects of turbine cooling on combined cycle efficiency. 53

4-1. Longitudinal Creep Conditions and Results For Coarse-Grained MA 754 59

4-2. Transverse Creep Conditions and Results For Coarse-Grained MA 754 59

4-3. Apparent Stress Exponents and Threshold Stresses for High Temperature Creep..... 60

4-4. Creep-Rupture Test Conditions and Results for Fine-Grained MA 754 62

4-5. Corrosion Rate for Fine Grained MA 754. .71

4-6. Alloy I-617 72 


\section{Development of a Supercritical Carbon Dioxide Brayton Cycle: Improving VHTR Efficiency and Testing Material Compatibility}

\section{INTRODUCTION}

The U.S. and other countries address major challenges related to energy security and the environmental impacts of fossil fuels. Solutions to these issues include carbon-free electricity generation and hydrogen production for fuel cell car, fertilizer synthesis, petroleum refining, and other applications. The Very High Temperature Gas Reactor (HTGR) [INEEL, 2004] has been recognized as a promising technology for high efficiency electricity generation and high temperature process heat applications. Therefore, the U.S. needs to make the HTGR intrinsically safe and proliferation-resistant. The U.S. and the world, however, must still overcome certain technical issues and the cost barrier before it can be built in the U.S. The establishment of a nuclear power cost goal of 3.3 cents $/ \mathrm{kWh}$ is desirable in order to compete with fossil combined-cycle, gas turbine power generation. This goal requires approximately a $30 \%$ reduction in power cost for state-of-the-art nuclear plants. It has been demonstrated that this large cost differential can be overcome only by technology improvements that lead to a combination of better efficiency and more compatible reactor materials.

\subsection{Objective}

The objectives of this research are (1) to develop a supercritical carbon dioxide Brayton cycle in the secondary power conversion side that can be applied to some Generation-IV reactors such as the HTGR and supercritical water reactor, (2) to improve the plant net efficiency by using the carbon dioxide Brayton cycle, and (3) to test material compatibility at high temperatures and pressures. The reduced volumetric flow rate of carbon dioxide due to higher density compared to helium will reduce compression work, which eventually increase turbine work enhancing the plant net efficiency.

\subsection{Background}

The VHTR is a graphite-moderated helium-cooled reactor that uses a direct or an indirect gas cycle to convert the heat generated by nuclear fission in the reactor and transferred to the coolant gas into electrical energy by means of a helium turbo-generator. The VHTR technology has been developed since the 1950s and has introduced the high-temperature gas-cooled reactor (HTGR) [IAEA, 1984]. HTGRs work on the principle of passing a cooling gas through the core, then running the heated gas directly to a steam generator or turbine. These reactors have been built in England and have been largely researched in Germany. The Arbeitsgemeinschaft Versuchsreactok (AVR), 15-MWe test reactor located in Forschungszentrum Juelich, was constructed starting in 1961. First criticality was achieved in 1966 . The AVR has operated for 21 years. In 1974, the reactor outlet temperature was raised to $9500^{\circ} \mathrm{C}$, which was needed to test very-high-temperature nuclear process heat applications. The most recent VHTR built is the Chinese HTR-10 (10 MW), which achieved first criticality December 2000 [Schleifenheimer, 1970, Gilli et al., 1975, Zierman, 1984]. HTR-10 [Hu et al., 2004] was designed to be operated up to $9500^{\circ} \mathrm{C}$ for investigating diverse power generation systems (e.g., gas turbine) and nuclear process heat applications [Generation IV Roadmap, 2001]. Recently, Eskom, a power company based in South Africa, submitted a nuclear installation license application to the National Nuclear Regulator (NNR). It proposes to locate the installation on Eskom property within the owner-controlled boundary of Koeberg Nuclear Power Station located in the Western Cape. In the United States, the Department of Energy will soon select one site out 
of three candidate locations where a VHTR can be built. The popularity on the VHTR, therefore, grows. Hopefully, this will change Americans' perception of nuclear reactors if the energy crisis and ozone layer depletion from fossil power plant $\mathrm{CO} 2$ emissions get more serious.

The VHTR has several advantages over light water reactors. These include fuel integrity, a proliferation-resistant and relatively simple fuel cycle, online fuel maintenance, and modularity for remote areas needing electricity and for the energy-starved underdeveloped countries with little power generation infrastructure. In addition to the modularity, the VHTR offers unique simplicity (single-phase), scalability, and structural volume $\left(10 \mathrm{~kW} / \mathrm{ft}^{2}\right.$ for VHTR versus $6 \mathrm{~kW} / \mathrm{ft}^{2}$ for AP-1000). However, some technical and economical challenges must be overcome, particularly reactor safety and costs. Our concerns about the VHTR are its economics and the technical problems of materials exposed to the hightemperature environment. The VHTR (current reference design by INEEL and MIT [INEEL, 1999, Nicholas, 2001]) or prismatic fuel modular reactor (PMR) technologies will lead to industrial projects that will satisfactorily meet Generation IV goals and will be judged to be deployable about 2010 to 2015 . These HTGR systems rely on strongly synergetic research work:

- $\quad$ High-temperature capability steels for both reactor plant and power conversion applications - $\quad$ High-temperature systems technology.

Since VHTRs are high-temperature gas reactors, material behavior for long periods of time will require sustainability and confirmation. Operation temperatures below $1000 \mathrm{C}$ can be realized with available material and knowledge, unless new materials are developed or new surface applications are developed. Higher temperatures need considerable material qualification and development of new hightemperature alloys, special treatment surfaces, or fiber-reinforced ceramics and compounds. Without development of new materials, at 950 to $1000 \mathrm{C}$ the lifetime of available high-temperature alloys will be limited. Components exposed to high temperature may have to be replaced every 15 to 20 years if no better materials can be qualified [Generation IV Roadmap, 2001]. Replacement will be a challenge for the design (e.g., modular arrangements), whereas improving high-temperature alloys or surface coatings remains a medium-term R\&D task. Again, the VHTR offers an alternative approach to commercializing nuclear power, compared to other fission-power-producing systems such as light water reactors, and liquid metal-cooled fast breeder reactors. Gas cooling for nuclear reactors had been considered in the United States. The fundamental design of the VHTR is aimed at achieving a system without any physical process that could cause an internally or externally induced radiation hazard outside the site boundary. The thermal-hydraulic stabilization is achieved by modularizing the core with a relatively low-power density $(<4.5 \mathrm{MW} / \mathrm{m} 3)$, such that the integrated heat loss capability from the reactor exceeds the decay heat production of the core under all conceivable accident conditions. Using helium as a coolant, which is both chemically and radiogically inert, combined with the improved net plant efficiency achieved by using supercritical carbon dioxide in the secondary side, allows using a high primary-coolant temperature $\left(950^{\circ} \mathrm{C}\right)$, which yields high thermal efficiencies.

In conclusion, plant design should be streamlined for technically sound, robust, passively safe, and low-cost production. Although gas reactors were developed in the past with limited success, the innovations of modularity and integrated state-of-art passive safety systems, coupled with improved safety design and plant efficiencies, make this design potentially very attractive from a technical and economic perspective. 


\section{TASK 1: DEVELOPMENT OF $\mathrm{CO}_{2}$ BRAYTON CYCLE}

\section{Task 1-1: Development of the Efficiency Equation of Turbine and Compressor for the Real Gas}

The objective of this task involves mathematical derivations of the turbine and compressor efficiency. When supercritical $\mathrm{CO}_{2}$ gas is expanded and compressed in a real gas fashion through a sequence of turbines and compressors, the isentropic formulas shown in most thermodynamic books are no longer useful. The polytropic expansion can be correlated using the definition of the isentropic expansion, as shown in Figure 2-1.

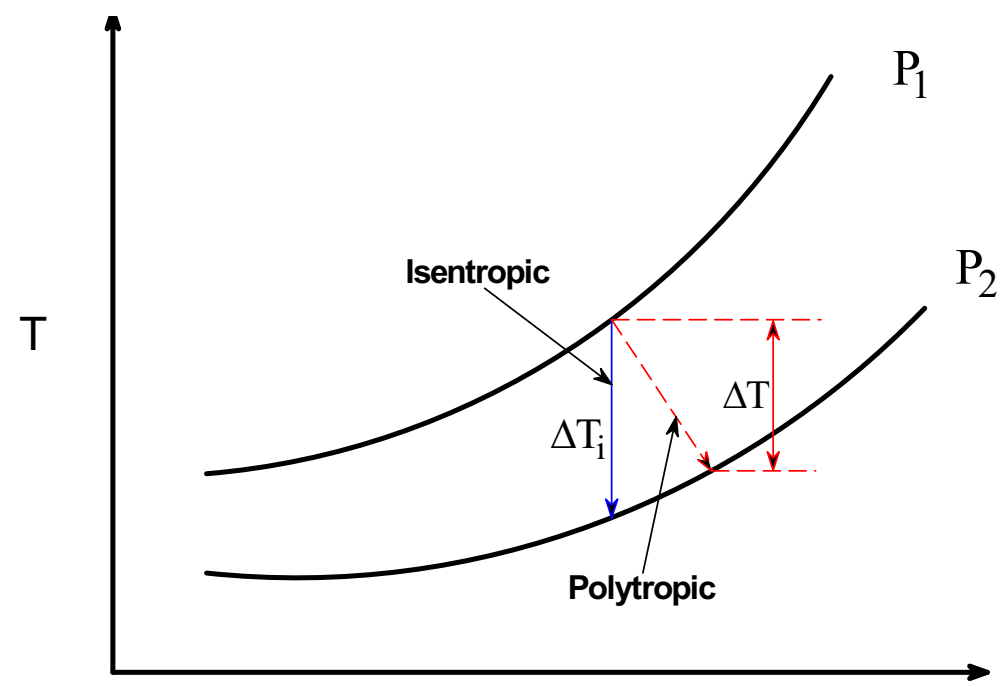

$S$

Figure 2-1. Polytropic efficiency.

With the first law of thermodynamic, the mathematical derivation starts as shown below:

$c_{p}=c_{v}+R$

dividing by $\mathrm{c}_{\mathrm{v}}$ yields

$\frac{\mathrm{c}_{\mathrm{p}}}{c_{v}}=1+\frac{R}{c_{v}}=\gamma$

or

$\gamma-1=\frac{\mathrm{R}}{\mathrm{c}_{\mathrm{p}}}$

For adiabatic process,

$d u=-d w$

or 
$c_{v} d T=-P d v$

for a real gas we can write

$c_{v}=-\frac{z R T}{v} d v$

where $z$ is the compressibility factor. The compressibility factor, $z$ in Equation (6) is not a constant.

However, for the mathematical simplification for the approximate analytical solution, it is assumed to be constant as well as $\gamma$ defined in Equation (3). For the range of the pressure and temperatures, the deviation is approximated within $7 \%$ errors. However, if we use a mean value between the upper and lower pressure and temperature, the error is approximated within $4 \%$, which is acceptable in the engineering field.

Integration of the equation 6 and rearranging the equation give

$$
(1+z \cdot(\gamma-1)) \cdot \ln \frac{T_{2}}{T_{1}}=z \cdot(\gamma-1) \cdot \ln \frac{P_{2}}{P_{1}}
$$

or

$$
\frac{T_{2}}{T_{1}}=\left(\frac{P_{2}}{P_{1}}\right)^{\frac{z(\gamma-1)}{1+z(\gamma-1)}}
$$

When $z=1$ (ideal gas), equation 8 becomes:

$$
\frac{T_{2}}{T_{1}}=\left(\frac{P_{2}}{P_{1}}\right)^{\frac{\gamma-1}{\gamma}}
$$

In order to correlate the polytropic expansion, the following equation is written based on Figure 2-1 [Perry, 1984].

$\eta_{\text {poly }} \equiv \frac{\Delta T}{\Delta T_{i}} \equiv$ Constant

or

$\frac{d T_{i}}{T}=\frac{d T}{\eta_{p o l y} T}$

From a combination of equation 8 and 11 gives,

$$
\frac{1}{\eta_{p o l y}} \frac{d T}{T}=\frac{z(\gamma-1)}{1+z(\gamma-1)} \frac{d P}{P}
$$


Integration of equation 12 gives

$\frac{T_{2}}{T_{1}}=\left(\frac{P_{2}}{P_{1}}\right)^{\frac{\eta_{p o l y} z(\gamma-1)}{1+z(\gamma-1)}}$

or

$\frac{T_{2}}{T_{1}}=\left(\frac{P_{2}}{P_{1}}\right)^{\frac{\eta_{p o l y} z \frac{R}{c_{p}}}{(z-1) \frac{R}{c_{p}}+1}}$

Similarly, the efficiency for the compressor was developed to be

$\frac{T_{2}}{T_{1}}=\left(\frac{P_{2}}{P_{1}}\right)^{\frac{\frac{z}{\eta_{p o l y}} \frac{R}{c_{p}}}{(z-1) \frac{R}{c_{p}}+1}}$

Figure 2-2 depicts a T-S representation of the reference Brayton cycle in the power conversion scheme.

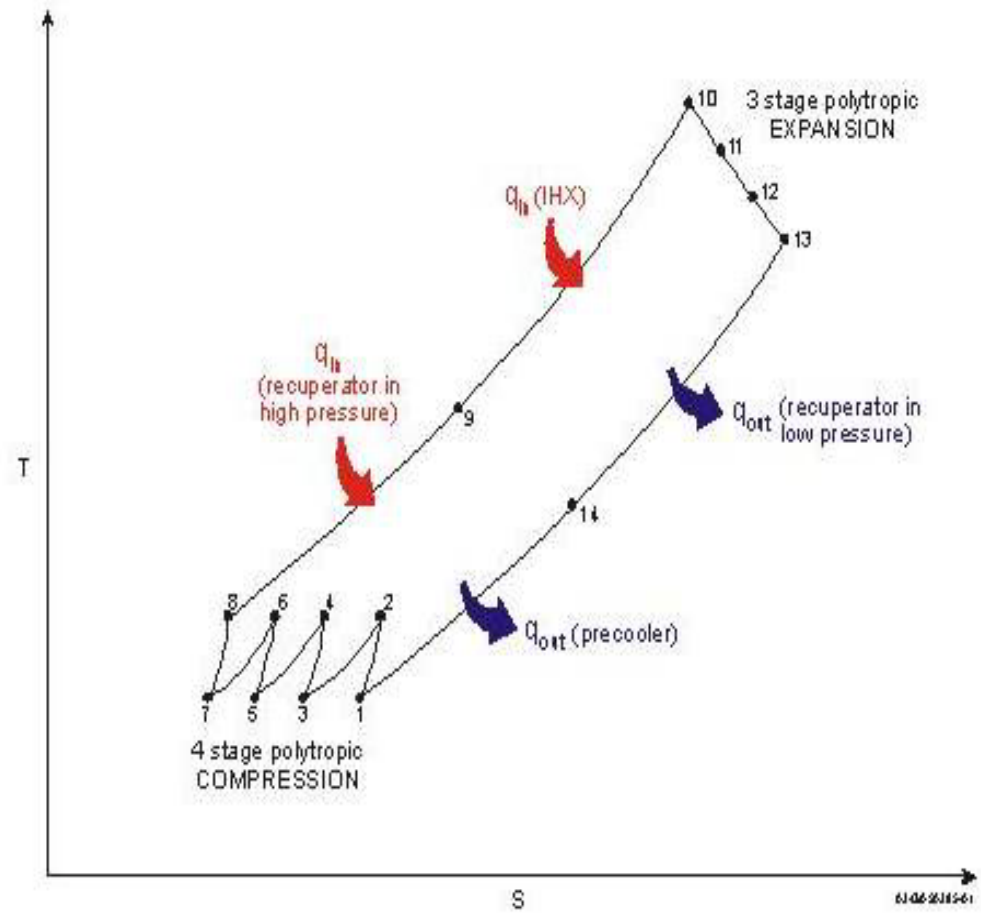

Figure 2-2. T-S diagram for the VHTR reference design in the power conversion side. 
The overall plant busbar efficiency with polytropic compression and expansion is defined as:

$\eta_{\text {net }}=\frac{W_{T} \eta_{\text {gen }}-W_{\text {cir }} / \eta_{\text {motor }}-W_{s}}{Q_{\text {th }}}$

where $W_{T}$ is the power turbine output power, $\eta_{\text {gen }}$ is the generator efficiency, $W_{\text {cir }}$ is the circulator input power, $\eta_{\text {motor }}$ is the motor efficiency, $W_{s}$ is the stationary loads, and $Q_{t h}$ is the reactor thermal power.

\section{Task 1-2: Comparison of Supercritical CO2 Properties with Equations of State}

The objective of this task involves checking thermal and transport properties of $\mathrm{CO}_{2}$ gas between references [Reid et al., 1977, Reid et a., 1987, Rivken, 1988, and Perry et al., 1997] and a number of equations of state (EOS) in the Aspen Plus [Aspentech, 2001] and HYSYS codes [Aspentech, 2001].

Thermal and transport properties of $\mathrm{CO}_{2}$ were compared and we found that the NIST database (http://webbook.nist.gov/chemistry/fluid) is very accurate. Also the Lee-Kesler-Plocker equation of state is the most accurate EOS defined in Aspen Plus and HYSYS. The Peng-Robinson EOS [Peng and Robinson, 1976] is good for helium and other fluids. Therefore, the NIST database is used for our scoping calculations and the Lee-Kesler-Plocker EOS [Knapp, H., 1989] is used for all the $\mathrm{CO}_{2}$ computer simulation while the Peng-Robinson EOS is used for helium and other fluids.

The equation of state (EOS) is important in defining the properties of supercritical $\mathrm{CO}_{2}$. Depending on the EOS, the $\mathrm{CO}_{2}$ properties vary specifically in the temperature range below $1300 \mathrm{~K}$, as shown Figure 2-3. In the figure, the specific heat ratio defined as $\gamma$ is compared to the supercritical $\mathrm{CO}_{2}$ database from the National Institute of Science and Technology (NIST) [NIST, 2002] and those calculated using the Soave EOS. Figure 2-4 shows compressibility factor of carbon dioxide.

\section{COMPARISION OF SPECIFIC HEAT DATA}

NIST Data Base and So ave EOS

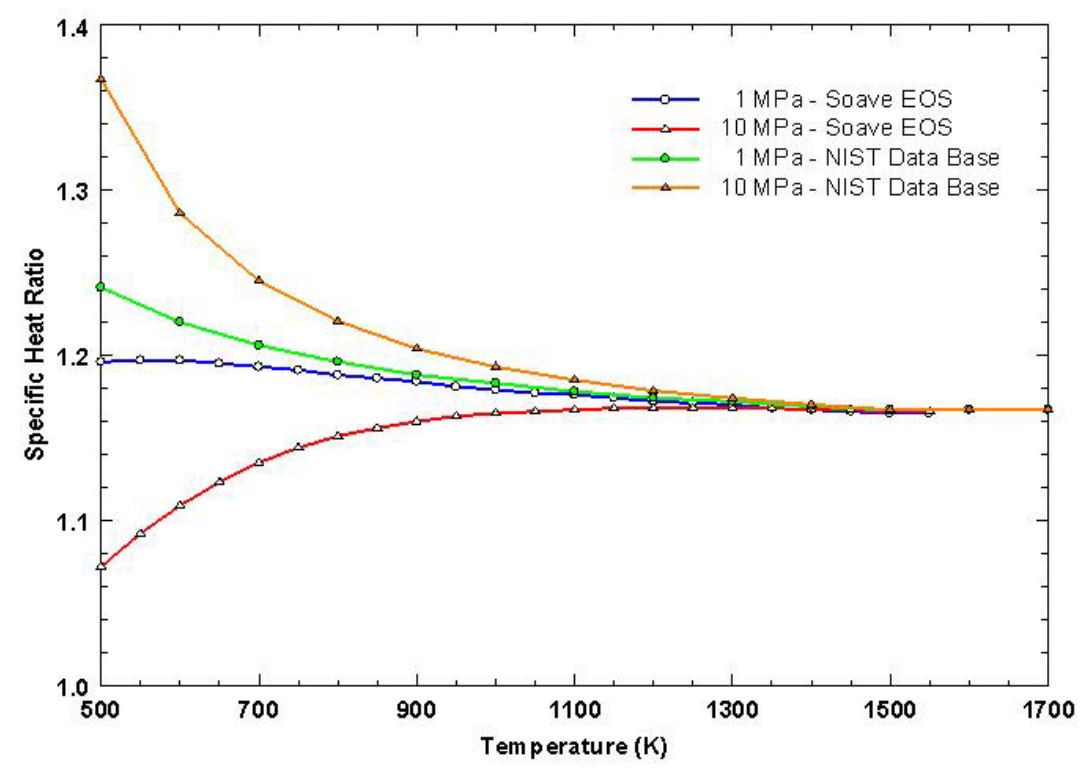

Figure 2-3. Comparison of specific heat data. 


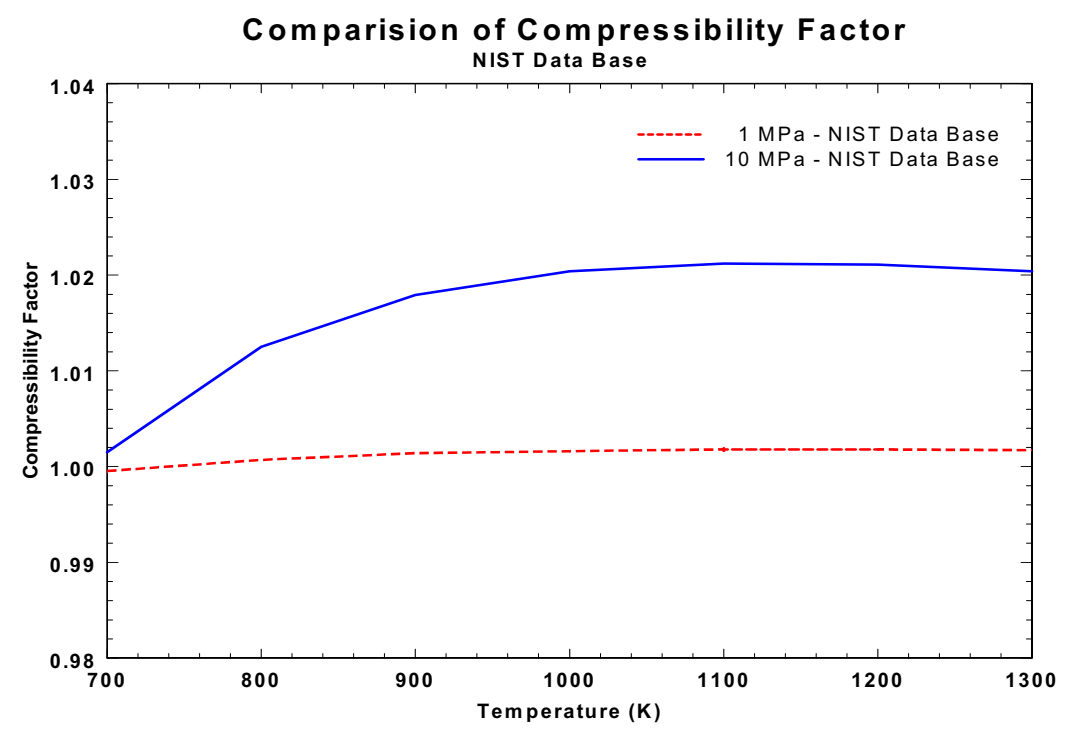

Figure 2-4. Compressibility factor of $\mathrm{CO}_{2}$.

A comparison of RELAP5/ATHENA [INEEL, 2005] code-calculated values with an independent source of data [Perry 1984] was made. The comparison concentrated on the sub-critical gas and supercritical regions since these regions are of primary interest for analysis of gas-cooled fast reactors. Thermodynamic properties were compared for a wide range of pressures, from 0.8 to $20.7 \mathrm{MPa}$, and temperatures, from 227 to $1255 \mathrm{~K}$. ATHENA calculations were performed at five specific pressure points and over the temperature range given by Perry. The comparisons between the values calculated by ATHENA and given by Perry are summarized in Figures 2-5 and 2-6, which show fluid density and specific enthalpy, respectively. A constant of $218.57 \mathrm{~kJ} / \mathrm{kg}$ was subtracted from the enthalpy values reported by Perry to account for a different enthalpy datum. This value was obtained by subtracting the enthalpy predicted by the NIST database for saturated liquid at $0^{\circ} \mathrm{C}$ from the value used by Perry.

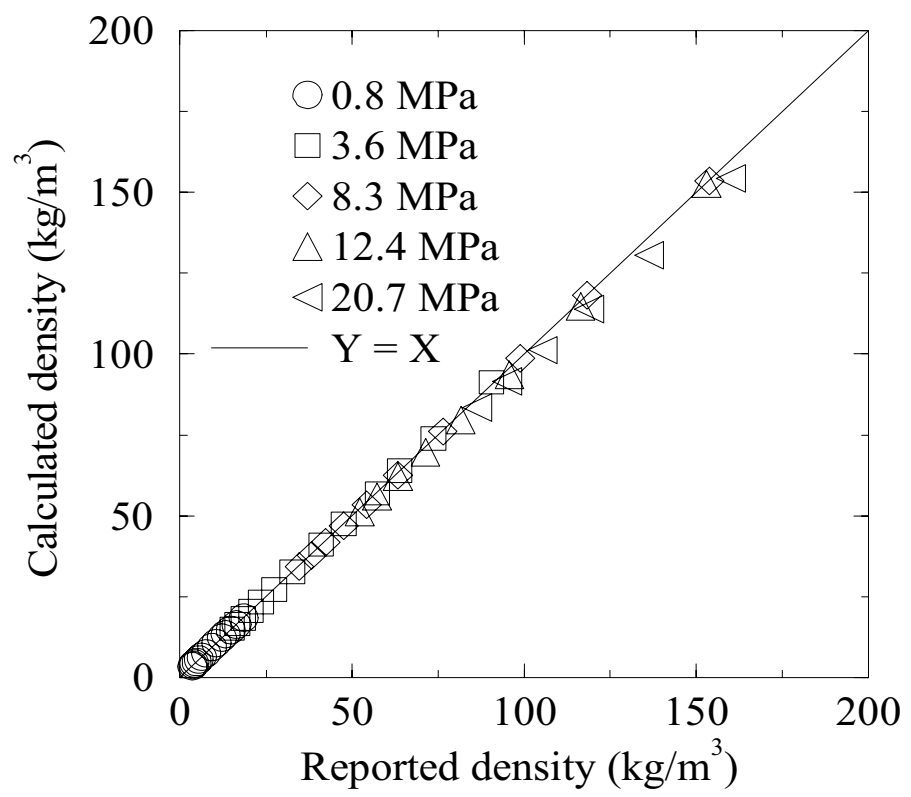

Figure 2-5. A comparison of calculated and reported fluid densities. 


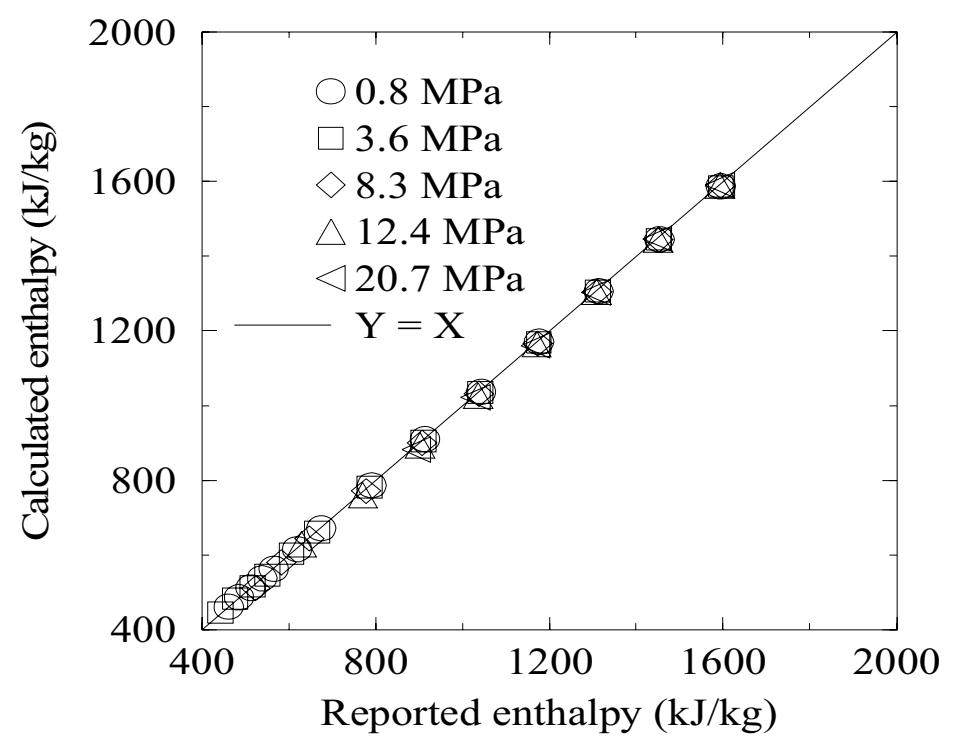

Figure 2-6. A comparison of calculated and reported specific enthalpies.

The fluid densities calculated by ATHENA were in excellent agreement with the values reported by Perry, as shown in Figure 2-5. On average, the densities calculated by ATHENA were within 1.0\% of the values reported by Perry. The standard deviation, which was based on 51 data points, was $1.3 \%$. The largest deviation was $4.2 \%$ and occurred at the highest pressure. The difference between densities at 20.7 $\mathrm{MPa}$, which was consistent as a function of temperature, was caused by differences between the NIST database and Perry. As expected, the results calculated by ATHENA were consistent with stand-alone calculations using the NIST database.

The specific enthalpies calculated by ATHENA were in excellent agreement with the values reported by Perry. On average, the enthalpies calculated by the code were within $0.4 \%$ of the values reported by Perry. The standard deviation was $0.5 \%$. The largest deviation was $2.3 \%$. For this case, the results calculated by ATHENA were also consistent with stand-alone calculations using the NIST database. Because the validation included variations in temperature at constant pressure, the agreement in specific heat capacity, which was not reported by Perry, is expected to be similar to that shown for enthalpy.

\section{Task 1-3: Selection of the Optimization Computer Code}

We used both the HYSYS [HYSYS, 2001] and ASPEN PLUS computer [Aspen Plus, 2001] codes to simulate the VHTR reference design. HYSYS has the capability to model polytropic expansion and compression process through both turbines and compressors as opposed to ASPEN PLUS, which only models isentropic expansion and compression flows. Therefore, the more accurate results can be obtained using HYSYS. ASPEN PLUS has a larger chemical database; however, our system deals with helium in the primary side, which is an inert fluid, and $\mathrm{CO}_{2}$ in the power conversion side, which is included in the HYSYS database. In addition, HYSYS is a more user-friendly code than is ASPEN PLUS. Therefore, we selected to use the HYSYS computer code for the process optimization and simulation for the project.

We simulated a reference design using both HYSYS and ASPEN PLUS to compare the results [Oh, 2003]. Figures 2-7 and 2-8 show simulation results. Table 2-1 shows the detailed comparison between these simulations with the reference design parameters. 


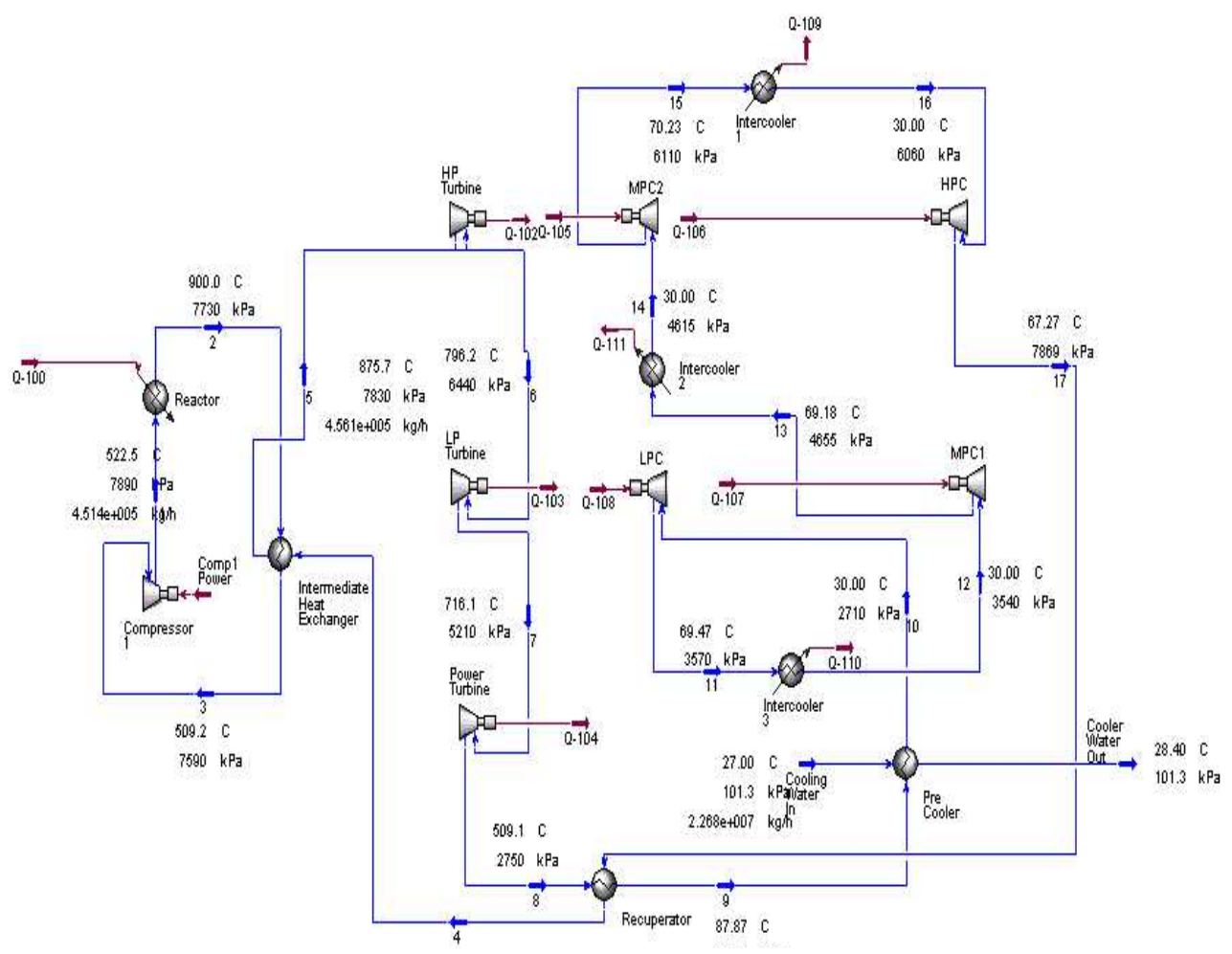

Figure 2-7. HYSYS results for the baseline case with helium.

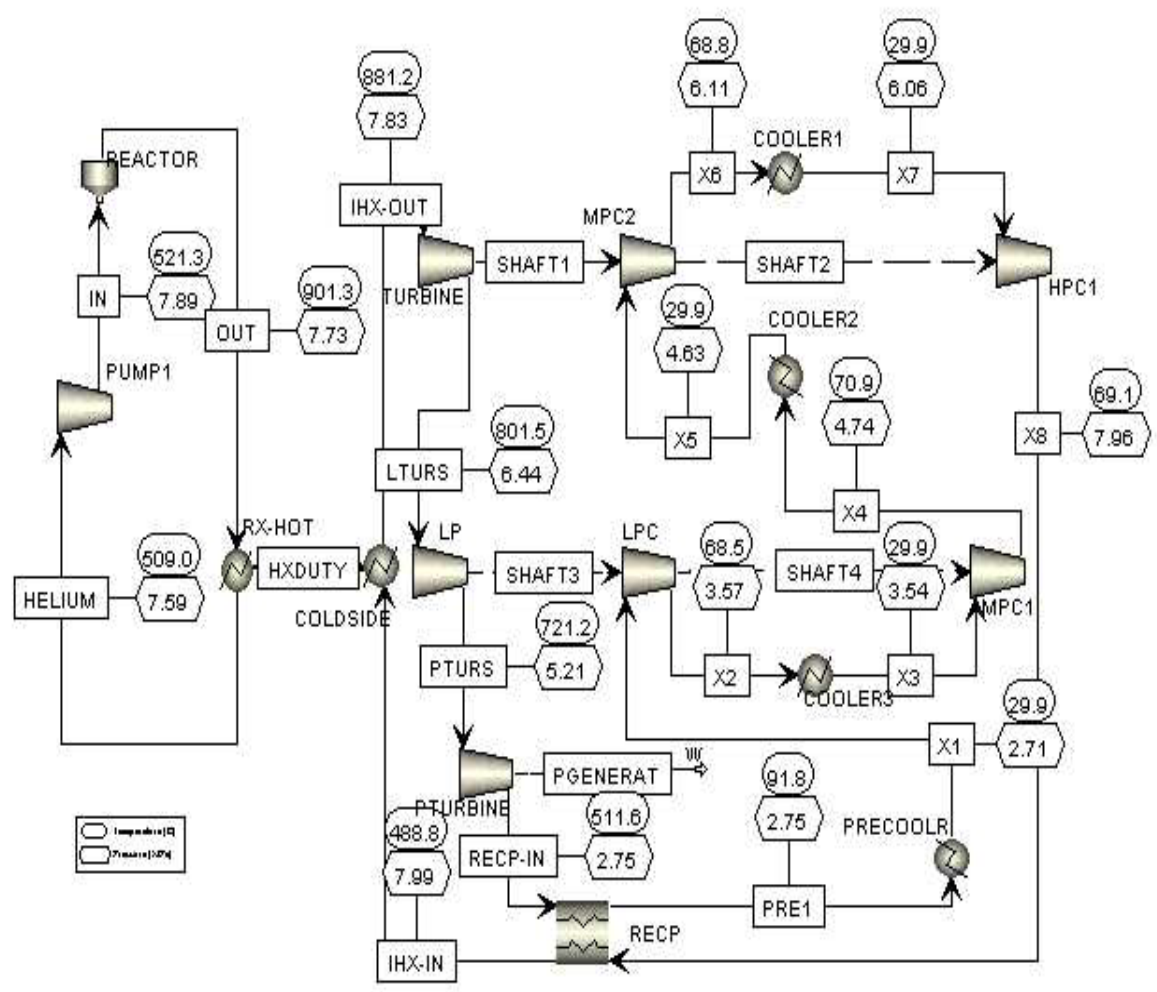

Figure 2-8. ASPEN PLUS results for the baseline case with helium. 
Table 2-1. Temperature and pressure comparisons from the reference design, ASPEN PLUS and HYSYS models.

\begin{tabular}{|c|c|c|c|}
\hline & REFERENCE DESIGN & ASPEN PLUS & HYSYS \\
\hline \multirow{2}{*}{$\begin{array}{l}\text { Heat Exchange } \\
\text { Outlet }\end{array}$} & $879.4^{\circ} \mathrm{C}$ & $882.2^{\circ} \mathrm{C}$ & $882.2^{\circ} \mathrm{C}$ \\
\hline & $7.83 \mathrm{MPa}$ & $7.73 \mathrm{MPa}$ & $7.73 \mathrm{MPa}$ \\
\hline \multirow[t]{2}{*}{ HP Turbine Outlet } & $799.2^{\circ} \mathrm{C}$ & $801.4^{\circ} \mathrm{C}$ & $796.2^{\circ} \mathrm{C}$ \\
\hline & $6.44 \mathrm{MPa}$ & $6.44 \mathrm{MPa}$ & $6.44 \mathrm{MPa}$ \\
\hline \multirow[t]{2}{*}{ LP Turbine Outlet } & $719.0^{\circ} \mathrm{C}$ & $721.2^{\circ} \mathrm{C}$ & $716.1^{\circ} \mathrm{C}$ \\
\hline & $5.21 \mathrm{MPa}$ & $5.21 \mathrm{MPa}$ & $5.21 \mathrm{MPa}$ \\
\hline \multirow[t]{2}{*}{ Power Turbine Outlet } & $511.0^{\circ} \mathrm{C}$ & $511.6^{\circ} \mathrm{C}$ & $509.1^{\circ} \mathrm{C}$ \\
\hline & $2.75 \mathrm{MPa}$ & $2.76 \mathrm{MPa}$ & $2.75 \mathrm{MPa}$ \\
\hline \multirow{2}{*}{$\begin{array}{l}\text { Recuperator Outlet } \\
\text { LP Side }\end{array}$} & $96.1^{\circ} \mathrm{C}$ & $91.8^{\circ} \mathrm{C}$ & $87.9^{\circ} \mathrm{C}$ \\
\hline & $2.73 \mathrm{MPa}$ & $2.75 \mathrm{MPa}$ & $2.73 \mathrm{MPa}$ \\
\hline \multirow[t]{2}{*}{ Precooler Outlet } & $30.0^{\circ} \mathrm{C}$ & $29.0^{\circ} \mathrm{C}$ & $30.0^{\circ} \mathrm{C}$ \\
\hline & $2.71 \mathrm{MPa}$ & $2.71 \mathrm{MPa}$ & $2.71 \mathrm{MPa}$ \\
\hline \multirow{2}{*}{$\begin{array}{l}\text { LP Compressor } \\
\text { Outlet }\end{array}$} & $69.7^{\circ} \mathrm{C}$ & $68.5^{\circ} \mathrm{C}$ & $69.5^{\circ} \mathrm{C}$ \\
\hline & $3.75 \mathrm{MPa}$ & $3.75 \mathrm{MPa}$ & $3.75 \mathrm{MPa}$ \\
\hline \multirow[t]{2}{*}{ Intercooler1 Outlet } & $30.0^{\circ} \mathrm{C}$ & $29.9^{\circ} \mathrm{C}$ & $30.0^{\circ} \mathrm{C}$ \\
\hline & $3.54 \mathrm{MPa}$ & $3.54 \mathrm{MPa}$ & $3.54 \mathrm{MPa}$ \\
\hline \multirow{2}{*}{$\begin{array}{l}\text { MP1 Compressor } \\
\text { Outlet }\end{array}$} & $69.7^{\circ} \mathrm{C}$ & $70.9^{\circ} \mathrm{C}$ & $69.2^{\circ} \mathrm{C}$ \\
\hline & 4.67 MPa & 4.74 MPa & 4.66 MPa \\
\hline \multirow[t]{2}{*}{ Intercooler2 Outlet } & $30.0^{\circ} \mathrm{C}$ & $29.9^{\circ} \mathrm{C}$ & $30.0^{\circ} \mathrm{C}$ \\
\hline & $4.63 \mathrm{MPa}$ & $4.63 \mathrm{MPa}$ & $4.62 \mathrm{MPa}$ \\
\hline \multirow{2}{*}{$\begin{array}{l}\text { MP2 Compressor } \\
\text { Outlet }\end{array}$} & $69.7^{\circ} \mathrm{C}$ & $68.8^{\circ} \mathrm{C}$ & $70.2^{\circ} \mathrm{C}$ \\
\hline & $6.11 \mathrm{MPa}$ & $6.11 \mathrm{MPa}$ & $6.11 \mathrm{MPa}$ \\
\hline \multirow[t]{2}{*}{ Intercooler3 Outlet } & $30.0^{\circ} \mathrm{C}$ & $29.9^{\circ} \mathrm{C}$ & $30.0^{\circ} \mathrm{C}$ \\
\hline & $6.06 \mathrm{MPa}$ & $6.06 \mathrm{MPa}$ & $6.06 \mathrm{MPa}$ \\
\hline \multirow{2}{*}{$\begin{array}{l}\text { HP Compressor } \\
\text { Outlet }\end{array}$} & $69.7^{\circ} \mathrm{C}$ & $69.1^{\circ} \mathrm{C}$ & $67.3^{\circ} \mathrm{C}$ \\
\hline & $8.00 \mathrm{MPa}$ & $7.96 \mathrm{MPa}$ & $7.87 \mathrm{MPa}$ \\
\hline \multirow{2}{*}{$\begin{array}{l}\text { Recuperator Outlet } \\
\text { HP Side }\end{array}$} & $488.9^{\circ} \mathrm{C}$ & $488.8^{\circ} \mathrm{C}$ & $488.8^{\circ} \mathrm{C}$ \\
\hline & $7.99 \mathrm{MPa}$ & $7.95 \mathrm{MPa}$ & $7.99 \mathrm{MPa}$ \\
\hline
\end{tabular}




\section{Task 1-4: Layout of the CO2 Thermal Cycle and Initial Calculations}

We created the layout and simulated the $\mathrm{CO}_{2}$ Brayton cycle using HYSYS. A case with three turbines and four compressors is shown in Figure 2-9. We established an initial material and mass balance to make sure that all flow streams have positive pressure drops and there are no temperature crossovers between the tube side and shell side in the loop heat exchangers and recuperator. We then set the optimization design variables, along with a number of optimization constraints, to make the optimization scheme feasible. Following a number of simulations and optimizations, the case shown in Figure 2-9 gives $53.7 \%$ net plant efficiency with the $\mathrm{CO}_{2}$ Brayton cycle, which is higher than the baseline case with the helium cycle of $47 \%$. The net plant efficiency will be improved further in future tasks by revamping the flow schematic if necessary.

The details of the conditions on each stream are summarized in Table 2 shown below:

Table 2-2 also contains a point comparison of the results presented in the reference design Figures 2-7 and 2-9.

The difference of volumetric flow between Figures 2-7 (helium cycle) and 2-9 $\left(\mathrm{S}-\mathrm{CO}_{2}\right.$ cycle) is the reduced volumetric flow of S-CO2 in the power conversion unit of $3,012 \mathrm{~m} / \mathrm{s}$ vs. $3676 \mathrm{~m}^{3} / \mathrm{h}$ for the helium Brayton cycle. This results in less compression work and more turbine output work, which results in an ultimate improvement of efficiency.

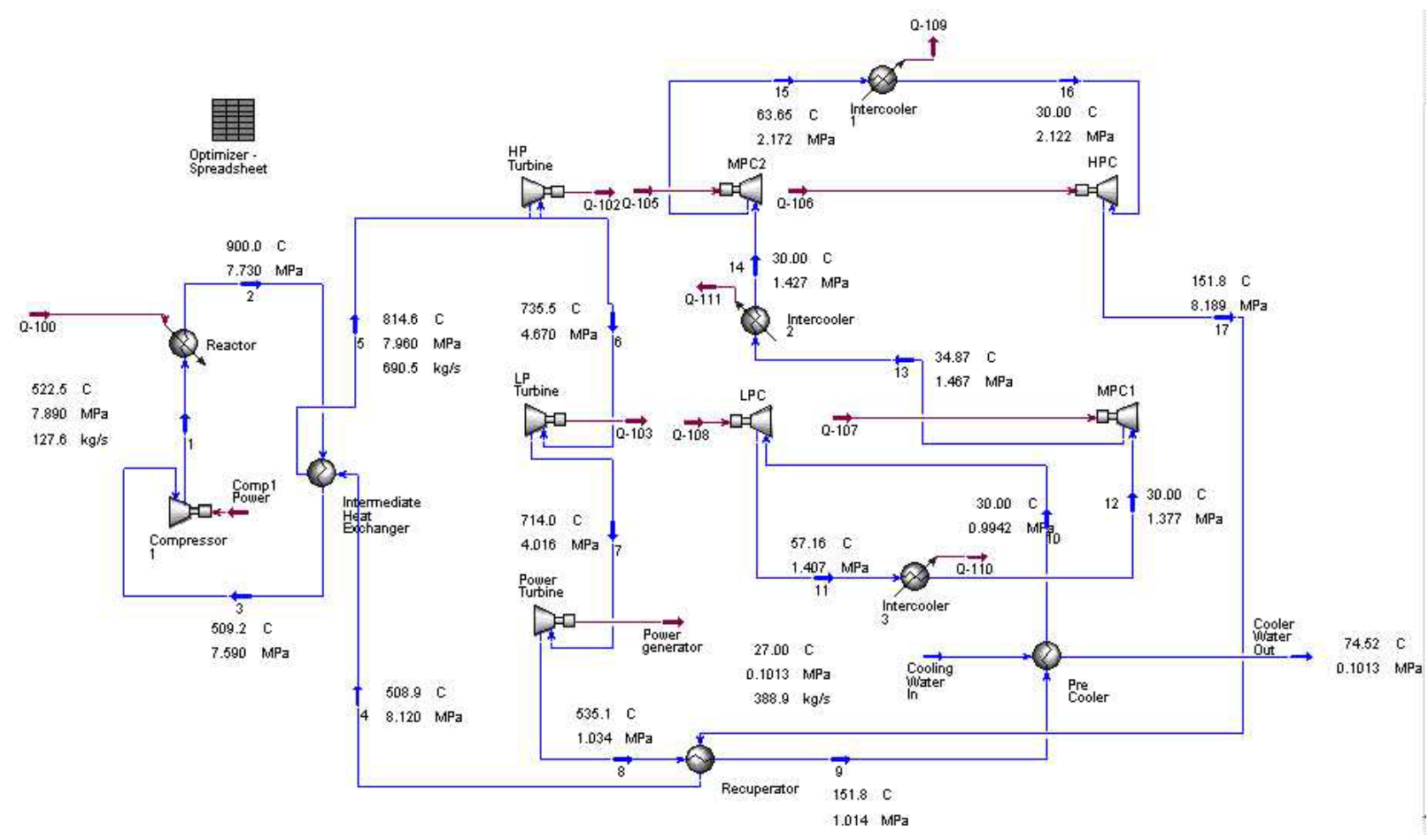

Figure 2-9. Layout of CO2 Brayton cycle with HYSYS. 
Table 2-2. Temperature and pressure comparisons from the reference design, ASPEN PLUS and HYSYS models.

\begin{tabular}{|c|c|c|c|}
\hline & $\begin{array}{c}\text { Reference Design Helium } \\
\text { Brayton Cycle }\end{array}$ & $\begin{array}{c}\text { HYSYS } \\
\text { Helium Brayton Cycle }\end{array}$ & $\begin{array}{c}\text { HYSYS } \\
\text { CO2 Brayton } \\
\text { Cycle }\end{array}$ \\
\hline \multirow{2}{*}{ Heat Exchanger Outlet } & $879.4^{\circ} \mathrm{C}$ & $875.7^{\circ} \mathrm{C}$ & $814.6^{\circ} \mathrm{C}$ \\
\hline & $7.83 \mathrm{MPa}$ & $7.83 \mathrm{MPa}$ & $7.98 \mathrm{MPa}$ \\
\hline \multirow{2}{*}{ HP Turbine Outlet } & $799.2^{\circ} \mathrm{C}$ & $796.2^{\circ} \mathrm{C}$ & $735.5^{\circ} \mathrm{C}$ \\
\hline & $6.44 \mathrm{MPa}$ & $6.44 \mathrm{MPa}$ & $4.67 \mathrm{MPa}$ \\
\hline \multirow{2}{*}{ LP Turbine Outlet } & $719.0^{\circ} \mathrm{C}$ & $716.1^{\circ} \mathrm{C}$ & $714^{\circ} \mathrm{C}$ \\
\hline & $5.21 \mathrm{MPa}$ & $5.21 \mathrm{MPa}$ & $4.016 \mathrm{MPa}$ \\
\hline \multirow{2}{*}{ Power Turbine Outlet } & $511.0^{\circ} \mathrm{C}$ & $509.1^{\circ} \mathrm{C}$ & $535.1^{\circ} \mathrm{C}$ \\
\hline & $2.75 \mathrm{MPa}$ & $2.75 \mathrm{MPa}$ & $1.034 \mathrm{MPa}$ \\
\hline \multirow{2}{*}{ Recuperator Outlet LP } & $96.1^{\circ} \mathrm{C}$ & $87.87^{\circ} \mathrm{C}$ & $151.8^{\circ} \mathrm{C}$ \\
\hline & $2.73 \mathrm{MPa}$ & $2.73 \mathrm{MPa}$ & $1.014 \mathrm{MPa}$ \\
\hline \multirow{2}{*}{ Precooler Outlet } & $30.0^{\circ} \mathrm{C}$ & $30.0^{\circ} \mathrm{C}$ & $30^{\circ} \mathrm{C}$ \\
\hline & $2.71 \mathrm{MPa}$ & $2.71 \mathrm{MPa}$ & $0.9942 \mathrm{MPa}$ \\
\hline \multirow{2}{*}{ LP Compressor Outlet } & $69.7^{\circ} \mathrm{C}$ & $69.5^{\circ} \mathrm{C}$ & $57.16^{\circ} \mathrm{C}$ \\
\hline & $3.57 \mathrm{MPa}$ & $3.57 \mathrm{MPa}$ & $1.407 \mathrm{MPa}$ \\
\hline \multirow{2}{*}{ Intercooler1 Outlet } & $30.0^{\circ} \mathrm{C}$ & $30.0^{\circ} \mathrm{C}$ & $30.0^{\circ} \mathrm{C}$ \\
\hline & $3.54 \mathrm{MPa}$ & $3.54 \mathrm{MPa}$ & $1.377 \mathrm{MPa}$ \\
\hline \multirow{2}{*}{ MP1 Compressor Outlet } & $69.7^{\circ} \mathrm{C}$ & $69.2^{\circ} \mathrm{C}$ & $34.87^{\circ} \mathrm{C}$ \\
\hline & 4.67 MPa & $4.66 \mathrm{MPa}$ & $1.467 \mathrm{MPa}$ \\
\hline \multirow{2}{*}{ Intercooler2 Outlet } & $30.0^{\circ} \mathrm{C}$ & $30.0^{\circ} \mathrm{C}$ & $30.0^{\circ} \mathrm{C}$ \\
\hline & $4.63 \mathrm{MPa}$ & $4.62 \mathrm{MPa}$ & $4.62 \mathrm{MPa}$ \\
\hline \multirow{2}{*}{ MP2 Compressor Outlet } & $69.7^{\circ} \mathrm{C}$ & $70.2^{\circ} \mathrm{C}$ & $70.2^{\circ} \mathrm{C}$ \\
\hline & $6.11 \mathrm{MPa}$ & $6.11 \mathrm{MPa}$ & $6.11 \mathrm{MPa}$ \\
\hline \multirow{2}{*}{ Intercooler3 Outlet } & $30.0^{\circ} \mathrm{C}$ & $30.0^{\circ} \mathrm{C}$ & $30.0^{\circ} \mathrm{C}$ \\
\hline & $6.06 \mathrm{MPa}$ & $6.06 \mathrm{MPa}$ & $6.06 \mathrm{MPa}$ \\
\hline \multirow{2}{*}{ HP Compressor Outlet } & $69.7^{\circ} \mathrm{C}$ & $67.3^{\circ} \mathrm{C}$ & $67.3^{\circ} \mathrm{C}$ \\
\hline & 8.00 MPa & $7.87 \mathrm{MPa}$ & $7.87 \mathrm{MPa}$ \\
\hline \multirow{2}{*}{ Recuperator Outlet HP } & $488.9^{\circ} \mathrm{C}$ & $488.8^{\circ} \mathrm{C}$ & $488.8^{\circ} \mathrm{C}$ \\
\hline & $7.99 \mathrm{MPa}$ & $7.99 \mathrm{MPa}$ & $7.99 \mathrm{MPa}$ \\
\hline
\end{tabular}




\section{Task 1-5: Perform baseline calculations along with Task 1-4}

1. Task Status and Significant Results

The task 1-5 involves a number of baseline calculations based on a number of shaft arrangements that determine the number of turbines and compressors used in the secondary sides. Schematics of the shaft arrangement are shown in Figures 2-10 to 2-13.

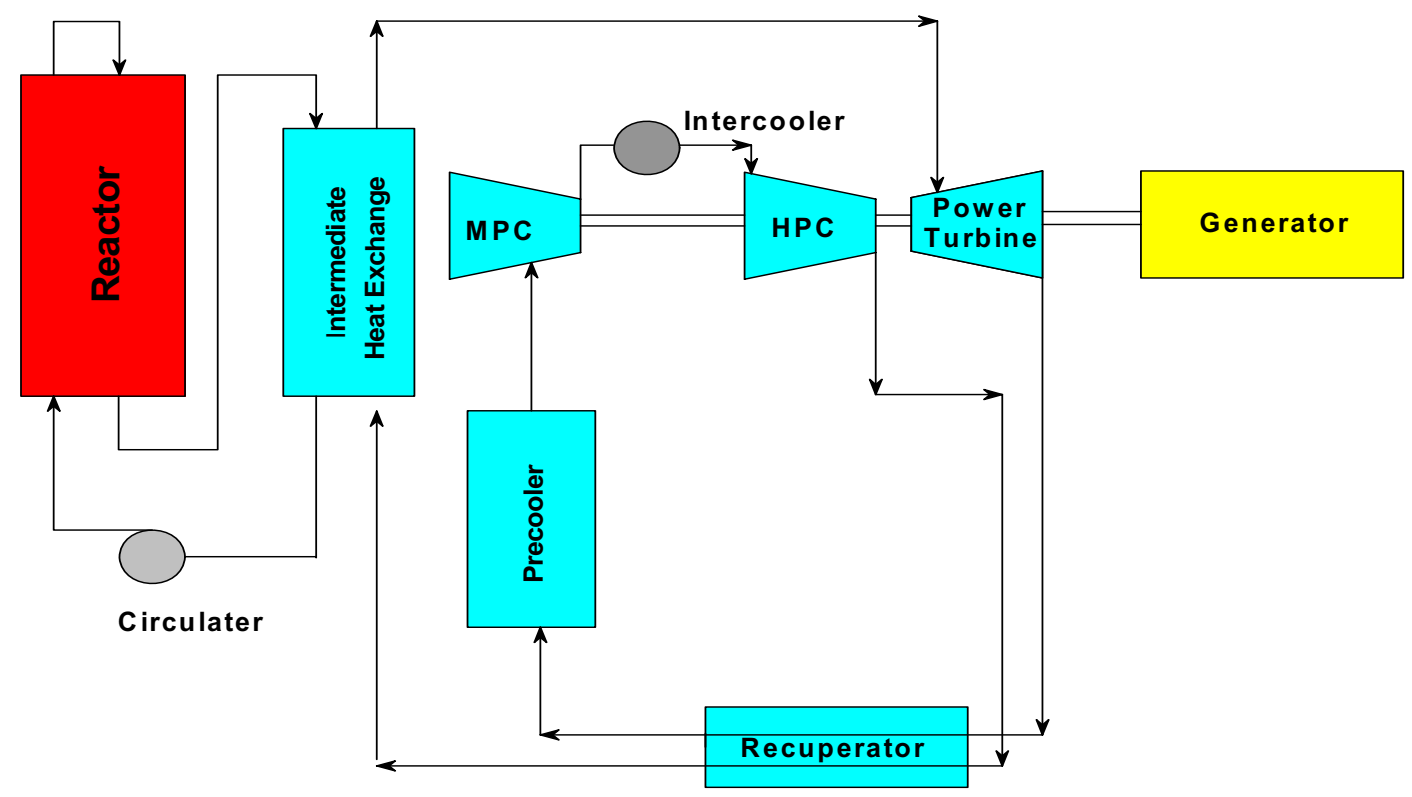

Figure 2-10. One shaft arrangement.

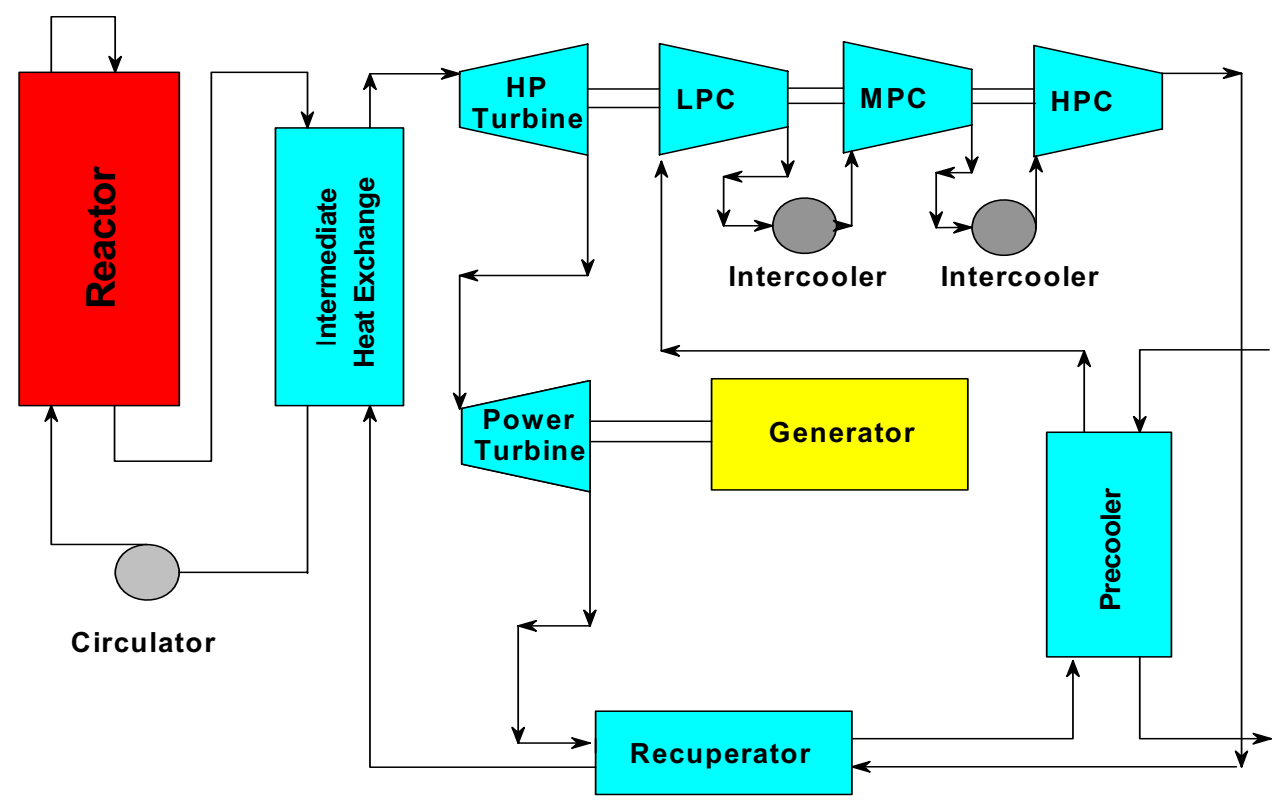

Figure 2-11. Two shaft arrangement. 


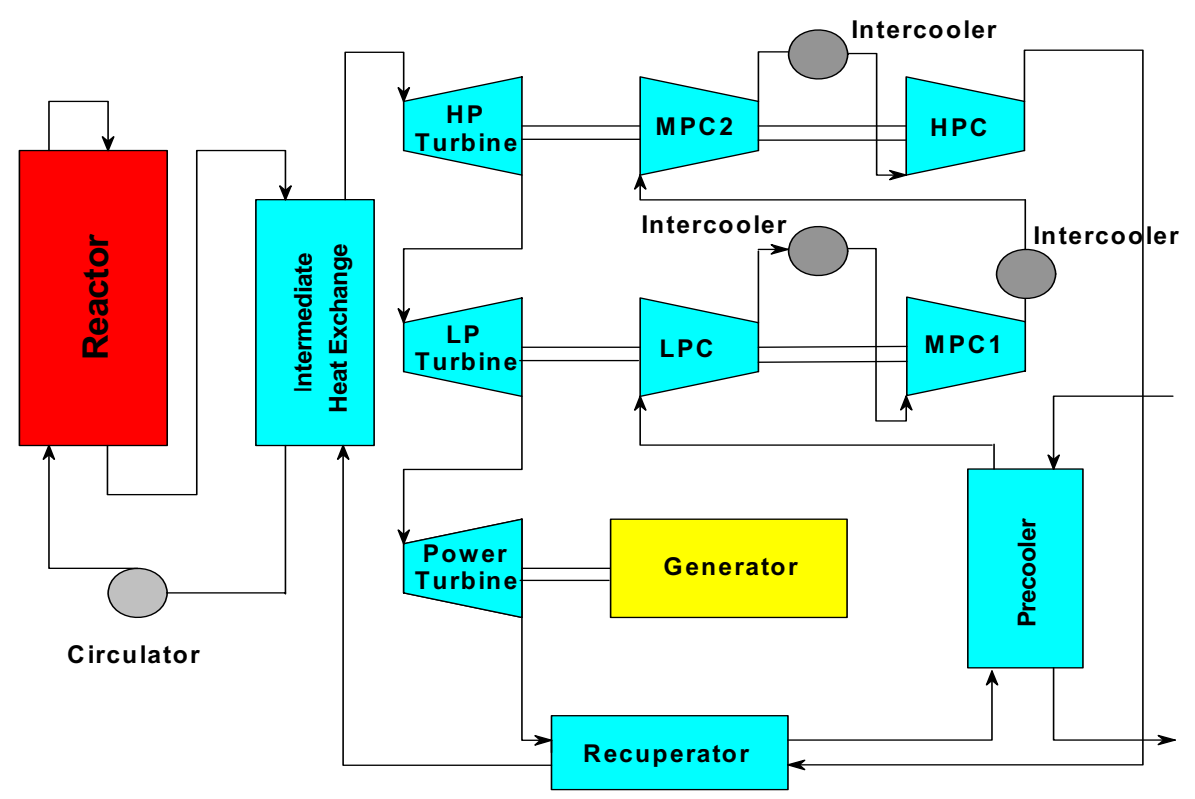

Figure 2-12. Three shaft arrangement.

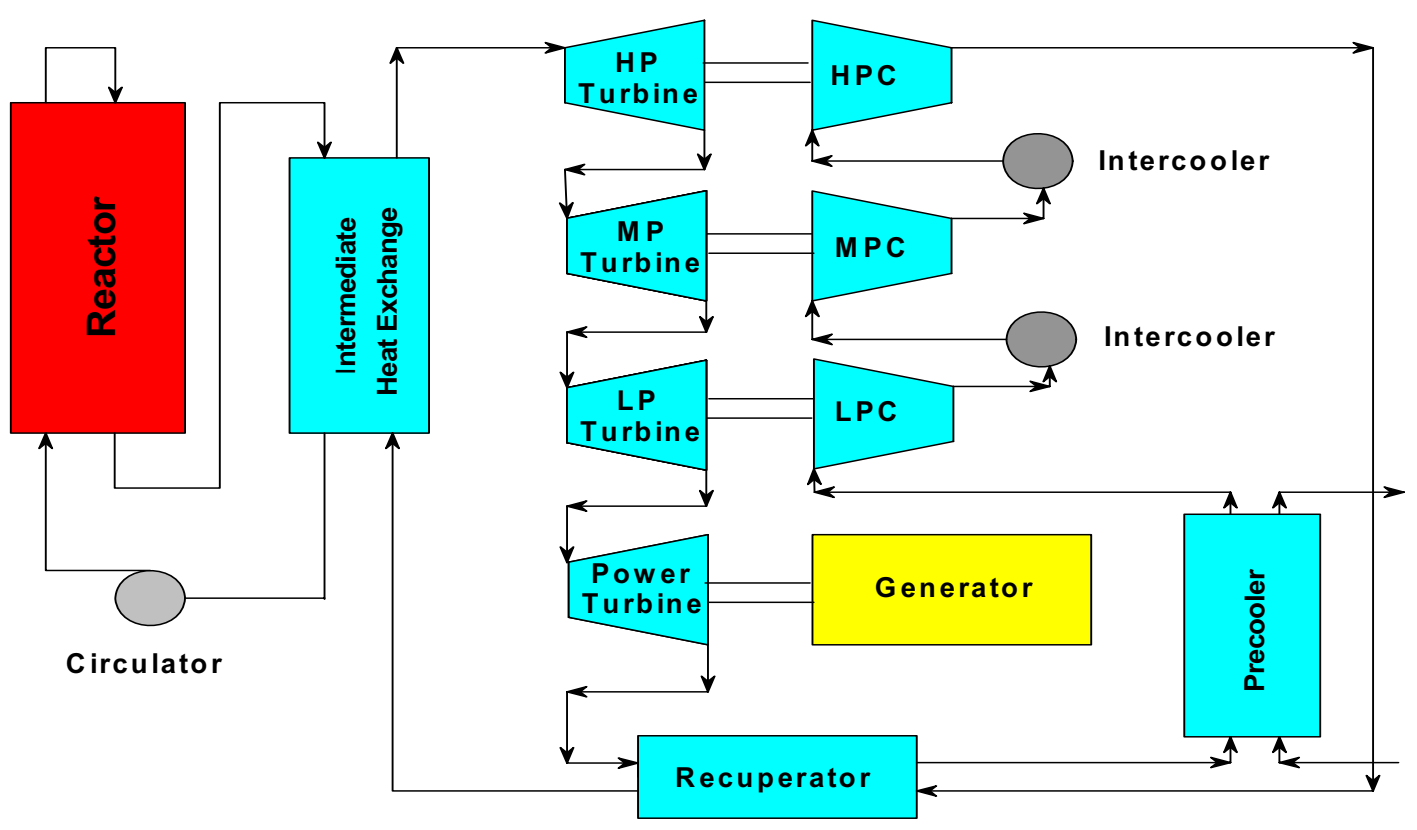

Figure 2-13. Four shaft arrangement. 
Figures 2-14 to 2-17 show steady-state results using HYSYS for the shaft configuration aforementioned above:

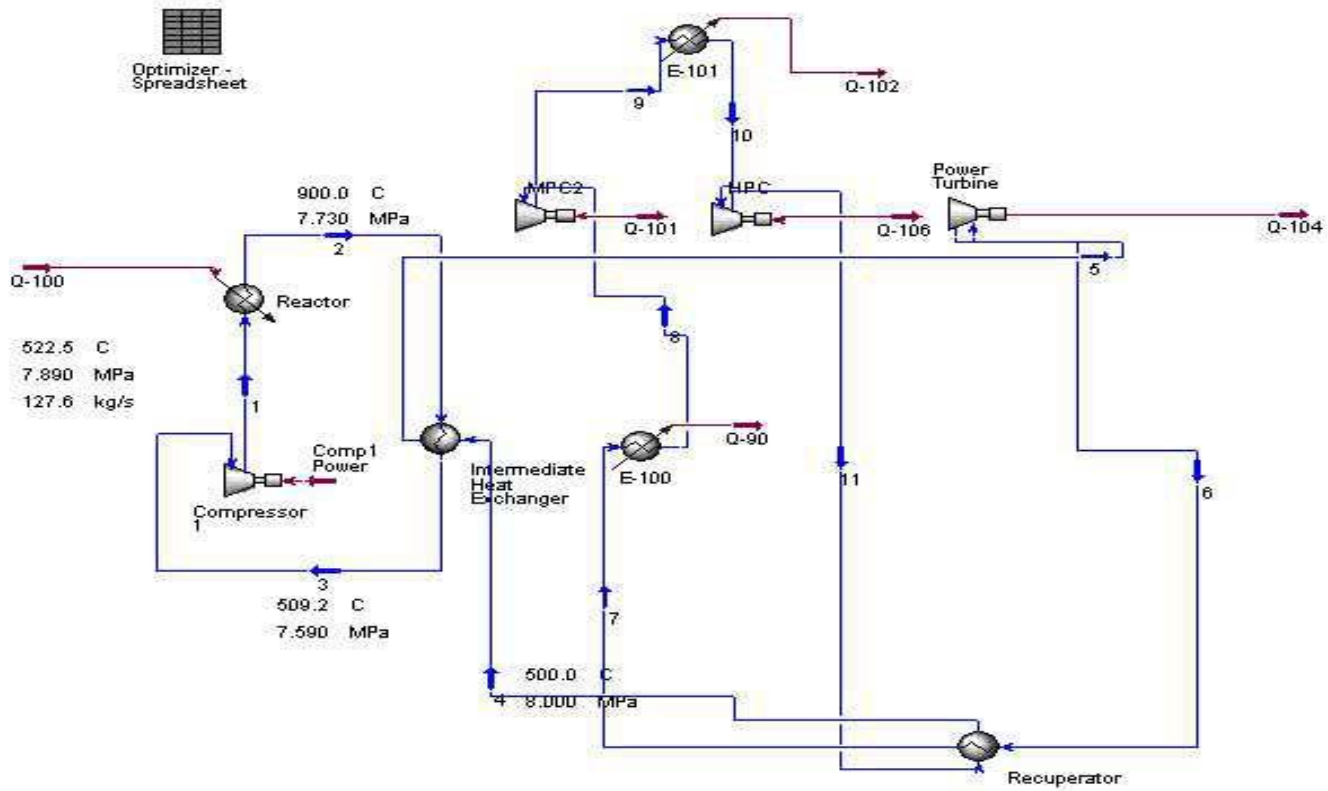

Figure 2-14. HYSYS one shaft model

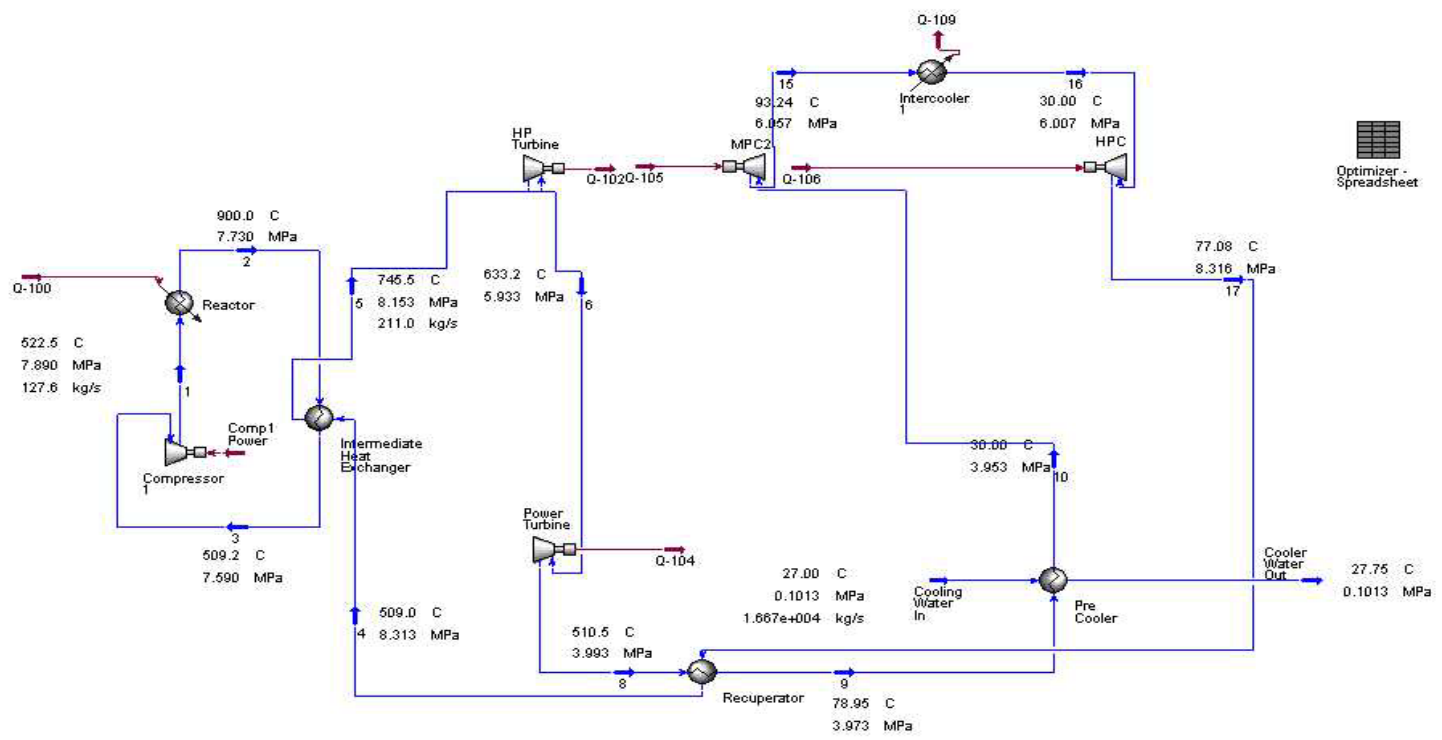

Figure 2-15. HYSYS two shaft model 


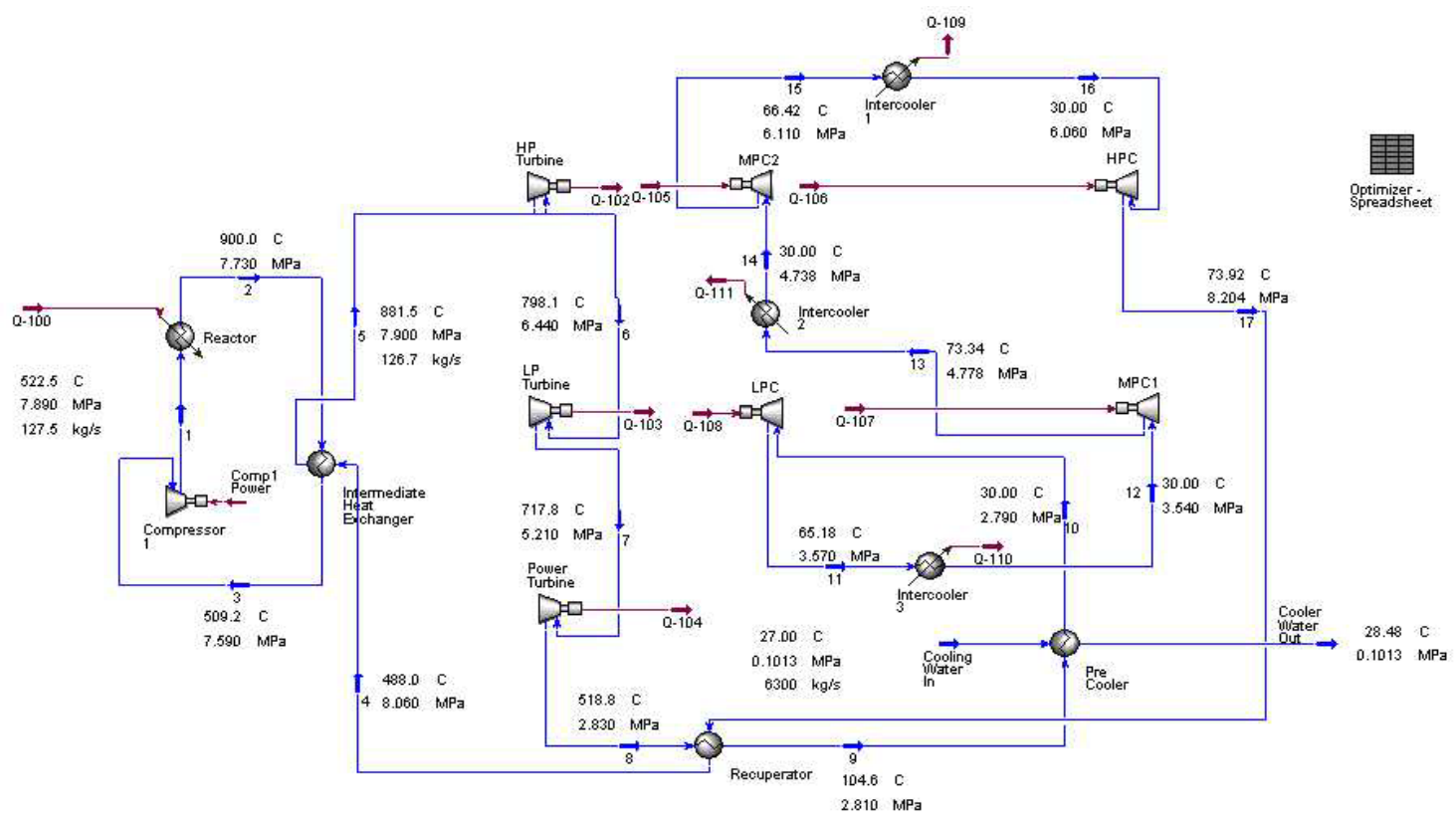

Figure 2-16. HYSYS three shaft model

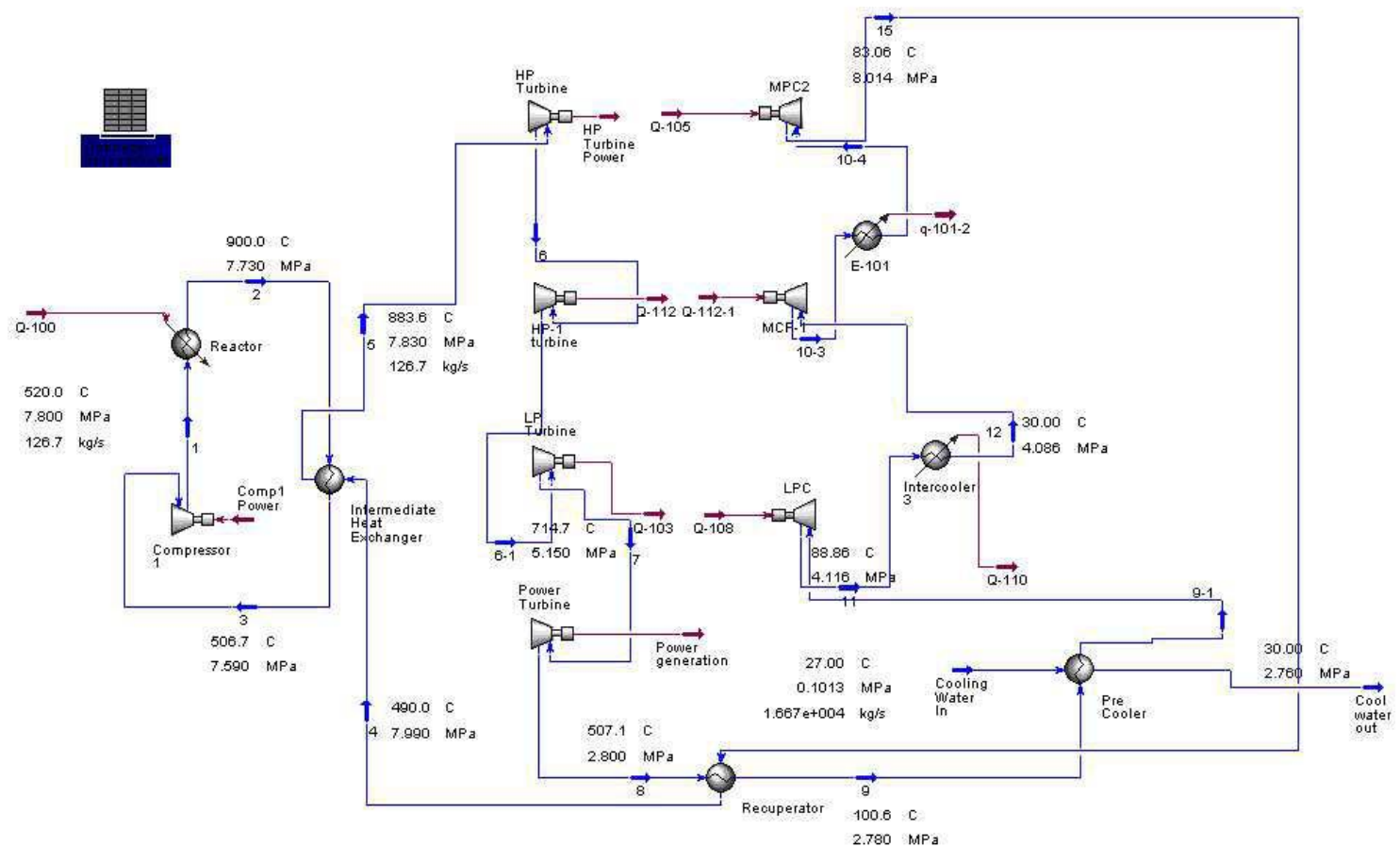

Figure 2-17. HYSYS four shaft model 
Table 2-3. Comparisons of one-shaft vs. multiple-shafts.

\begin{tabular}{|c|c|c|c|c|}
\hline \\
\hline & One-shaft & Two-shaft & Three-shaft & Four-shaft \\
\hline Busbar efficiency & $47 \%$ & $49 \%$ & $48 \%$ & $49 \%$ \\
\hline \multirow{2}{*}{ Heat Exchanger Outlet } & $736.5^{\circ} \mathrm{C}$ & $745.5^{\circ} \mathrm{C}$ & $881.5^{\circ} \mathrm{C}$ & $883.6^{0} \mathrm{C}$ \\
\hline & $7.84 \mathrm{MPa}$ & $8.15 \mathrm{MPa}$ & $7.9 \mathrm{MPa}$ & $7.83 \mathrm{MPa}$ \\
\hline \multirow{2}{*}{ HP Turbine Outlet } & $\mathrm{N} / \mathrm{A}$ & $633.2^{\circ} \mathrm{C}$ & $798.1^{\circ} \mathrm{C}$ & $829.0^{\circ} \mathrm{C}$ \\
\hline & N/A & $5.93 \mathrm{MPa}$ & $6.44 \mathrm{MPa}$ & $6.86 \mathrm{MPa}$ \\
\hline \multirow{2}{*}{ HP-1 Turbine } & N/A & $\mathrm{N} / \mathrm{A}$ & $\mathrm{N} / \mathrm{A}$ & $774.5^{\circ} \mathrm{C}$ \\
\hline & $\mathrm{N} / \mathrm{A}$ & $\mathrm{N} / \mathrm{A}$ & $\mathrm{N} / \mathrm{A}$ & $5.98 \mathrm{MPa}$ \\
\hline \multirow{2}{*}{ LP Turbine Outlet } & $\mathrm{N} / \mathrm{A}$ & $\mathrm{N} / \mathrm{A}$ & $717.8^{\circ} \mathrm{C}$ & $714.7^{0} \mathrm{C}$ \\
\hline & $\mathrm{N} / \mathrm{A}$ & $\mathrm{N} / \mathrm{A}$ & $5.21 \mathrm{MPa}$ & $5.15 \mathrm{MPa}$ \\
\hline \multirow{2}{*}{ Power Turbine Outlet } & $514.6^{\circ} \mathrm{C}$ & $510.5^{\circ} \mathrm{C}$ & $518.8^{\circ} \mathrm{C}$ & $507.1^{0} \mathrm{C}$ \\
\hline & $3.98 \mathrm{MPa}$ & $3.93 \mathrm{MPa}$ & $2.83 \mathrm{MPa}$ & $2.8 \mathrm{MPa}$ \\
\hline \multirow{2}{*}{ Recuperator Outlet LP } & $86.7^{\circ} \mathrm{C}$ & $78.9^{\circ} \mathrm{C}$ & $104.6^{\circ} \mathrm{C}$ & $100.6^{0} \mathrm{C}$ \\
\hline & $3.98 \mathrm{MPa}$ & $3.97 \mathrm{MPa}$ & $2.81 \mathrm{MPa}$ & $2.78 \mathrm{MPa}$ \\
\hline \multirow{2}{*}{ Precooler Outlet } & $30.0^{\circ} \mathrm{C}$ & $30.0^{\circ} \mathrm{C}$ & $30^{\circ} \mathrm{C}$ & $30 .{ }^{0} \mathrm{C}$ \\
\hline & $3.96 \mathrm{MPa}$ & $3.95 \mathrm{MPa}$ & $2.79 \mathrm{MPa}$ & $2.76 \mathrm{MPa}$ \\
\hline \multirow{2}{*}{ LP Compressor Outlet } & N/A & N/A & $65.2^{\circ} \mathrm{C}$ & $88.9^{\circ} \mathrm{C}$ \\
\hline & $\mathrm{N} / \mathrm{A}$ & $\mathrm{N} / \mathrm{A}$ & $3.57 \mathrm{MPa}$ & 4.12 MPa \\
\hline \multirow{2}{*}{ Intercooler1 Outlet } & N/A & $\mathrm{N} / \mathrm{A}$ & $30.0^{\circ} \mathrm{C}$ & $30 .{ }^{\circ} \mathrm{C}$ \\
\hline & $\mathrm{N} / \mathrm{A}$ & $\mathrm{N} / \mathrm{A}$ & $6.06 \mathrm{MPa}$ & $5.57 \mathrm{MPa}$ \\
\hline \multirow{2}{*}{ MP1 Compressor Outlet } & $\mathrm{N} / \mathrm{A}$ & $\mathrm{N} / \mathrm{A}$ & $73.3^{\circ} \mathrm{C}$ & $83.5^{\circ} \mathrm{C}$ \\
\hline & $\mathrm{N} / \mathrm{A}$ & $\mathrm{N} / \mathrm{A}$ & $4.78 \mathrm{MPa}$ & $5.57 \mathrm{MPa}$ \\
\hline \multirow{2}{*}{ Intercooler2 Outlet } & $\mathrm{N} / \mathrm{A}$ & $\mathrm{N} / \mathrm{A}$ & $30.0^{\circ} \mathrm{C}$ & $\mathrm{N} / \mathrm{A}$ \\
\hline & $\mathrm{N} / \mathrm{A}$ & $\mathrm{N} / \mathrm{A}$ & $4.74 \mathrm{MPa}$ & $\mathrm{N} / \mathrm{A}$ \\
\hline \multirow{2}{*}{ MP2 Compressor Outlet } & $91 .^{\circ} \mathrm{C}$ & $93.2^{\circ} \mathrm{C}$ & $66.4^{\circ} \mathrm{C}$ & $83.1{ }^{0} \mathrm{C}$ \\
\hline & 6. $\mathrm{MPa}$ & $6.06 \mathrm{MPa}$ & $6.11 \mathrm{MPa}$ & 8.01 MPa \\
\hline \multirow{2}{*}{ Intercooler3 Outlet } & $30.0^{\circ} \mathrm{C}$ & $30.0^{\circ} \mathrm{C}$ & $30.0^{\circ} \mathrm{C}$ & $30 .{ }^{0} \mathrm{C}$ \\
\hline & $5.99 \mathrm{MPa}$ & $6.0 \mathrm{MPa}$ & $3.54 \mathrm{MPa}$ & $4.09 \mathrm{MPa}$ \\
\hline \multirow{2}{*}{ HP Compressor Outlet } & $71.7^{\circ} \mathrm{C}$ & $77.1^{\circ} \mathrm{C}$ & $73.9^{\circ} \mathrm{C}$ & N/A \\
\hline & $8.01 \mathrm{MPa}$ & $8.31 \mathrm{MPa}$ & $8.20 \mathrm{MPa}$ & $\mathrm{N} / \mathrm{A}$ \\
\hline \multirow{2}{*}{ Recuperator Outlet HP } & $500 .{ }^{\circ} \mathrm{C}$ & $509 .{ }^{\circ} \mathrm{C}$ & $488.8^{\circ} \mathrm{C}$ & $490^{\circ} \mathrm{C}$ \\
\hline & $8.0 \mathrm{MPa}$ & $8.31 \mathrm{MPa}$ & $8.06 \mathrm{MPa}$ & $7.99 \mathrm{MPa}$ \\
\hline Pressure ratio & 2.1 & 2.1 & 2.9 & 2.9 \\
\hline $\begin{array}{l}\text { Avg. turbine workload } \\
\text { (MW) }\end{array}$ & a & 124 & 52 & 37.2 \\
\hline
\end{tabular}


The tradeoff among the number of shaft will be further investigated in this study. Although many believe that the three or four shaft system is more expensive, turbine designers disagree with them. Some US turbo-manufacturer allow powers no higher than $52 \mathrm{MW}$ (70 kHP) for a single turbine while Japanese turbomachinery can manufacture turbines much higher than $52 \mathrm{MW}$.

Using helium gas in the secondary flow loop as a baseline, Brayton cycle efficiencies were calculated with HYSYS process optimization scheme and these results were compared with the Visual Basics model that was originally developed by Ron Ballinger at MIT and modified by us. The detailed baseline calculations with various shaft configurations will be reported in the annual report. The Brayton cycle efficiency with helium is $48 \%$, which also compares well with the Visual Basic model developed from this study. The Brayton cycle with supercritical $\mathrm{CO}_{2}$ for the three-shaft configuration produces a Brayton cycle efficiency of 54\%, an improvement over the helium cycle. 


\section{TASK 2: IMPROVEMENT OF VHTR NET EFFICIENCY}

\section{Task 2-1 Parametric study due to enhancement of each component's efficiency}

The objective of this task is to determine the overall plant busbar efficiency by the combination of the increased efficiency of each component in the secondary side of the HTGR. To accomplish this task, we performed a parametric study of the effect of each component on the overall Brayton cycle efficiency.

\section{Turbine Inlet Temperature}

The inlet temperature to the high-pressure turbine is dependent on the temperature at which coolant exits the core and the effectiveness of IHX. For a given power conversion unit with a fixed IHX effectiveness the turbine inlet temperature is solely dependent on the primary outlet temperature.

Plotting the cycle efficiency and cycle pressure ratio as function of IHX primary outlet temperature, it is observed that there exists a maximum cycle efficiency for a given core exit temperature. It is also observed that the cycle pressure ratio increases, as the core outlet temperature is increases but decreases as the IHX primary outlet temperature is increased. Maximum cycle efficiency coincides with an optimum pressure ratio.

Other considerations must be made when selecting the core exit temperature. One such consideration is the IHX primary outlet temperature; ASME has specified that this outlet cannot exceed $400{ }^{\circ} \mathrm{C}$. Table 4 summarizes results of parametric study as a function of turbine inlet temperature using the Visual Basic model. Figures 3-1 and 3-2 show cycle efficiency vs. IHX primary outlet temperature, and cycle pressure ratio vs. IHX primary outlet temperature, respectively as a function of core outlet temperatures.

Table 3-1. Parametric study as a function of the turbine inlet temperature.

\begin{tabular}{|c|c|c|c|c|c|c|c|}
\hline $\begin{array}{c}\text { IHX } \\
\text { Effectiveness }\end{array}$ & $\begin{array}{c}\text { Core Outlet } \\
\text { Temperature } \\
{ }^{\circ} \mathrm{C}\end{array}$ & $\begin{array}{c}\text { Core Inlet } \\
\text { Temperature } \\
{ }^{\circ} \mathrm{C}\end{array}$ & $\begin{array}{c}\text { Primary } \\
\text { Outlet } \\
\text { Temperature } \\
{ }^{\circ} \mathrm{C}\end{array}$ & $\begin{array}{c}\text { IHX } \\
\text { Secondary } \\
\text { Inlet } \\
\text { Temperature } \\
{ }^{\circ} \mathrm{C}\end{array}$ & $\begin{array}{c}\text { IHX } \\
\text { Secondary } \\
\text { Outlet } \\
\text { Temperature } \\
{ }^{\circ} \mathrm{C}\end{array}$ & $\begin{array}{c}\text { Cycle } \\
\text { Pressure } \\
\text { Ratio }\end{array}$ & $\begin{array}{c}\text { Plant } \\
\text { Busbar } \\
\text { Efficiency } \\
\%\end{array}$ \\
\hline & 850 & 400 & 388.25 & 348.10 & 809.86 & 4.6569 & 42.55 \\
\hline & & 420 & 407.90 & 369.46 & 811.56 & 4.2427 & 43.16 \\
\hline & & 440 & 427.55 & 390.83 & 813.28 & 3.8784 & 43.67 \\
\hline & & 460 & 447.20 & 412.19 & 814.99 & 3.5564 & 44.08 \\
\hline & & 480 & 466.85 & 433.55 & 816.70 & 3.2705 & 44.39 \\
\hline & & 500 & 486.50 & 454.91 & 818.40 & 3.0159 & 44.58 \\
\hline & & 520 & 506.15 & 476.47 & 820.11 & 2.7883 & 44.64 \\
\hline & & 540 & 525.80 & 497.63 & 821.82 & 2.5840 & 44.57 \\
\hline & & 560 & 545.45 & 518.99 & 823.53 & 2.4002 & 44.34 \\
\hline & & 600 & 584.75 & 561.71 & 826.95 & 2.0839 & 43.32 \\
\hline & & 620 & 604.40 & 583.07 & 828.65 & 1.9475 & 42.44 \\
\hline & & 640 & 624.06 & 604.43 & 830.36 & 1.8233 & 41.24 \\
\hline & & 400 & 388.25 & 343.76 & 855.52 & 5.3357 & 43.65 \\
\hline & & 420 & 407.90 & 365.11 & 857.22 & 4.8568 & 44.32 \\
\hline
\end{tabular}




\begin{tabular}{|c|c|c|c|c|c|c|c|}
\hline $\begin{array}{c}\text { IHX } \\
\text { Effectiveness }\end{array}$ & $\begin{array}{c}\text { Core Outlet } \\
\text { Temperature } \\
{ }^{\circ} \mathrm{C}\end{array}$ & $\begin{array}{c}\text { Core Inlet } \\
\text { Temperature } \\
{ }^{\circ} \mathrm{C}\end{array}$ & $\begin{array}{c}\text { IHX } \\
\text { Primary } \\
\text { Outlet } \\
\text { Temperature } \\
{ }^{\circ} \mathrm{C} \\
\end{array}$ & $\begin{array}{c}\text { IHX } \\
\text { Secondary } \\
\text { Inlet } \\
\text { Temperature } \\
{ }^{\circ} \mathrm{C} \\
\end{array}$ & $\begin{array}{c}\text { IHX } \\
\text { Secondary } \\
\text { Outlet } \\
\text { Temperature } \\
{ }^{\circ} \mathrm{C} \\
\end{array}$ & $\begin{array}{c}\text { Cycle } \\
\text { Pressure } \\
\text { Ratio }\end{array}$ & $\begin{array}{c}\text { Plant } \\
\text { Busbar } \\
\text { Efficiency } \\
\%\end{array}$ \\
\hline & & 440 & 427.55 & 386.48 & 858.92 & 4.4357 & 44.90 \\
\hline & & 460 & 447.20 & 407.84 & 860.64 & 4.0641 & 45.40 \\
\hline & & 480 & 466.85 & 429.30 & 862.34 & 3.7345 & 45.80 \\
\hline & & 500 & 486.50 & 450.56 & 864.06 & 3.4412 & 46.11 \\
\hline & & 520 & 506.15 & 471.92 & 865.76 & 3.1791 & 46.32 \\
\hline & & 540 & 525.80 & 493.28 & 867.47 & 2.9442 & 46.43 \\
\hline & & 560 & 545.45 & 514.65 & 869.18 & 2.7330 & 46.42 \\
\hline & & 580 & 565.10 & 536.00 & 870.89 & 2.5424 & 46.28 \\
\hline & & 600 & 584.75 & 557.36 & 872.59 & 2.3700 & 46.00 \\
\hline & & 620 & 604.40 & 578.72 & 874.31 & 2.2135 & 45.54 \\
\hline & & 640 & 624.05 & 600.09 & 876.01 & 2.0712 & 44.89 \\
\hline & 950 & 400 & 388.25 & 338.80 & 907.50 & 6.1970 & 44.75 \\
\hline & & 420 & 407.90 & 360.16 & 909.22 & 5.6347 & 45.47 \\
\hline & & 440 & 427.55 & 381.52 & 910.92 & 5.1411 & 46.11 \\
\hline & & 460 & 447.20 & 402.88 & 912.62 & 4.7058 & 46.67 \\
\hline & & 480 & 466.85 & 424.25 & 914.34 & 4.3204 & 47.15 \\
\hline & & 500 & 486.50 & 445.61 & 916.05 & 3.9777 & 47.55 \\
\hline & & 520 & 506.15 & 466.97 & 917.76 & 3.6718 & 47.87 \\
\hline & & 540 & 525.80 & 488.33 & 919.46 & 3.3979 & 48.11 \\
\hline & & 560 & 545.45 & 509.69 & 921.17 & 3.1517 & 48.35 \\
\hline & & 580 & 565.10 & 531.05 & 922.88 & 2.9299 & 48.31 \\
\hline & & 600 & 584.75 & 552.41 & 912.59 & 2.7293 & 48.26 \\
\hline & & 620 & 604.40 & 573.77 & 926.29 & 2.5475 & 48.09 \\
\hline & & 640 & 624.05 & 595.13 & 927.74 & 2.3808 & 47.82 \\
\hline & 1000 & 400 & 388.25 & 333.07 & 958.20 & 7.1653 & 46.42 \\
\hline & & 420 & 407.90 & 354.43 & 959.51 & 6.5014 & 47.21 \\
\hline & & 440 & 427.55 & 375.79 & 960.81 & 5.9199 & 47.93 \\
\hline & & 460 & 447.20 & 397.15 & 962.11 & 5.4080 & 48.59 \\
\hline & & 480 & 466.85 & 418.52 & 963.42 & 4.9556 & 49.17 \\
\hline & & 500 & 486.50 & 439.87 & 964.72 & 4.5541 & 49.69 \\
\hline & & 520 & 506.15 & 461.24 & 966.02 & 4.1963 & 50.15 \\
\hline & & 540 & 525.80 & 482.60 & 967.32 & 3.8764 & 50.54 \\
\hline & & 560 & 545.45 & 503.96 & 968.62 & 3.5895 & 50.86 \\
\hline & & 580 & 565.10 & 525.32 & 969.92 & 3.3319 & 51.11 \\
\hline & & 600 & 584.75 & 546.68 & 971.22 & 3.0992 & 51.29 \\
\hline & & 620 & 604.40 & 568.04 & 972.51 & 2.8884 & 51.39 \\
\hline & & 640 & 624.05 & 589.40 & 973.81 & 2.6970 & 51.41 \\
\hline
\end{tabular}




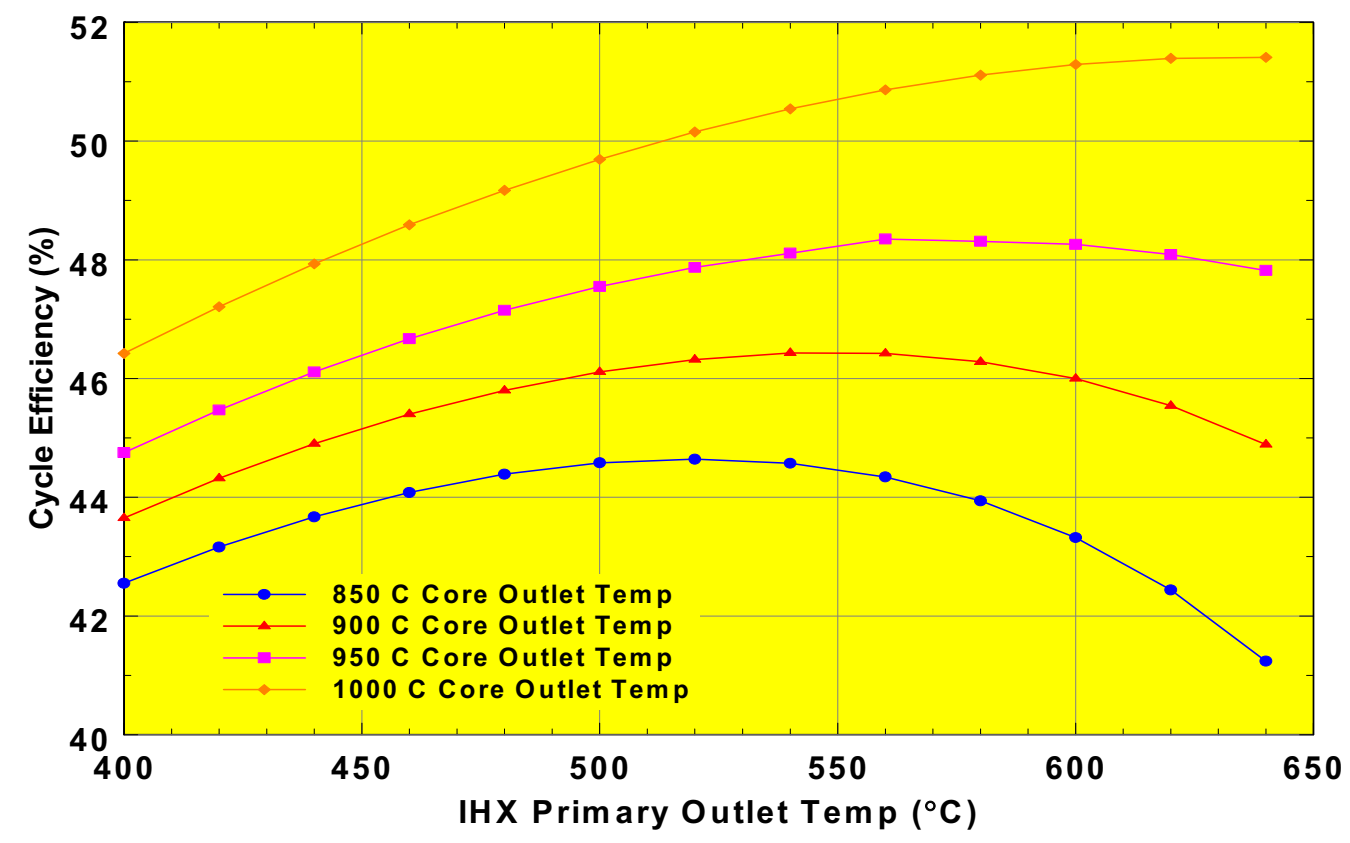

Figure 3-1. Cycle efficiency as a function of IHX primary outlet temperature for different reactor core outlet temperature.

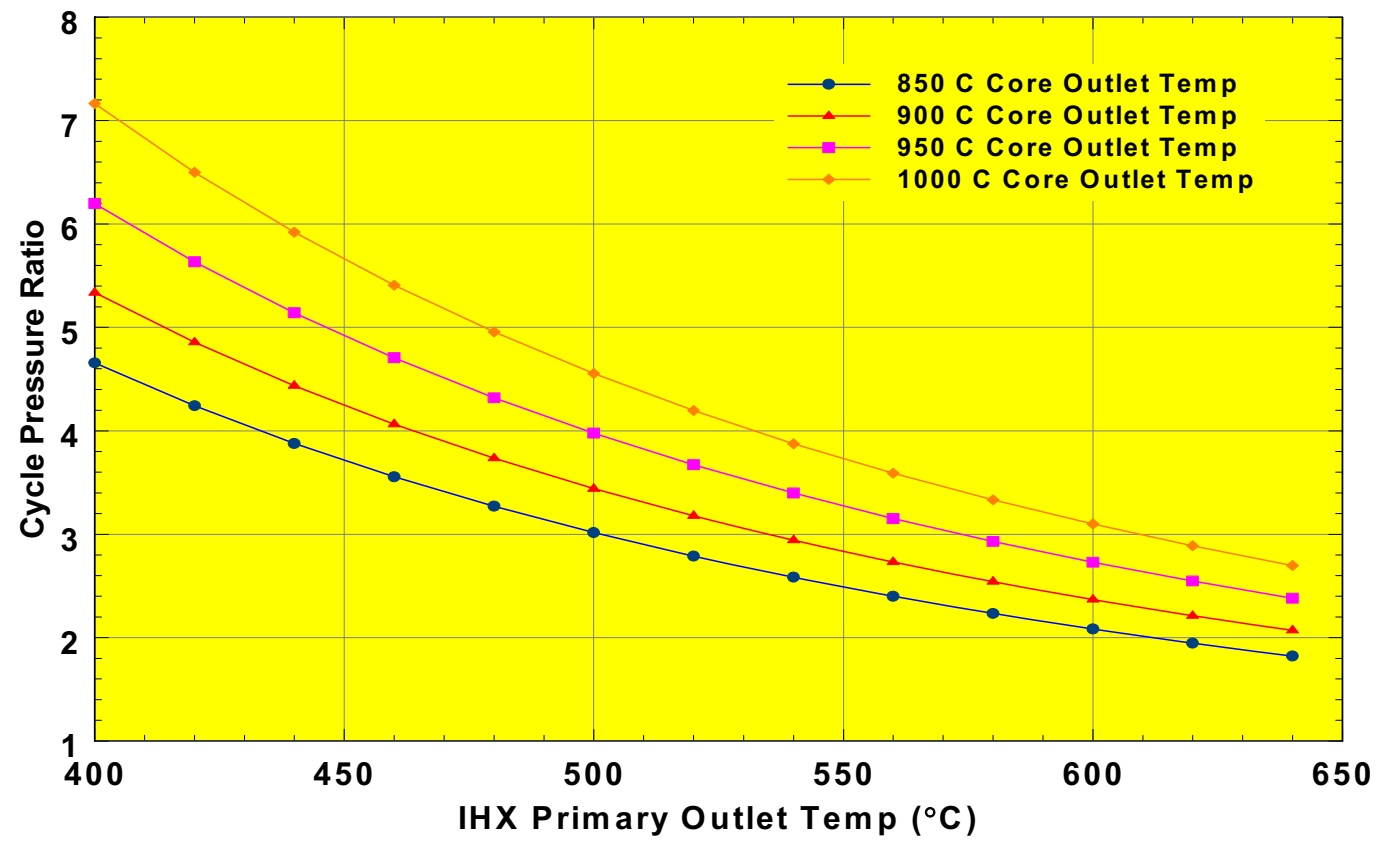

Figure 3-2. Cycle pressure ratio as a function of IHX primary outlet temperature for different reactor core outlet temperature. 


\section{Other Parameters}

Important parameters for improving the Brayton cycle efficiency are increasing the reactor core outlet temperature, increasing the efficiencies of the compressor, turbine, intermediate heat exchanger, and others. The reactor core outlet temperature was varied between $850^{\circ} \mathrm{C}$ and $1000^{\circ} \mathrm{C}$. For each of the fixed outlet temperatures $\left(850^{\circ} \mathrm{C}, 900^{\circ} \mathrm{C}, 950^{\circ} \mathrm{C}\right.$ and $\left.1000^{\circ} \mathrm{C}\right)$, the inlet temperature to the core was varied between $400^{\circ} \mathrm{C}$ and $640^{\circ} \mathrm{C}$. All of the above cases are based on a three shaft arrangement for the helium Brayton cycle, using an intermediate heat exchanger effectiveness factor of $92 \%$, a $90 \%$ polytropic efficiency for the compressors and turbines, and a $30^{\circ} \mathrm{C}$ cooling temperature to the precooler and the three intercoolers.

The mass flow rate through the core needed to remove $250 \mathrm{MW}$ of thermal energy from the reactor core is a function of the required temperature drop across the core. Thus, the pressure drop across the core is a function of the core mass flow rate. Previously we did not account for the effect of the pressure drop on the Brayton cycle efficiency. For these calculations, we used a pressure drop equation shown below that is based on a pebble bed reactor.

The friction pressure drop $\Delta \mathrm{P}_{\mathrm{f}}$ through a pebble bed of height $\mathrm{H}$ [Oh and Moore, 2004] can be expressed as

$$
\Delta \mathrm{P}_{\mathrm{f}}=\psi \cdot \frac{\mathrm{H}}{\mathrm{d}_{\mathrm{h}}} \cdot \frac{\rho_{\text {ave }}}{2} \cdot \mathrm{U}_{\mathrm{p}}^{2}
$$

where $\psi$ is the pressure drop coefficient, $H$ is the height of the core, $d_{h}$ is the hydraulic diameter, $\rho_{\text {ave }}$ is the average density of the fluid in the core, and $U_{p}$ is the mean velocity in the gaps between the particles.

The new V-B numerical model with the new pressure drop correlation was benchmarked against a three-shaft baseline case based on HYSYS simulation. The results and comparison are shown in Table 32 .

Table 3-2. Comparison between HYSYS simulation and Visual-Basic based model.

\begin{tabular}{|c|c|c|c|c|c|}
\hline $\begin{array}{c}\text { Calculation } \\
\text { Method }\end{array}$ & $\begin{array}{c}\text { Inlet temperature/ } \\
\text { pressure to HP } \\
\text { turbine }\end{array}$ & $\begin{array}{c}\text { Outlet } \\
\text { temperature/pressure } \\
\text { to HP compressor }\end{array}$ & $\begin{array}{c}\text { Total } \\
\text { compression } \\
\text { work } \\
\text { (MW) }\end{array}$ & $\begin{array}{c}\text { Total } \\
\text { turbine } \\
\text { work } \\
\text { (MW) }\end{array}$ & $\begin{array}{c}\text { Busbar } \\
\text { efficiency }\end{array}$ \\
\hline HYSYS & $8650 \mathrm{C} / 746 \mathrm{MPa}$ & $74.50 \mathrm{C} / 7.9 \mathrm{MPA}$ & 111.7 & 129.5 & $47 \%$ \\
\hline V-B Model & $8640 \mathrm{C} / 746 \mathrm{MPa}$ & $77.50 \mathrm{C} / 8.0 \mathrm{MPA}$ & 112.7 & 129.9 & $46 \%$ \\
\hline
\end{tabular}

Figure 3-3 shows a three-dimensional plot of the plant busbar efficiency (this terminology is used in the turbomachinery) as a function of reactor inlet and outlet temperatures for a three-shaft $250 \mathrm{MW}$ thermal helium Brayton cycle using a 92\% effectiveness factor for the intermediate heat exchange and 90 $\%$ polytropic efficiency for the turbines and compressors. 


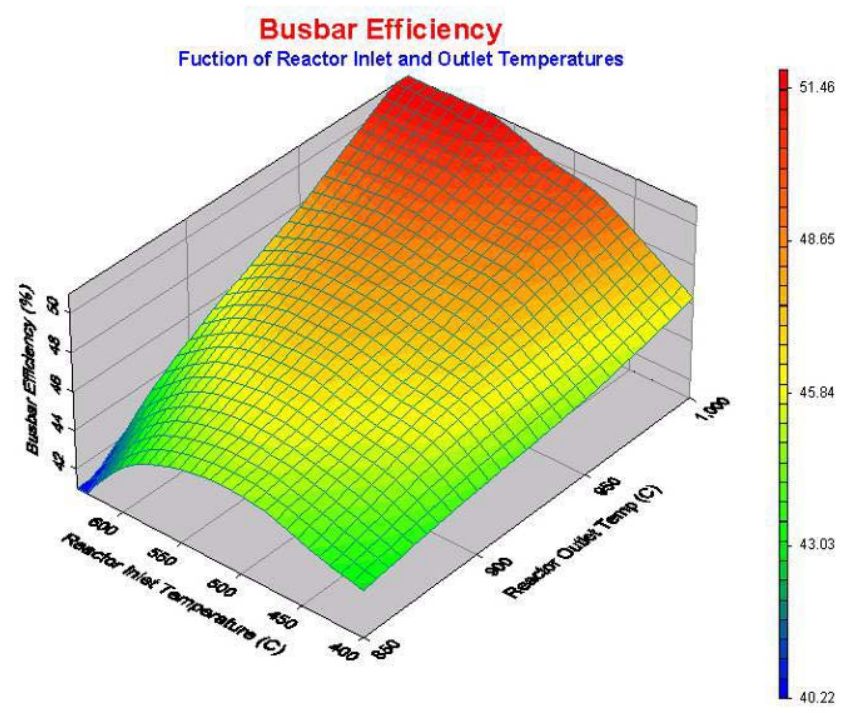

Figure 3-3. Busbar efficiency as a function of temperature difference across the reactor.

We investigated the effect of compressor efficiency on the overall Brayton cycle efficiency by varying the compressor efficiency from 90 to $94 \%$ as shown in Figure 3-4.

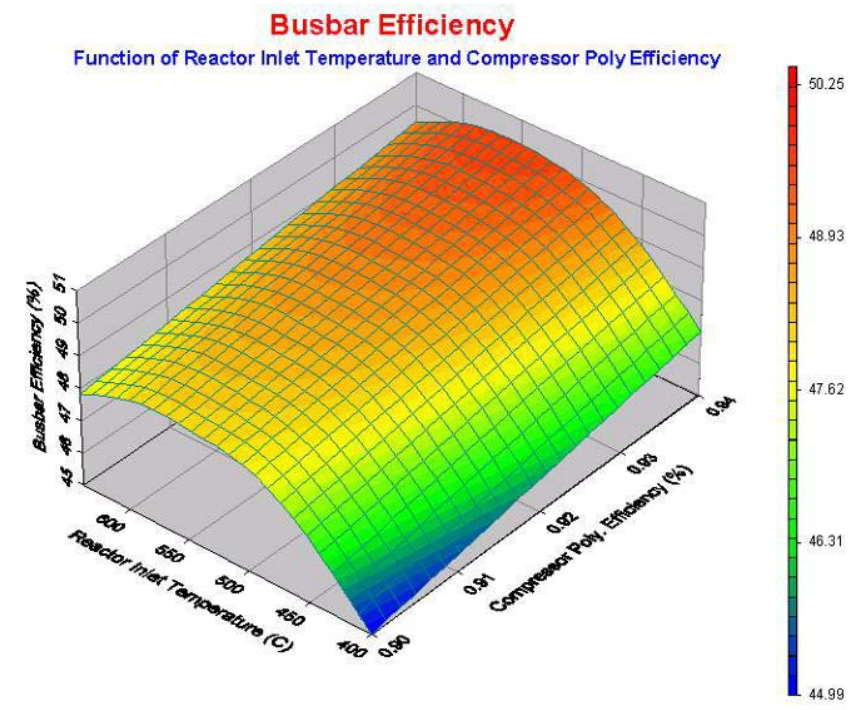

Figure 3-4. Busbar efficiency as a function of compressor efficiencies and reactor inlet temperatures.

A practical way of reducing compressor work is to keep the specific volume of the gas as small as possible during the polytropic compression. This is achieved by maintaining the temperature of the gas as low as possible because specific volume is proportional to temperature. By dividing the compression process into stages and cooling the gas between stages, the total work done during the compression process is reduced. By reducing the compressor inlet temperature by $1^{0} \mathrm{C}$, the overall cycle efficiency increases by $0.131 \%$ as shown in Figure 3-5. 


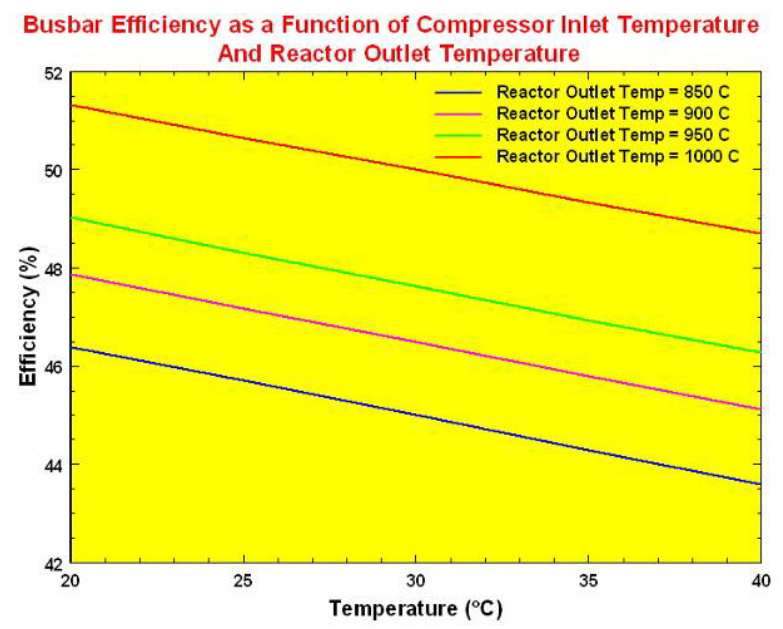

Figure 3-5. Busbar efficiency at various cooling temperature.

We also investigated the sensitivity of the effectiveness of intermediate heat exchanger (IHX) on the overall busbar efficiency. If the effectiveness of IHX is improved from $90 \%$ to $92 \%$ at a core outlet temperature of $950^{\circ} \mathrm{C}$ and a core inlet temperature of $400^{\circ} \mathrm{C}$, for example, there is an initial improvement of the overall Brayton efficiency by $0.65 \%$. The IHX effectiveness has less impact on the efficiency compared to the compressor efficiency.

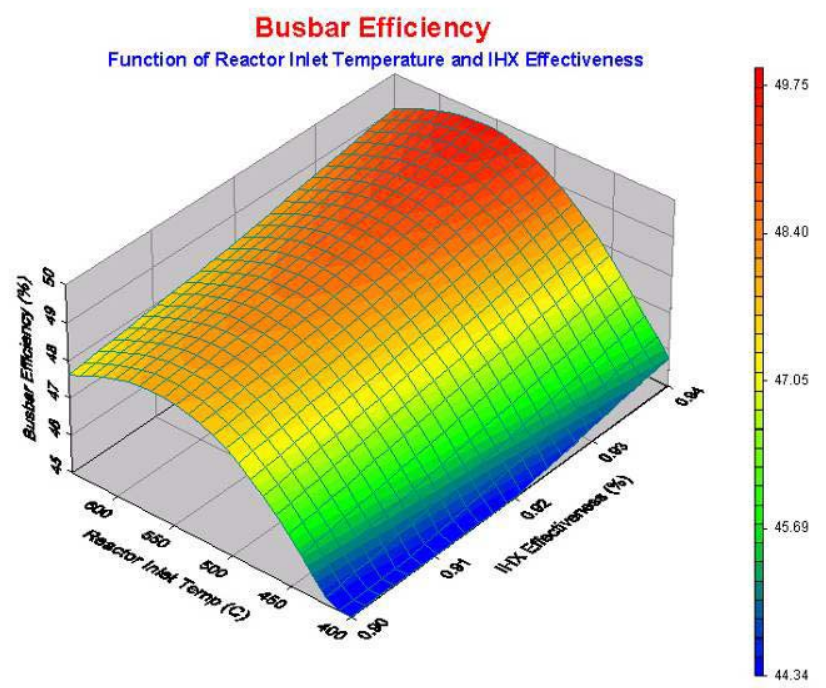

Figure 3-6. Busbar efficiency as a function of IHX efficiencies and reactor inlet temperatures.

Figure 3-7 shows how the temperature difference across the reactor impacts the power turbine inlet temperature that is very important to the overall efficiency. 


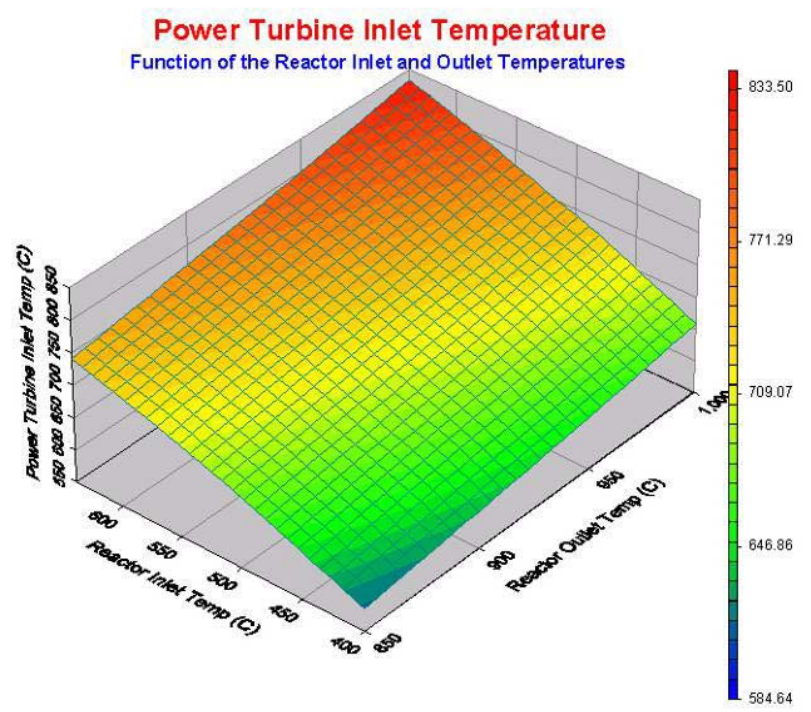

Figure 3-7. Power turbine inlet temperature as a function of temperature drop across the reactor.

The objective of this task is to determine the overall plant cycle efficiency by the combination of the increased efficiency of each component in the secondary side of the HTGR. To accomplish this task, we performed a number of parametric studies to determine the effect of each component on the overall Brayton cycle efficiency.

In order to calculate the pressure and temperature at the exit of a polytropic expansion or compression process, pressure-enthalpy $(\mathrm{P}-\mathrm{H})$ data from the NIST database was used. The procedure is described below and depicted in graphical form in Figure 3-8:

1. Starting Point 1, follow the line of constant entropy to the required discharge pressure of $\mathrm{P}_{2}$, locating the isentropic discharge state point of $2_{\text {is }}$.

2. With these two points located, the differential isentropic enthalpy can be calculated from the following equation:

$\Delta \mathrm{h}_{\mathrm{is}}=\mathrm{h}_{2_{\text {is }}}-\mathrm{h}_{1}$

3. Calculate the real discharge enthalpy of point 2 using:

$\mathrm{h}_{2}=\frac{\Delta \mathrm{h}_{\text {is }}}{\eta_{\text {is }}}+\mathrm{h}_{1}$

where $\eta_{\text {is }}$ is the isentropic process efficiency. The point 2 is on the same pressure $\mathrm{P}_{2}$ line shown on Figure 3-9. At the point 2, temperature can be obtained on the same temperature isotherm line in Figure 3-8.

The actual discharge temperature can now be obtained from the P-H diagram [GPSA, 2003] or P-H database. The helium properties were incorporated as a property look-up table. In these calculations, we used pressure-temperature-enthalpy data from the NIST database. 


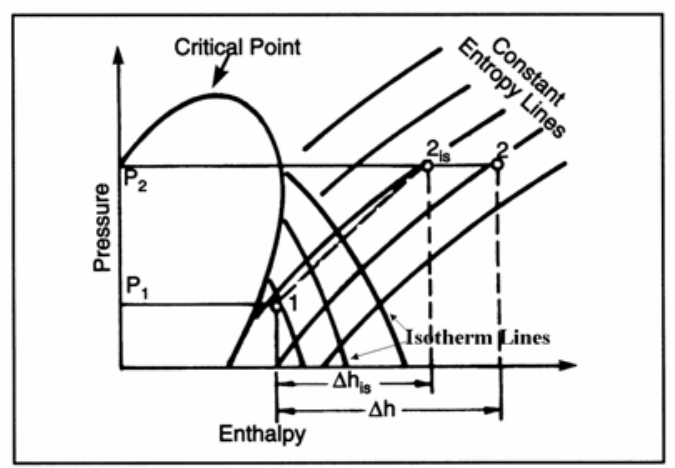

Figure 3-8. Pressure-Enthalpy diagram.

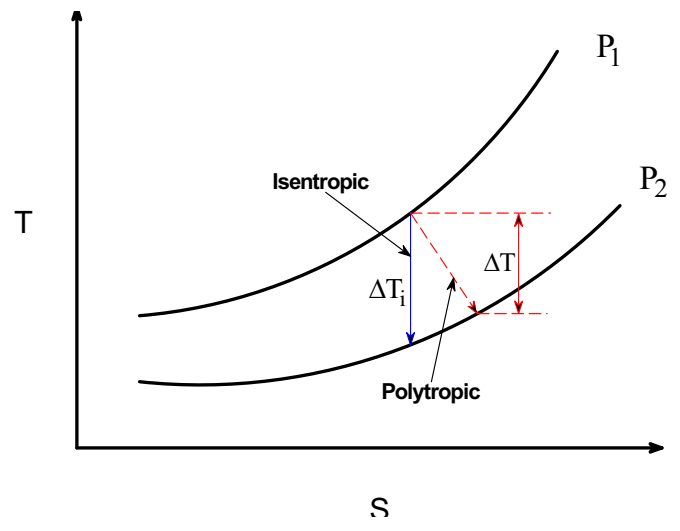

Figure 3-9. T-S diagram for isentropic and polytropic compression.

In the preceding quarters, we used heat capacities of helium for calculating the stream conditions through all unit-operation components. However, heat capacity of supercritical $\mathrm{CO}_{2}$ has a spiked value around the supercritical condition of pressure of $7.29 \mathrm{MPa}$ and temperature of $31^{\circ} \mathrm{C}$. Therefore, there was a need to use an enthalpy database for avoiding numerical instabilities when dealing with step increased value of heat capacity around the supercritical condition.

As part of Task 2, improvement of the net efficiency, there was a need to validate our Visual Basics and HYSYS models. Results from both the HYSYS simulation and the Visual Basic model were compared with Japanese calculations based on the 300 MWe GTHGR 300 [Yan, 2003] that was developed by the Japan Atomic Energy Research Institute (JAERI). Figure 3-10 is a schematic of the GTHTR300 power conversion cycle. As shown, the GTHTR 300-power conversion cycle selected for validation uses no cycle intercooling.

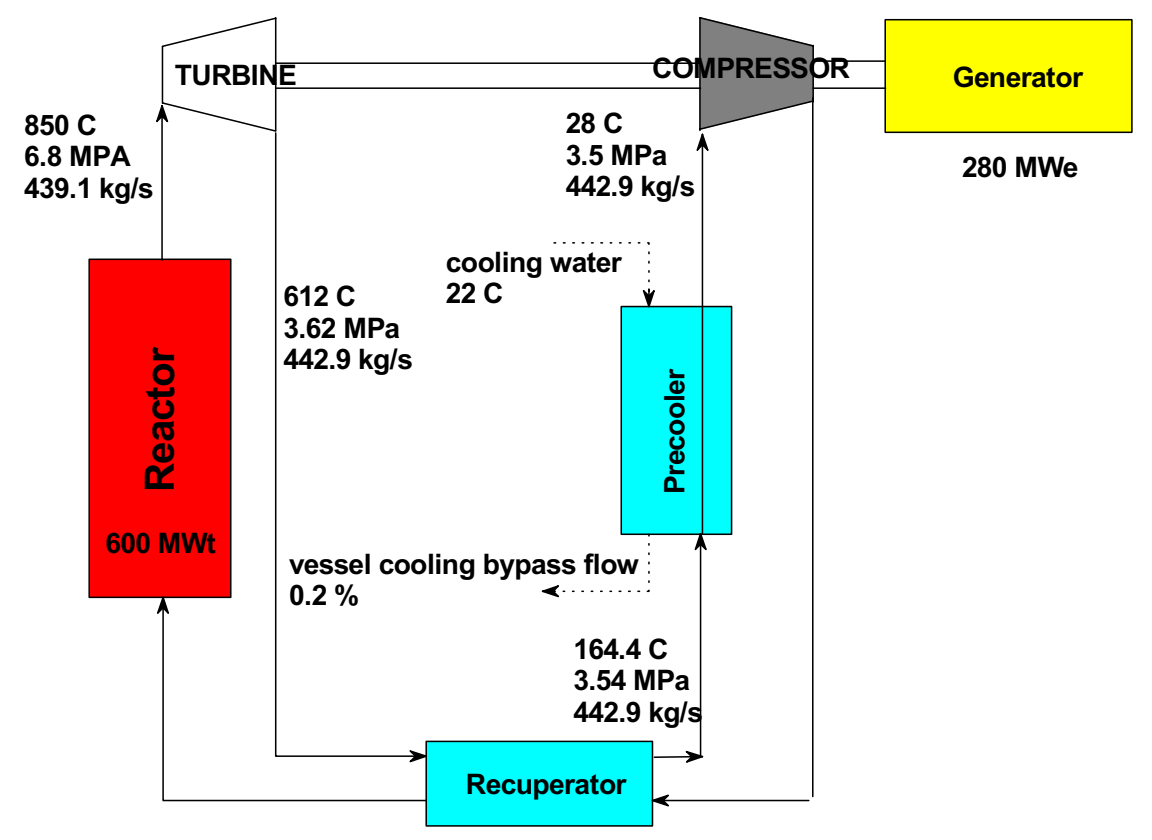

Figure 3-10. GTHTR300 Schematic. 
Figures 3-11 and 3-12 show comparisons of cycle efficiencies and pressure ratios, respectively at various reactor inlet temperatures and a reactor outlet temperature of $850^{\circ} \mathrm{C}$. Turbine polytropic efficiency of $92.8 \%$, compressor polytropic efficiency of $90.5 \%$, recuperator efficiency of $95 \%$, and inlet compressor temperature of $28^{\circ} \mathrm{C}$ were used. The Visual Basic model gives lower efficiencies than those of HYSYS except at the maximum efficiency point. The one difference between HYSYS and V-B model lies in a different helium property database. V-B model uses NIST database while HYSYS uses an equation of state to define the helium properties.

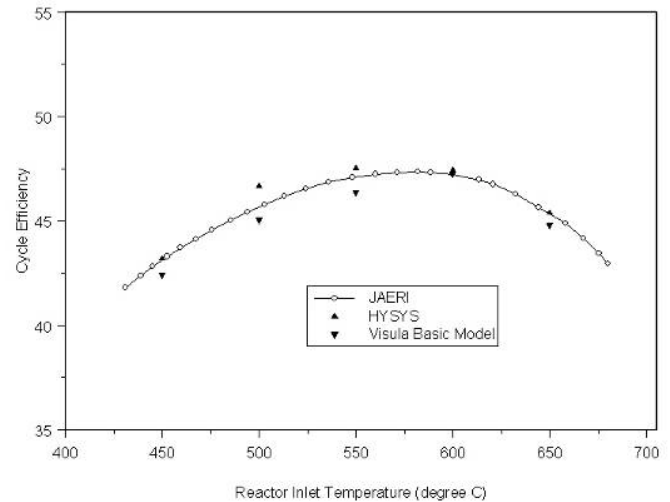

Figure 3-11. Comparison of cycle efficiency.

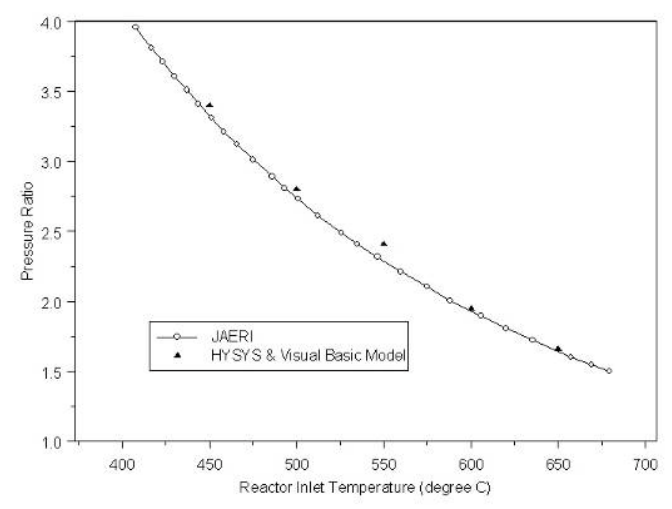

Figure 3-12. Comparison of pressure ratio.

Cycle efficiency is most sensitive to core outlet temperature, which is transferred to the inlet stream of the high-pressure turbine through an intermediate heat exchanger.

Based on a three-shaft $250 \mathrm{MW}$ thermal HTGR, we summarize cycle sensitivities to key cycle parameters shown in Table 3-3.

Table 3-3. Cycle efficiency sensitivity to key cycle parameters.

\begin{tabular}{|l|c|c|}
\hline \multicolumn{1}{|c|}{ Cycle parameters } & Change in cycle parameter & Change in cycle efficiency (\%) \\
\hline Turbine inlet temperature & $+50^{\circ} \mathrm{C}$ & +2.1 \\
\hline Recuperator efficiency & $+1 \%$ & +1.6 \\
\hline Reactor vessel cooling flow & $+1 \%$ & -0.1 \\
\hline Compressor inlet temperature & $+5.0^{\circ} \mathrm{C}$ & -1.2 \\
\hline Compressor efficiency & $+1 \%$ & +0.8 \\
\hline Turbine efficiency & $+1 \%$ & +1.0 \\
\hline
\end{tabular}

In order to check the accuracy of HYSYS simulation, the $\mathrm{CO}_{2}$ pressure-enthalpy diagram was used to compare with HYSYS simulation results. The method used is the same procedure described above. Figures 3-13 and 3-14 illustrate how to obtain the HPC exit temperature of $113^{\circ} \mathrm{C}$ from the P-H diagram. Figure 3-13 shows HYSYS results for one case using $\mathrm{CO}_{2}$ with a $\mathrm{HPC}$ exit temperature of $113^{\circ} \mathrm{C}$. We need to validate this temperature using the P-H diagram shown in Figure 3-14. As shown in Figure 3-14, once the red point 2 in step 3 described above is determined, the temperature isotherm line is crossed at $113^{\circ} \mathrm{C}$, which is the same result obtained from the HYSYS simulation. 


\section{HPC Exit Temperature Check on $\mathrm{CO} 2$ Brayton cycle}

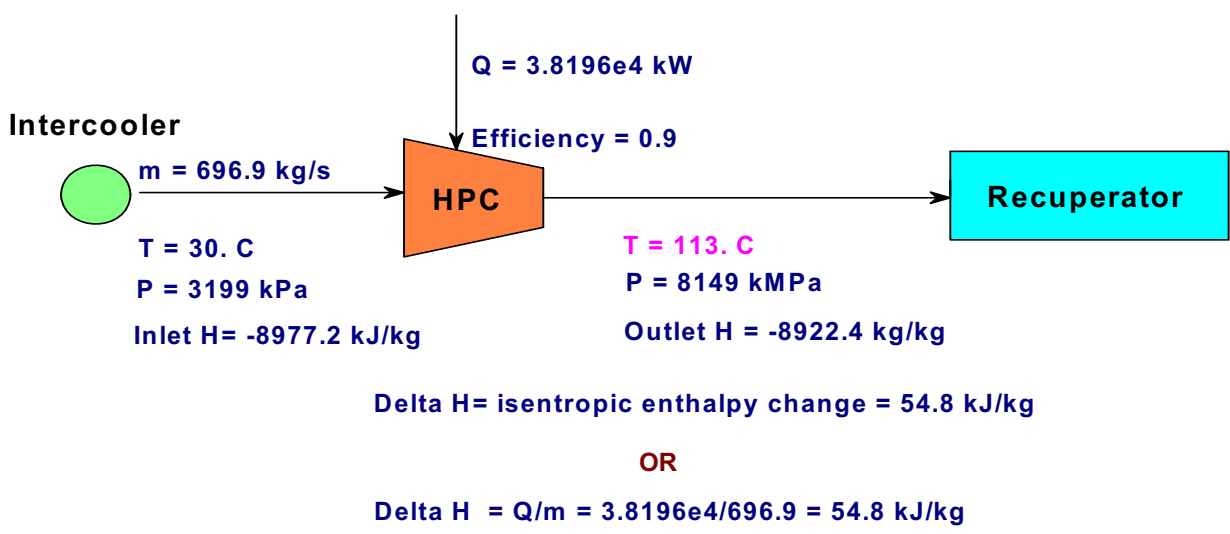

Polytropic enthalpy change $=$ isentropic enthalpy change $/$ efficiency $=60.9 \mathrm{~kJ} / \mathrm{kg}$

Figure 3-13. Stream property of the inlet and outlet of the high-pressure compressor from HYSYS simulation.

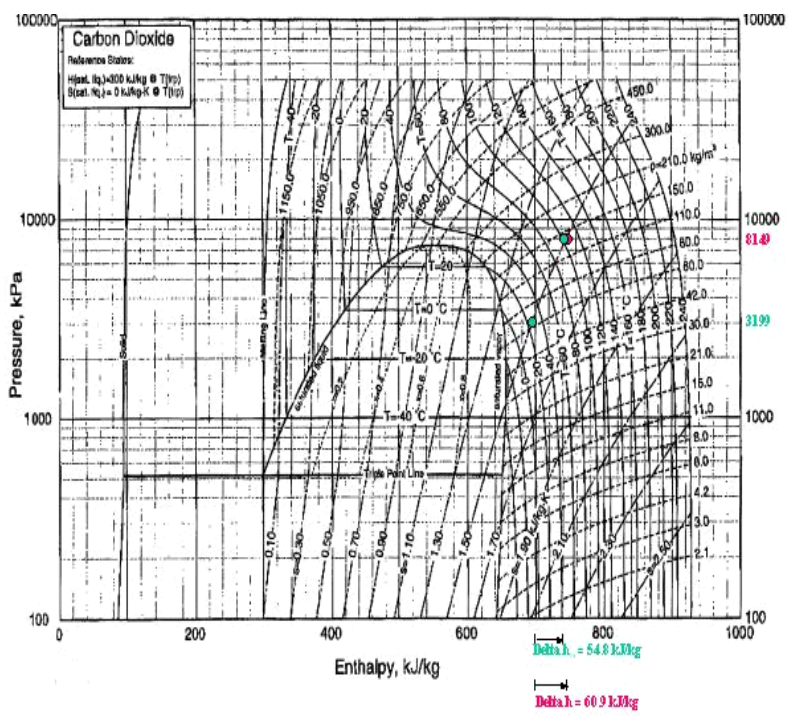

Figure 3-14. $\mathrm{CO}_{2}$ pressure-enthalpy diagram and paths to obtain the $\mathrm{HPC}$ exit temperature of $113^{0} \mathrm{C}$. 


\section{Task 2-2: Optimization of VHTR Plant}

The objective of this task is to improve the overall plant cycle efficiency by the combination of the increased efficiency of each component in the secondary side of the HTGR. To accomplish this task, we performed a number of HYSYS simulation to investigate the pressure effect on the overall cycle efficiency. The high pressure of the working fluid permits the turbo machine to be compact due to the higher density of the fluid. For example, the density of $\mathrm{CO}_{2}$ at $20 \mathrm{MPa}$ and $800^{\circ} \mathrm{C}$ is 2.43 times higher than that of $\mathrm{CO}_{2}$ at $8 \mathrm{MPa}$ and $800^{\circ} \mathrm{C}$. It shows the same trend for helium $(2.44$ times higher for helium at $20 \mathrm{MPa}$ and $800^{\circ} \mathrm{C}$ than that of helium at $8 \mathrm{MPa}$ and $800^{\circ} \mathrm{C}$ ). Generally system pressure increases the cycle efficiency. However, the optimized system pressure should be determined by energy and mass balance on each component where the condition does not cause temperature crossover around the recuperator and intermediate heat exchanger. The heat transfer of various working fluids affects the final design and operating conditions, which results in various cycle efficiencies. Using HYSYS optimization option, a wide range of system pressures from $6 \mathrm{MPa}$ to $20 \mathrm{MPa}$ were examined along with a wide range of temperatures, which will provide an optimized efficiency.

Figure 3-15 shows a typical example of a HYSYS simulation using a three-shaft arrangement, a system pressure of $13 \mathrm{MPa}$ and other conditions described as follows: polytropic efficiency of turbine $92 \%$, compressor efficiency of $90 \%$, a reactor outlet temperature of $900^{\circ} \mathrm{C}$, a compressor inlet temperature of $30^{\circ} \mathrm{C}$, three inter coolers (a pressure drop of $20 \mathrm{kPa}$ each), a recuperator effectiveness of $95 \%$, IHX effectiveness of $90 \%$, pressure drops of $140 \mathrm{kPa}$ for the IHX primary side and $150 \mathrm{kPa}$ for the secondary side, and a pressure drops of $20 \mathrm{kPa}$ for precooler.

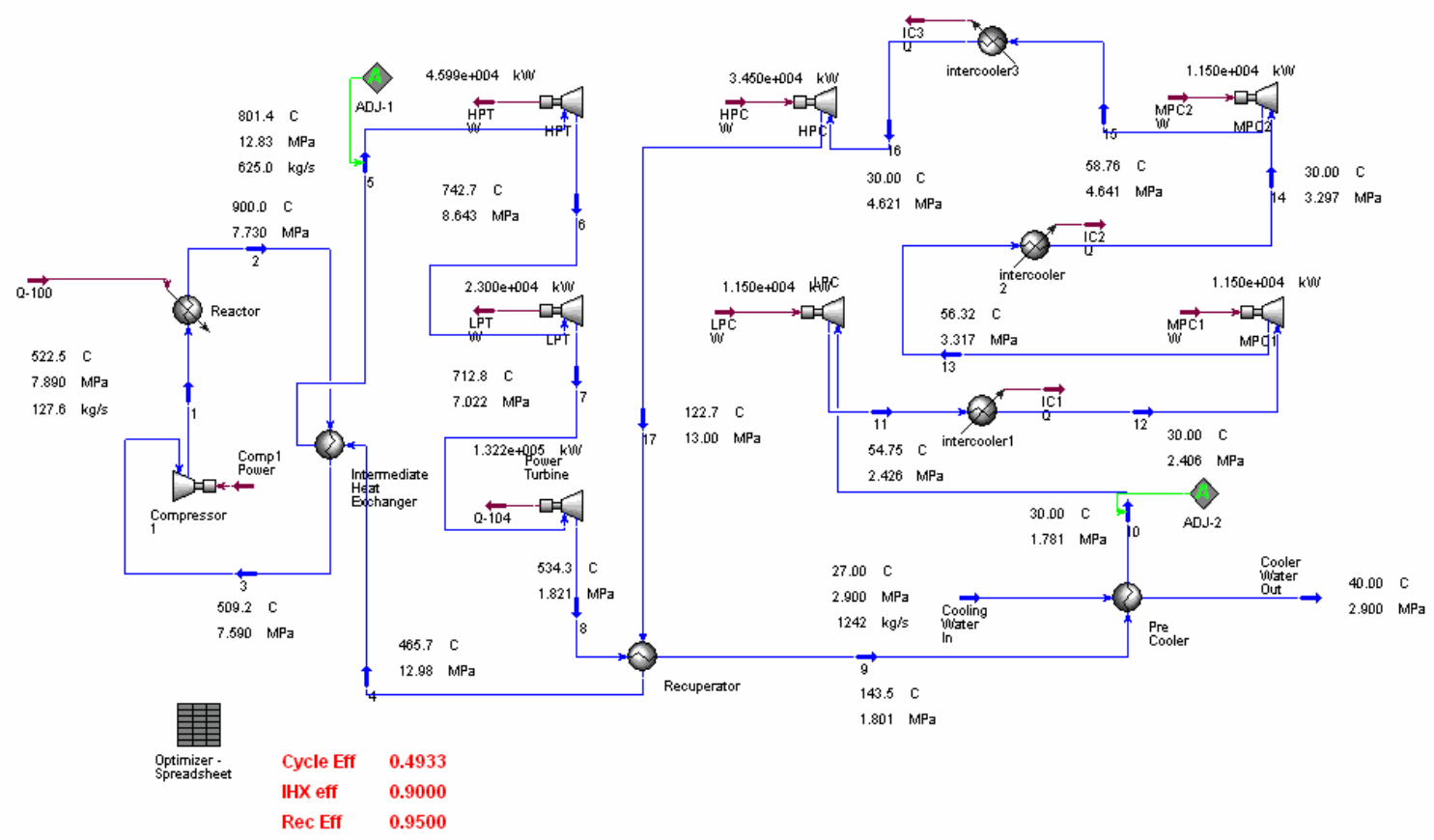

Figure 3-15. HYSYS Schematic for a supercritical CO2 cycle with $49.3 \%$ efficiency. 
The preliminary results of the pressure effect on the cycle efficiency and the size of the recuperator using a supercritical $\mathrm{CO}_{2}$ cycle, indirect 3-shaft arrangement are presented in Table 3-4.

Table 3-4. Results of the pressure effect on the efficiency.

\begin{tabular}{|c|c|c|c|}
\hline Pressure in PCS & Mass flow rate $(\mathrm{kg} / \mathrm{s})$ & $\begin{array}{c}\text { UA value for } \\
\text { recuperator }(\mathrm{kJ} / \mathrm{C}-\mathrm{hr})\end{array}$ & Cycle efficiency \\
\hline $6.3 \mathrm{MPa}$ & 700 & $2.7095 \mathrm{e} 7$ & $48 \%$ \\
\hline $13 \mathrm{MPa}$ & 625 & $1.885 \mathrm{e} 7$ & $49.3 \%$ \\
\hline $20 \mathrm{MPa}$ & 560 & $1.507 \mathrm{e} 7$ & $50.3 \%$ \\
\hline
\end{tabular}

where UA is universal heat transfer coefficient times heat transfer area.

In order to maintain an effectiveness factor of $95 \%$ for the recuperator, the following calculation was implemented into the HYSYS simulation: The effectiveness $\varepsilon$ of a heat exchanger is defined as the ratio of the actual heat transfer rate to the maximum heat transfer rate.

$$
\begin{aligned}
& \varepsilon \equiv \frac{q}{q_{\text {max }}} \\
& q_{\text {max }}=C_{\text {min }}\left(T_{h, i}-T_{c, i}\right)
\end{aligned}
$$

where $\mathrm{C}_{\min }$ is either $\mathrm{C}_{\text {cold }}$ or $\mathrm{C}_{\text {hot }}$, whichever is smaller.

$$
\begin{aligned}
& C_{\text {cold }}=c_{p, \text { cold }} \dot{m}_{\text {cold }} \\
& C_{\text {hot }}=c_{p, h o t} \dot{m}_{\text {hot }}
\end{aligned}
$$

The effectiveness is set for each heat exchanger ( $90 \%$ for the intermediate heat exchanger and $95 \%$ for the recuperator).

Next, the $\mathrm{q}_{\max }$ is determined using equation 3-2 through 3-4. In the case of Helium $\mathrm{c}_{\mathrm{p}}$ is constant through the heat exchanger and $\mathrm{C}_{\min }$ is not a function of temperature. However, in the case of $\mathrm{CO}_{2}$ or other real gases $c_{p}$ is not constant and $\mathrm{C}_{\min }$ is a function of temperature. To account for this, the assumption was made that $c_{p}$ through the heat exchanger would be the average, $c_{p, a v g}$ of $c_{p, \text { in }}$ and $c_{p, o u t}$.

In order to fully define a heat exchanger, the inlet and outlet temperature and pressure must be known, along with the mass flow for both the hot and cold side of the heat exchanger. Therefore $q$ of the heat exchanger can be calculated.

HYSYS uses an adjust function to make the heat exchanger satisfy the effectiveness condition. Equations 3-1 and 3-2 and the heat exchanger conditions are entered into HYSYS. HYSYS then calculates $\mathrm{q}, \mathrm{q}_{\max }$ and $\varepsilon$ for the exchanger. A modifiable condition is then entered into HYSYS. This condition is adjusted, while the others are held constant, so that the heat exchanger satisfies the effectiveness condition. For the IHX the cold side outlet temperature is adjusted. While for the recuperator the hot side outlet pressure is adjusted. Therefore, if a condition is altered the modifiable condition can be adjusted to satisfy the effectiveness condition. 
Direct cycles versus indirect cycles were compared based on a $600 \mathrm{MW}$-thermal Japanese GTHTR and a $900^{\circ} \mathrm{C}$ reactor outlet temperature. Figure 3-16 shows HYSYS layout for the indirect cycle with $48 \%$ efficiency compared with a $52 \%$ for the direct cycle.

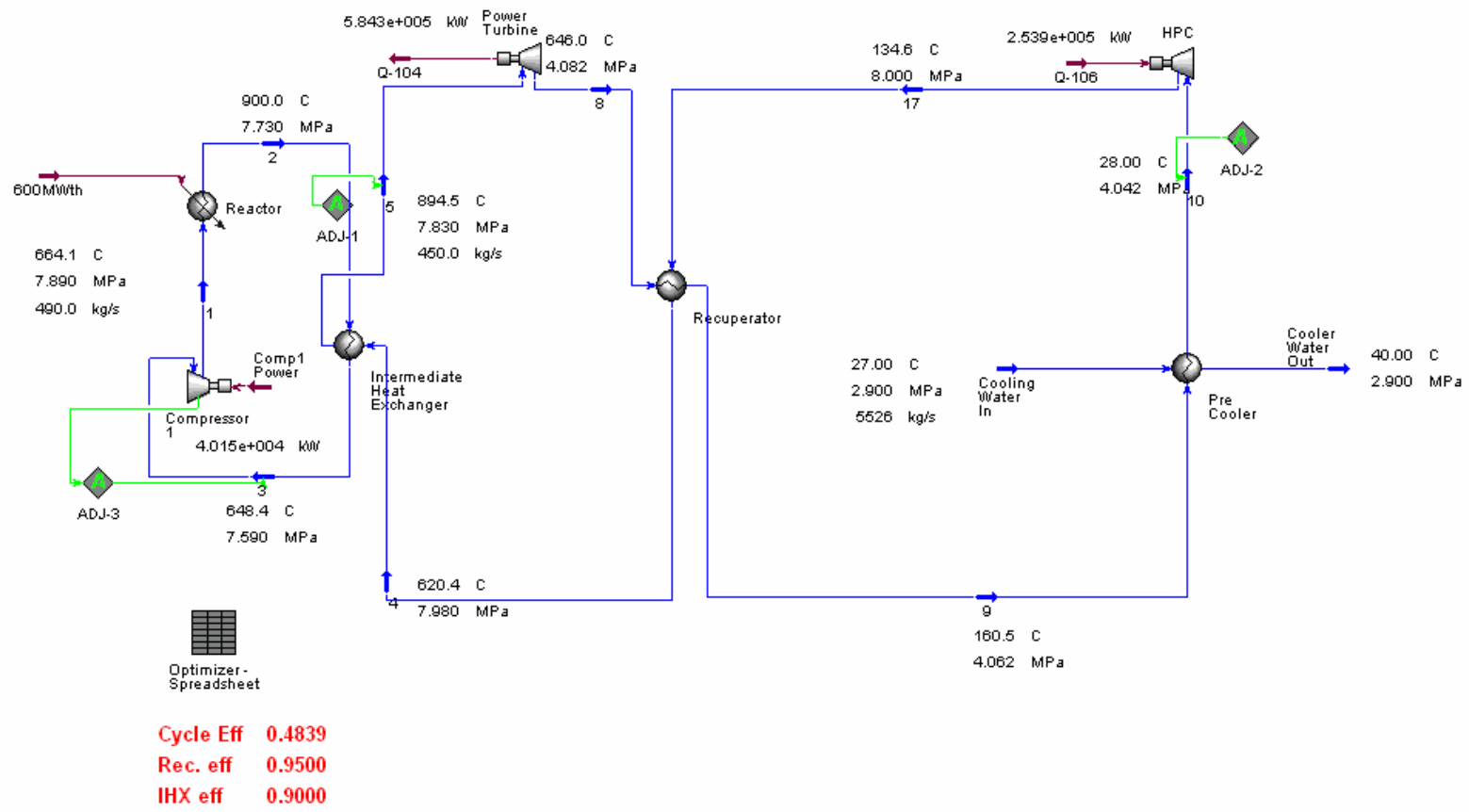

Figure 3-16. HYSYS layout for the indirect Brayton cycle.

\section{Task 2-3: Efficiency Calculations and Other Technical Issues}

The objective of this task is to include some of the important technical issues which were not cover in the preceding tasks: review of various working fluids, number of intercooler, an option for reheat, review on other cycles including recompression, a combined Brayton and Rankine cycle, and multiple reheat using molten salts for the intermediate flow loop.

This is the start of the third year of this NERI project thus some preliminary results from this year are presented in this report.

The working fluid is very important for the power conversion system (PCS) of the NGNP. The cycle efficiency, the size of all the components such as turbine, compressor, recuperator, intermediate heat exchanger for hydrogen production units, and other components will depend on the fluid because each different fluid has different heat transfer and transport properties. Due to the different properties of the fluids, the balance of plant will have varying energy and mass balances. The material sustainability in the PCS is also dependent on type of fluids in terms of corrosion, material creep (yield stress, ultimate tensile stress, ductility and others). Construction material used for all the components and piping in the PCS are exposed to high temperature and pressure, which are governed, by the fluid energy and mass balance.

We began to investigate the working fluid choices including nitrogen, and a binary mixture for the indirect cycle. A combined Brayton cycle will also be explored to see the improvement of the efficiency. 


\section{Working Fluids}

\section{$\underline{\text { Helium for both direct and indirect cycle }}$}

The direct helium cycle was simulated with an optimal pressure ratio of $\sim 1.93$. This gave a cycle efficiency of $50.9 \%$.

The indirect helium cycle was simulated assuming a compressor outlet pressure of $8 \mathrm{MPa}$. The cycle conditions were optimized with a secondary mass flow rate equal to the primary mass flow (439.1 $\mathrm{kg} / \mathrm{s}$ ) and a pressure ratio of $\sim 2.02$. This gave a cycle efficiency of $48.7 \%$.

\section{$\underline{\text { Nitrogen for indirect cycle }}$}

The indirect Nitrogen cycle was simulated assuming a compressor outlet pressure of $8 \mathrm{MPa}$. The optimal secondary mass flow rate was $2600 \mathrm{~kg} / \mathrm{s}$ and the optimal pressure ratio was $\sim 2.37$. This gave a cycle efficiency of $45.5 \%$.

\section{(c) $\mathrm{CO} 2$ for indirect cycle}

The indirect $\mathrm{CO}_{2}$ cycle was simulated assuming a compressor outlet pressure of $20 \mathrm{MPa}$. The higher compressor outlet pressure was used to take advantage of compression around the critical point and decrease compressor work. The optimal secondary mass flow rate was $1794 \mathrm{~kg} / \mathrm{s}$ and the optimal pressure ratio was $\sim 4.76$. This gave a cycle efficiency of $50.7 \%$.

The indirect $\mathrm{CO}_{2}$ cycle was also simulated at $8 \mathrm{MPa}$ for comparison. The mass flow rate was unchanged and the optimal pressure ratio was $\sim 6.8$. This gave a cycle efficiency of $46.4 \%$. This is closer to the other working fluid efficiencies. The other working fluids are insensitive to system pressure while an efficiency gain can be accomplished by increasing the pressure for $\mathrm{CO}_{2}$.

Assuming similar pressure drops in the heat exchangers and the same turbomachinery efficiencies, helium, nitrogen, and $\mathrm{CO}_{2}$ at $8 \mathrm{MPa}$ all have approximately the same cycle efficiency. However, the $\mathrm{CO}_{2}$ at $20 \mathrm{MPa}$ has a $\sim 4 \%$ higher efficiency than the other cycles due to the decreased compression work for the cycle as seen in Table 3-6. Helium and nitrogen are insensitive to maximum system pressure while an efficiency gain can be accomplished by increasing the pressure for $\mathrm{CO}_{2}$.

The reduced compression work due to compression around the critical point of $\mathrm{CO}_{2}$ makes it an attractive option for a secondary working fluid. However, $\mathrm{CO}_{2}$ is not inert compared with other fluids such as helium and nitrogen and more advanced materials are required to address potential corrosion issues. The tradeoff of increased capital cost and increased cycle efficiency would need to be studied further if a more in-depth economic analysis were to be carried out.

Table 3-5 compares the cycle efficiency, the work duty of the turbine and compressor, and the total heat transfer area ratio for different working fluids in the power conversion unit.

Pressure drops through the IHX and recuperator were calculated for various working fluids using a shell-tube type heat exchanger. Relative total area ratio can be varied depending on the final selection of heat exchanger. Overall heat transfer coefficients, U, were calculated and the ideal heat transfer area (assuming perfect counterflow) of the helium indirect cycle was used as a basis for comparing area ratios for each working fluid. As shown in Table 3-5, Nitrogen as a working fluid in the PCS needs the largest heat exchanger size compared with those of other fluids studied. The Framatome indirect cycle design therefore uses a helium-nitrogen mixture to increase the gas thermal conductivity and reduce the heat exchanger size. 
UA was calculated using the following equation:

$$
\mathrm{U}_{\mathrm{i}}=\frac{1}{\frac{1}{\mathrm{~h}_{\mathrm{i}}}+\frac{\mathrm{D}_{\mathrm{i}}}{\mathrm{D}_{\mathrm{L}}} \frac{\mathrm{x}_{\mathrm{w}}}{\mathrm{k}_{\mathrm{m}}}+\frac{\mathrm{D}_{\mathrm{i}}}{\mathrm{D}_{\mathrm{o}} \mathrm{h}_{\mathrm{o}}}}
$$

where $U_{i}$ is an universal heat transfer coefficient based on an inner diameter, $h$ is the heat transfer coefficient, $\mathrm{x}$ is thickness, $\mathrm{k}$ is thermal conductivity, $\mathrm{i}, \mathrm{o}, \mathrm{L}$ are inside, outside, and log-mean, respectively. $\mathrm{D}_{\mathrm{L}}$ is defined as:

$$
\mathrm{D}_{\mathrm{L}}=\frac{\mathrm{D}_{\mathrm{o}}-\mathrm{D}_{\mathrm{i}}}{\ln \left(\frac{\mathrm{D}_{\mathrm{o}}}{\mathrm{D}_{\mathrm{i}}}\right)}
$$

Table 3-5. Comparison of cycles for different working fluids

\begin{tabular}{|c|c|c|c|c|c|c|}
\hline Working Fluid & $\begin{array}{c}\text { Cycle } \\
\text { Efficiency }\end{array}$ & $\begin{array}{c}\text { Turbine Work } \\
(\mathrm{MW})\end{array}$ & $\begin{array}{c}\text { Compressor } \\
\text { Work } \\
(\mathrm{MW})\end{array}$ & $\begin{array}{c}\text { Total UA } \\
(\mathrm{MW} / \mathrm{K})\end{array}$ & $\begin{array}{c}\text { Total } \\
\text { Overall U } \\
\left(\mathrm{W} / \mathrm{m}^{2} \mathrm{~K}\right)\end{array}$ & $\begin{array}{c}\text { Area } \\
\text { Ratio }^{2}\end{array}$ \\
\hline He Direct (No IHX) & $50.9 \%$ & 542.9 & 237.7 & Recup: 42.9 & 204.6 & 0.65 \\
\hline He Indirect & $48.7 \%$ & 575.4 & 256.5 & $\begin{array}{c}\text { IHX: } 24.2 \\
\text { Recup: } 43.1\end{array}$ & 216.9 & 204.6 \\
\hline \\
\end{tabular}

Preliminary conclusions drawn from this investigation are:

- Among the three working fluids studied for the indirect PCS, supercritical $\mathrm{CO}_{2}$ has the highest cycle efficiency due to less compression work resulting from higher supercritical $\mathrm{CO}_{2}$ densities. . Supercritical $\mathrm{CO}_{2}$ also results in the smallest turbomachinery components.

- Helium direct cycle eliminates an IHX and consequently requires the smallest heat transfer area due to the higher heat capacity and thermal conductivity than those of other fluids.

- $\quad$ For the final selection of the best working fluid, or fluid mixture, trade-off studies need to be performed for efficiency, capital cost, maintenance cost, the stability of fluids through compressor, potential leakage from PCS, and other relevant issues. This project will include some of these issues later in FY-05 efforts.

\section{2-3-2 Effect of intercoolers}

The objective of this task is to find the cycle efficiency based on a variable number of intercooler in the secondary side of the HTGR or NGNP. In order to make a comparison with the supercritical $\mathrm{CO}_{2}$ 
cycle, cases using the helium Brayton cycle were made as a baseline. Then more complicated $\mathrm{CO}_{2}$ cycle will be investigated in the FY-05 first quarter, and will be reported next quarter.

To determine the effects of interstage cooling [Oh and Barner, 2006] on cycle efficiency 1, 2 and 3 intercoolers were added to the basic indirect recuperated Helium cycle. The pressure drop through the precooler was set at $20 \mathrm{kPa}$. With a 1-intercooler layout the intercooler pressure drop was set to $50 \mathrm{kPa}$. With 2 intercoolers the first intercooler pressure drop was set to $37 \mathrm{kPa}$ and the second intercooler set to a pressure drop of $50 \mathrm{kPa}$. With a 3 -intercooler layout the first, second and third intercooler pressure drops were set to 30,40 and $50 \mathrm{kPa}$, respectively. These pressure drops were chosen because they are representative of pressure drops used in the MIT studied on an indirect Helium Brayton cycle with a maximum system pressure of $8 \mathrm{MPa}$ [Wang, 2003].

A base design for each cycle was determined and input into HYSYS. HYSYS was then used to simulate and optimize each cycle.

The base cycle used in this study was the indirect Helium cycle and the operating conditions used are summarized in Table 3-6. The efficiency without intercooling was $45.19 \%$. The efficiency with 1,2 and 3 intercoolers was $48.25 \%, 48.92 \%$ and $49.07 \%$, respectively.

Table 3-6. Cycle conditions used for intercoolers

\begin{tabular}{|l|c|}
\hline \multicolumn{1}{|c|}{ Condition } & Value \\
\hline Reactor Power & $600 \mathrm{MW}$ \\
\hline Reactor Outlet Temp & $900 \mathrm{C}$ \\
\hline Turbine Polytropic Efficiency & $92 \%$ \\
\hline Compressor Polytropic Efficiency & $90 \%$ \\
\hline IHX Effectiveness & $90 \%$ \\
\hline Recuperator Effectiveness & $95 \%$ \\
\hline IHX Primary Side Pressure Drop & $150 \mathrm{kPa}$ \\
\hline IHX Secondary Side Pressure Drop & $175 \mathrm{kPa}$ \\
\hline Recuperator Hot Side Pressure Drop & $90 \mathrm{kPa}$ \\
\hline Recuperator Cold Side Pressure Drop & $50 \mathrm{kPa}$ \\
\hline Precooler Pressure Drop & $20 \mathrm{kPa}$ \\
\hline Intercooler Pressure Drop & $30 \mathrm{kPa}$ \\
\hline Compressor Inlet Temp & $28 \mathrm{C}$ \\
\hline Pressure Ratio & 2.1 \\
\hline
\end{tabular}

\section{Effect of reheat}

The objective of this task is to determine how much a reheat option can enhance the cycle efficiency and to find out technical issues associated with the reheat option. For these calculations, a cycle similar to the proposed Advanced High Temperature (AHTR) [Forsberg et al., 2004, Peterson, 2003] was used with Flibe, a fluoride molten salt, as a coolant fluid in the primary side and helium in the Brayton cycle.

Theoretically a combination of reheat and intercooling increases the cycle efficiency in a closed cycle, the implications have not been explored. Multiple-reheat is technically viable for closed gas cycles, as demonstrated by the PBMR turbomachinery design with three separate turbines. For gas-cooled reactors, a multiple reheat option may not be practical due to higher-pressure loss associated with gases, 
i.e., helium, supercritical $\mathrm{CO}_{2}$, and nitrogen. However, molten coolants can transport heat with low pumping power requirement, which becomes very attractive without any consideration of material problems associated with molten coolants at high temperatures.

Figure 3-15 shows the layout of the HYSYS simulation. In the primary side, stream 1 to 6 has Flibe as a coolant and in the secondary side, streams 7 through 21 has helium as a working fluid. The cycle efficiency from this simulation is $56 \%$, which is much higher than helium-helium cycle or helium-CO2 cycle. The detailed operating conditions are summarized in Table 6 . Similar calculations are being performed now and it will be reported in the next quarterly report.

Table 3-7. Summary of HYSYS simulation with multiple reheats.

\begin{tabular}{|c|c|}
\hline & Operating conditions \\
\hline Reactor Power & $600 \mathrm{MW}$-thermal \\
\hline Configuration & Indirect \\
\hline Mass flow of Flibe in the primary loop & $1,189 \mathrm{~kg} / \mathrm{s}$ \\
\hline Mass flow of helium in the secondary loop & $295 \mathrm{~kg} / \mathrm{s}$ \\
\hline \multirow{2}{*}{ Reactor Inlet, stream (6) } & $600^{\circ} \mathrm{C}$ \\
\hline & $0.1 \mathrm{MPa}(1 \mathrm{~atm})$ \\
\hline \multirow{2}{*}{ Reactor Outlet, stream (1) } & $700^{\circ} \mathrm{C}$ \\
\hline & $0.1 \mathrm{MPa}(1 \mathrm{~atm})$ \\
\hline \multirow{2}{*}{ IHX Inlets (stream (2) to( 5)) } & $700^{\circ} \mathrm{C}$ \\
\hline & $0.1 \mathrm{MPa}(1 \mathrm{~atm})$ \\
\hline \multirow{2}{*}{ HP Turbine Inlet/Outlet (8) / (9) } & $602^{\circ} \mathrm{C} / 525 \mathrm{C}$ \\
\hline & $7 \mathrm{MPa} / 5.46 \mathrm{MPa}$ \\
\hline \multirow{2}{*}{ MP Turbine Inlet/Outlet (10) / (11) } & $622^{\circ} \mathrm{C} / 525 \mathrm{C}$ \\
\hline & $5.46 \mathrm{MPa} / 4 \mathrm{MPa}$ \\
\hline \multirow{2}{*}{ LP Turbine Inlet/Outlet (12) / (13) } & $622 \mathrm{C} / 525 \mathrm{C}$ \\
\hline & $4 \mathrm{MPa} / 2.93 \mathrm{MPa}$ \\
\hline \multirow{2}{*}{ Turbine Inlet/Outlet (14) / (15) } & $623^{\circ} \mathrm{C} / 525 \mathrm{C}$ \\
\hline & $2.92 \mathrm{MPa} / 2.14 \mathrm{MPa}$ \\
\hline Recuperator Inlet/Outlet & $525 \mathrm{C} / 94 \mathrm{C}$ \\
\hline \multirow{2}{*}{ Compressor Inlet (17) } & $35^{\circ} \mathrm{C}$ \\
\hline & $2.5 \mathrm{MPa}$ \\
\hline \multirow{2}{*}{ LP Compressor Inlet (18) } & $35^{\circ} \mathrm{C}$ \\
\hline & $3.24 \mathrm{MPa}$ \\
\hline \multirow{2}{*}{ MP Compressor Inlet (19) } & $35^{\circ} \mathrm{C}$ \\
\hline & 4.2 $\mathrm{MPa}$ \\
\hline \multirow{2}{*}{ HP Compressor Inlet/Outlet (20/21) } & $35^{\circ} \mathrm{C} / 73 \mathrm{C}$ \\
\hline & $5.44 \mathrm{MPa} / 7.04 \mathrm{MPa}$ \\
\hline \multirow{2}{*}{ Outlet from Recuperator, shell side (7) } & $5040^{\circ} \mathrm{C}$ \\
\hline & $7 \mathrm{MPa}$ \\
\hline Cycle Efficiency & $56 \%$ \\
\hline
\end{tabular}




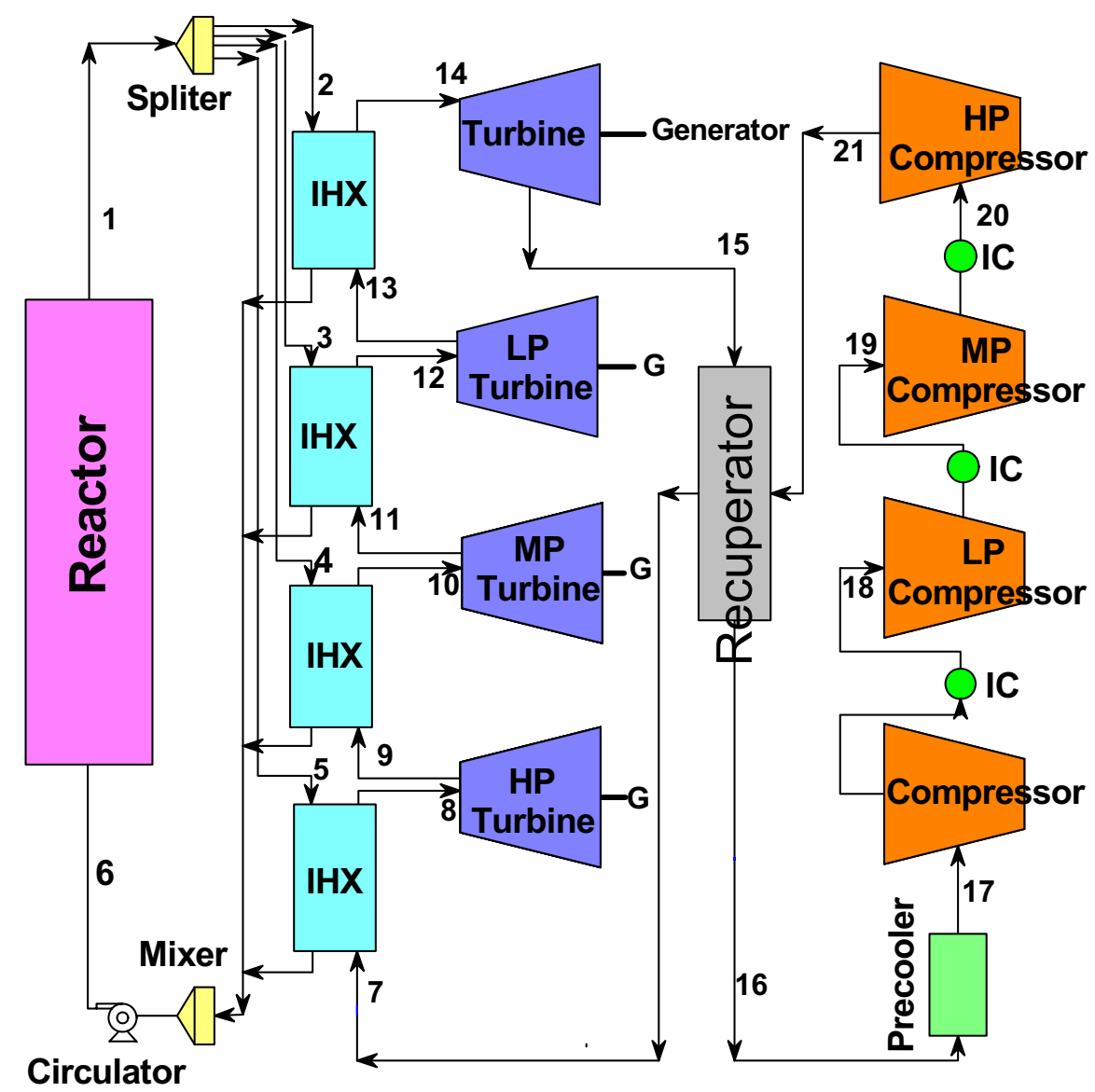

Figure 3-17. Cycle layout with multiple reheat option.

In order to improve the overall plant cycle efficiency by the combination of the increased efficiency of each component in the secondary side of the VHTR, we performed a number of HYSYS simulation to investigate interstage heating and cooling (IH\&C). IH\&C is an attractive option for improving the efficiency of the NGNP power conversion system. As additional stages are added, the average temperature over which input energy is added stays higher and/or the average temperature over which rejection energy is removed stays lower. If this were the only impact of the IH\&C, the cycle efficiency would always increase with more stages. But with each additional stage, pressure drop is present. Additional interstage pumping must be accomplished to make up for this additional pressure drop. Because the pumps are not $100 \%$ efficient, eventually the entropy loss during an additional pumping operation results in a smaller total energy input than without that stage. When this occurs, the cycle efficiency actually decreases.

Cycle efficiencies as well as differential cycle efficiencies (efficiency improvement per stage) were examined as a function of the number of input and rejection stages for several cycles including:

- Recuperated Helium Brayton cycle

- $\quad$ Recuperated $80 \% \mathrm{~N}_{2} 20 \%$ He (by weight) Brayton cycle

- $\quad$ Recuperated Supercritical $\mathrm{CO}_{2}$ Brayton with split flow cycle 
- Implication of gas or liquid intermediate loop

- $\quad$ Implication of IH\&C to system layout.

Interstage heating is used to increase the inlet temperature of the turbines and increase turbine work. However, interstage heating with a gas cooled reactor has not been found to be practical due to large pressure loss incurred to perform reheating [Peterson, 2003].

To determine the effects interstage cooling on cycle efficiency 1, 2 and 3 intercoolers were added to the basic indirect recuperated Helium and $\mathrm{N}_{2} / \mathrm{He}$ mixture cycles. The pressure drop through the precooler was set at $20 \mathrm{kPa}$. With a 1-intercooler layout the intercooler pressure drop was set to $50 \mathrm{kPa}$. With 2 intercoolers the first intercooler pressure drop was set to $37 \mathrm{kPa}$ and the second intercooler set to a pressure drop of $50 \mathrm{kPa}$. With a 3-intercooler layout the first, second and third intercooler pressure drops were set to 30, 40 and $50 \mathrm{kPa}$, respectively. These pressure drops were chosen because they are representative of pressure drops used by a MIT studied on an indirect Helium Brayton cycle with a maximum system pressure of $8 \mathrm{MPa}$ [Wang, 2003].

A base design for each cycle was determined and input into HYSYS. HYSYS was then used to simulate and optimize each cycle.

\section{Recuperated Helium Brayton cycle}

The base cycle used in for this study was the indirect Helium cycle and operating conditions used in this section are summarized in Table 3-6 [Oh et al., 2005]. The efficiency without intercooling was $45.19 \%$. The efficiency with 1, 2 and 3 intercoolers was $48.25 \%, 48.92 \%$ and $49.07 \%$, respectively.

\section{Recuperated 80\% N2 20\% He (by weight) Brayton cycle}

The base cycle used in for this study was the indirect $\mathrm{N}_{2} / \mathrm{He}$ cycle and conditions used in this section are shown in Table 3-8. The efficiency without intercooling was $45.29 \%$. The efficiency with 1,2 and 3 intercoolers was $49.39 \%, 50.19 \%$ and $50.47 \%$, respectively.

\section{Recuperated Supercritical CO2 Brayton with split flow cycle}

The base design chosen for the supercritical $\mathrm{CO}_{2}$ was developed at MIT [Dostal et al., 2004]. Split flow is an option for improving cycle efficiency when the working fluid is operated near its critical point. Around the critical point the fluid properties vary greatly. To take advantage of this the flow is split and a portion goes to a precooler before entering the compression stage. By compressing around the critical point the compressor work can be significantly reduced.

The model developed at MIT was repeated in HYSYS to ensure consistency between the two models. The MIT model with a $600 \mathrm{MW}(\mathrm{t})$ reactor power and a $700{ }^{\circ} \mathrm{C}$ reactor outlet temperature was simulated in HYSYS. The MIT model gave a cycle efficiency of $51.3 \%$ and the HYSYS model gave an efficiency of $51.1 \%$. Since the models were comparable the base model was then modified in HYSYS. The MIT design was modified to be an indirect cycle with a reactor outlet temperature of $867^{\circ} \mathrm{C}$. Next the heat flow in the IHX was set to $600 \mathrm{MW}(\mathrm{t})$ to be consistent with the amount of power supplied to the PCS. The design parameters for the modified cycle are detailed in Table 2.

The HYSYS optimized recompression cycle produced a cycle efficiency of $52.09 \%$ compared to the $51.1 \%$ for the base model. Although this cycle has a slightly higher efficiency, it may not be advantageous from the point of additional capital costs and the potential material problems due to the higher temperatures. 
Table 3-8. Cycle conditions used in $\mathrm{CO}_{2}$ split flow cycle

\begin{tabular}{|l|l|}
\hline \multicolumn{1}{|c|}{ Condition } & Value \\
\hline Reactor Power & $600 \mathrm{MW}$ \\
Reactor Outlet Temp & $900 \mathrm{C}$ \\
IHX outlet heat flow & $600 \mathrm{MW}$ \\
Turbine Polytropic Efficiency & $92 \%$ \\
Compressor Polytropic Efficiency & $90 \%$ \\
IHX Effectiveness & $90 \%$ \\
Recuperator Effectiveness & $<95 \%$ \\
IHX Secondary Side Pressure Drop & $140 \mathrm{kPa}$ \\
High Temp. Recuperator Hot Side Pressure Drop & $50 \mathrm{kPa}$ \\
Low Temp. Recuperator Hot Side Pressure Drop & $50 \mathrm{kPa}$ \\
Precooler Pressure Drop & $50 \mathrm{kPa}$ \\
Compressor Inlet Temp & $31 \mathrm{C}$ \\
System Pressure & $20 \mathrm{MPa}$ \\
System Pressure Ratio & 2.6 \\
\hline
\end{tabular}

\section{Implication of bottoming cycles}

A steam bottoming cycle can be used to further improve the efficiency of a cycle. The base design studied here was the Framatome cycle [Copsey, 2004]. The cycle efficiency of the combined cycle produces $49.56 \%$ due to the reduced pumping work for water in the Rankine cycle.

\section{Implication of interstage heating and cooling to system layout}

Comparing the results of additional intercoolers as seen in Table 3-9, after the first intercooling stage is added, additional stages result in much smaller efficiency increases,. This decreasing efficiency gain is due to the additional pressure drop incurred by adding intercoolers. Eventually the efficiency increase from adding an intercooler will be off set by the additional cost of the intercooler. At that point the addition of another intercooler is not feasible. 
Table 3-9. Comparison of cycle implication due to various cycle layouts and intermediate cooling

\begin{tabular}{|l|c|c|}
\hline \multicolumn{1}{|c|}{ Cycle layout } & Cycle Efficiency & Differential Efficiency Gain \\
\hline He Indirect no IC & $45.19 \%$ & N/A \\
\hline He Indirect 1 IC & $48.25 \%$ & $3.06 \%$ \\
\hline He Indirect 2 IC & $48.92 \%$ & $0.67 \%$ \\
\hline He Indirect 3 IC & $49.07 \%$ & $0.15 \%$ \\
\hline $\mathrm{N}_{2} /$ He Indirect no IC & $45.29 \%$ & N/A \\
\hline $\mathrm{N}_{2} /$ He Indirect 1 IC & $49.39 \%$ & $4.10 \%$ \\
\hline $\mathrm{N}_{2} /$ He Indirect 2 IC & $50.19 \%$ & $0.80 \%$ \\
\hline $\mathrm{N}_{2} /$ He Indirect 3 IC & 50.47 & 0.28 \\
\hline $\mathrm{CO}_{2}$ Split Flow & 52.09 & $\mathrm{~N} / \mathrm{A}$ \\
\hline $\mathrm{N}_{2} /$ He Indirect with a Combined Cycle & 49.56 & $\mathrm{~N} / \mathrm{A}$ \\
\hline
\end{tabular}

Observations from this section include:

- Intercooler increases the cycle efficiency due to lowering the inlet temperature to the compressor. A single intercooler improves the cycle efficiency by approximately $3 \%$. Once the first intercooler is used, the second and third intercooler provide much smaller efficiency increases.

- The reheat option was not investigated in this chapter. However, the reheat option needs to be fully investigated for liquid coolants such as molten salts, where the ability to deliver heat with low pumping power allows low-pressure-loss heaters to be used and located close to the turbomachinery.

We performed a number of HYSYS simulation to investigate a number of different cycle configurations: combined cycle and reheat cycle. In this report, results from the combined cycle are included.

A snapshot of HYSYS model is shown in Figure 3-18 along with the cycle configuration of the combined cycle in Figure 3-19. This indirect configuration is a Brayton cycle and a Rankine cycle. 


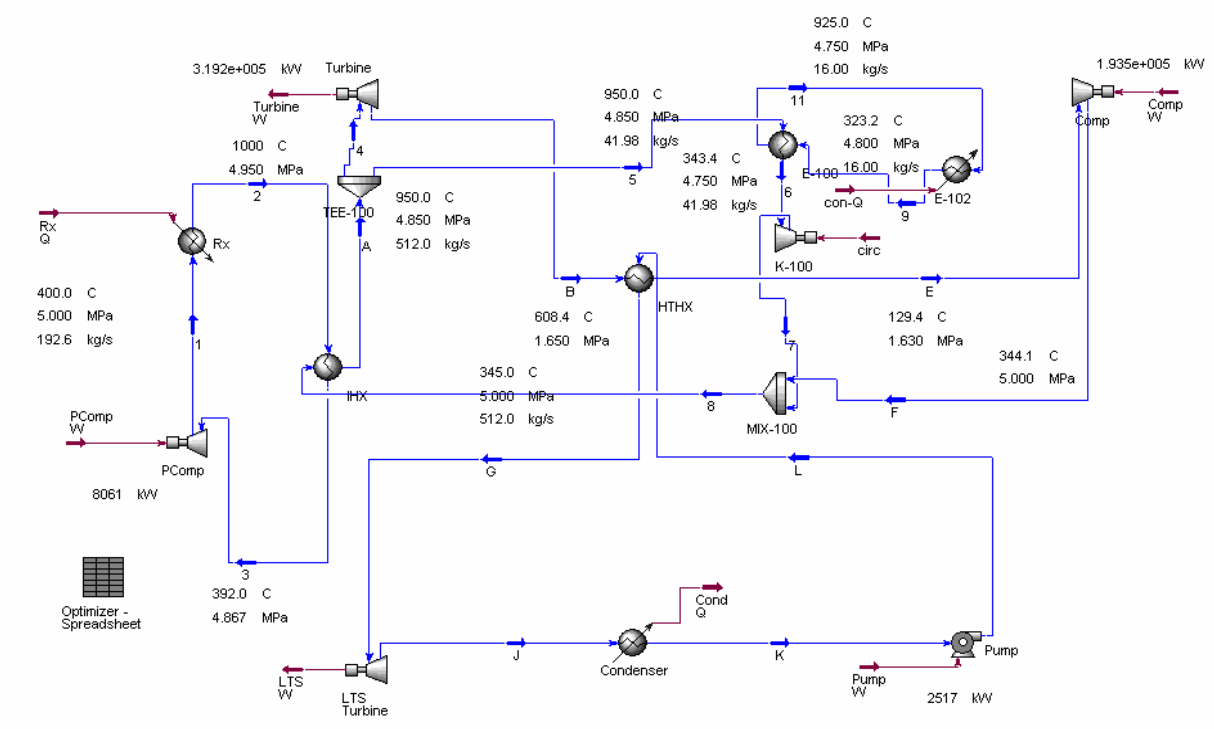

Thermal Efficiency $\quad 48.08$

Figure 3-18. Snapshot of HYSYS model of the combined cycle with $\mathrm{N}_{2} / \mathrm{He}$.

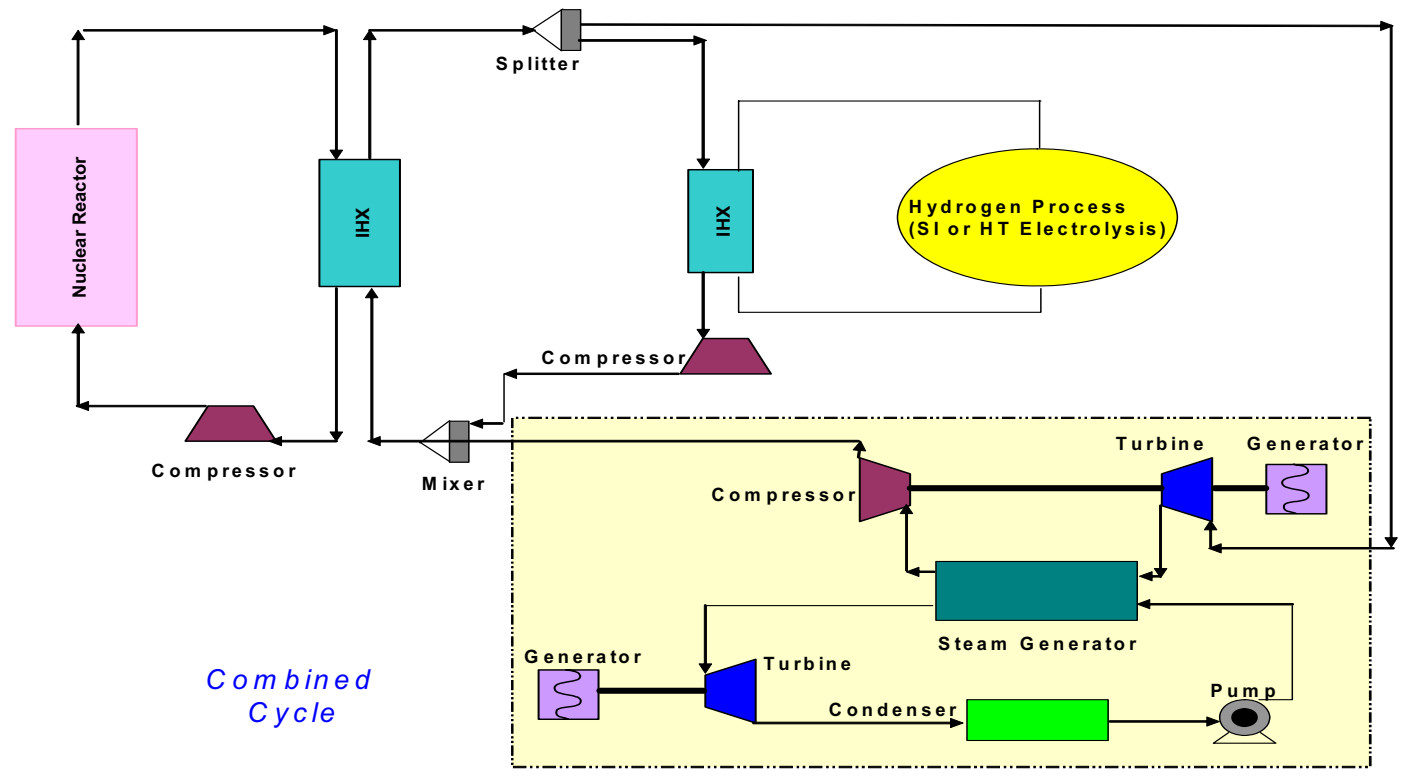

Figure 3-19. The combined cycle.

This configuration was developed by Framatome [Copsy et. al, 2004]. Heat from the reactor (600 $\mathrm{MWt}$ ) is transferred to a power conversion unit in which the heat transfer fluid is a binary mixture of 
nitrogen ( $80 \%$ by wt.) and helium ( $20 \%$ by weight). The majority of fluid is 0.636 mole fraction of helium vs. 0.364 mole fraction of nitrogen. This indirect cycle design facilitates an improvement of the cycle efficiency using a Rankine bottoming cycle. The key difference of this concept is the reduction of the reactor inlet temperature and lower pressures compared with that of GT-MHR and others. With reduced inlet temperature, the flow rate and circulator power is lower and lower pressures results in less stress problems in material and reduce wall thickness of reactor and other units in the system.

INL developed a combined cycle using $\mathrm{CO}_{2}$ as the working fluid in the Brayton cycle rather than $\mathrm{N}_{2} / \mathrm{He}$ proposed by Framatome. All the operating conditions are considered to be INL's intellectual properties. Table 3-10 shows the main differences between Framatome's $\mathrm{N}_{2} / \mathrm{He}$ cycle and $\mathrm{CO} 2$ cycle developed by INL. For these calculations, hydrogen generation process was included in both configurations. In terms of the overall cycle efficiency, the efficiency is nearly the same (48\%) for both configurations. The main advantage of the $\mathrm{CO}_{2}$ cycle over the $\mathrm{N}_{2} / \mathrm{He}$ cycle is that $\mathrm{CO}_{2}$ cycle reduces the size of the intermediate heat exchanger, turbines, and compressors due to the reduced volumetric flow of $\mathrm{CO}_{2}$ compared to $\mathrm{N}_{2} /$ helium.

Table 3-10. Comparison of the combined $\mathrm{N}_{2} / \mathrm{He}$ and combined with $\mathrm{CO}_{2}$ cycle.

\begin{tabular}{|c|c|c|}
\hline & $\begin{array}{c}\text { Combined Cycle with } \mathrm{N}_{2} / \text { Helium } \\
\text { in Brayton Cycle }\end{array}$ & $\begin{array}{c}\text { Combined Cycle with } \mathrm{CO}_{2} \text { in } \\
\text { Brayton Cycle }\end{array}$ \\
\hline Reactor Power & $600 \mathrm{MW}$-thermal & $600 \mathrm{MW}$-thermal \\
\hline Configuration & Indirect & Indirect \\
\hline Fluid in the reactor & Helium & Helium \\
\hline Fluid in Brayton Cycle & $\mathrm{N}_{2} / \mathrm{He}$ & $\mathrm{CO}_{2}$ \\
\hline \multirow{2}{*}{ Reactor Inlet } & $400^{\circ} \mathrm{C}$ & $400^{\circ} \mathrm{C}$ \\
\hline & $5 \mathrm{MPa}$ & $5 \mathrm{MPa}$ \\
\hline \multirow{2}{*}{ Reactor Outlet } & $1000^{\circ} \mathrm{C}$ & $1000^{\circ} \mathrm{C}$ \\
\hline & $4.95 \mathrm{MPa}$ & $4.95 \mathrm{MPa}$ \\
\hline \multirow{2}{*}{ IHX Outlet } & $392^{\circ} \mathrm{C}$ & $392^{\circ} \mathrm{C}$ \\
\hline & 4.867 MPa & 4.867 MPa \\
\hline \multirow{2}{*}{ Turbine Inlet } & $1000^{\circ} \mathrm{C}$ & $1000^{\circ} \mathrm{C}$ \\
\hline & $4.95 \mathrm{MPa}$ & $11 \mathrm{MPa}$ \\
\hline \multirow{2}{*}{ Compressor Inlet } & $129.4^{\circ} \mathrm{C}$ & $119.6^{\circ} \mathrm{C}$ \\
\hline & $1.63 \mathrm{MPa}$ & $1.63 \mathrm{MPa}$ \\
\hline Hot Pinch Temperature & $285.5 \mathrm{C}$ & 305.9 \\
\hline Cold Pinch Temperature & $283.1 \mathrm{C}$ & $282.8 \mathrm{C}$ \\
\hline UA* & $8.61 \mathrm{e} 7 \mathrm{~kJ} / \mathrm{C}-\mathrm{hr}$ & $3.03 \mathrm{e} 7 \mathrm{~kJ} / \mathrm{C}-\mathrm{hr}$ \\
\hline Std. Vol. Flow & $4800 \mathrm{~m}^{3} / \mathrm{h}$ & $3489 \mathrm{~m}^{3} / \mathrm{h}$ \\
\hline Cycle Efficiency & $48 \%$ & $48 \%$ \\
\hline
\end{tabular}

The reheat cycle configuration is shown in Figure 3-20. 


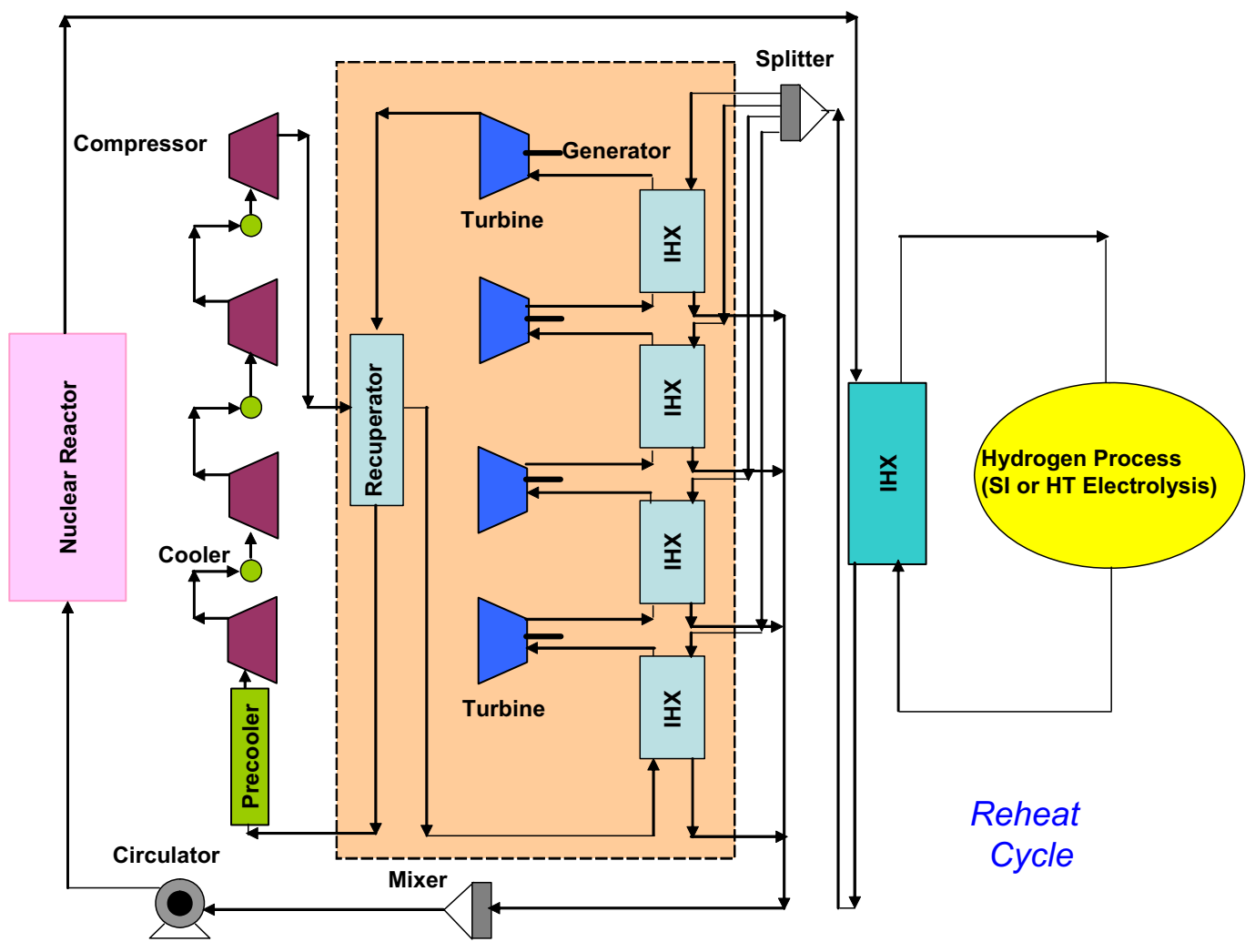

Figure 3-20. Reheat Cycle with $\mathrm{CO}_{2}$ fluid in the power conversion unit.

The idea of this configuration [Ingersoll et. al, 2004] is to enhance the cycle efficiency by increasing the inlet temperatures to the turbines by using four intermediate heat exchangers. This configuration consists of the primary loop with an intermediate heat exchanger that couples the hydrogengenerating plant. The heat transfer media of the primary loop is helium and $\mathrm{CO}_{2}$ was used in the power conversion unit. The reactor power is $600 \mathrm{MW}$ thermal and the energy to the turbomachinery is transferred to four turbines and compressors. The preliminary calculations indicate that the cycle efficiency is approximately $59 \%$. The detailed calculations are being performed. From the detailed study, the pros and cons of this configuration compared with others will be discussed.

\section{Task 2-4. Power Conversion Unit of VHTR Coupled to Hydrogen Plant}

Actually this task was not proposed in our original proposal. However, PCU coupled with hydrogen plant through the intermediate heat exchanger [Oh, et al., 2006] is very important. Therefore, we performed this extra task and included preliminary results in this report.

To accomplish this task, we performed a number of HYSYS simulation to investigate a number of different cycle configurations: 3-shaft Brayton, combined, and reheated cycle. In this report, results from the combined cycle are included.

In order to be consistent for the comparison purpose, we established assumptions and defined method we used for these calculations. 
Both direct and indirect cycles have been postulated for use in the VHTR. The direct cycle eliminates the need for an intermediate heat exchanger (IHX) between the primary and secondary loop and therefore has a higher efficiency. However this poses increased development risk due to no separation between the reactor and cycle components. An indirect cycle has decreased risk and only a small decrease in efficiency while also allowing for the use of $\mathrm{CO}_{2}$ as a working fluid in the secondary side. Furthermore, the Independent Technology Review Group [INEEL, 2004] recommended the use of an indirect cycle for the VHTR. For these reason an indirect cycle was assumed for this study.

The intermediate heat transport loop was assumed to be the same for all configurations. The loop was developed by Davis et. al. [2005] and consists of piping to the hydrogen process plant, a heat exchanger between the loop and hydrogen process plant called the process heat exchanger (PHX), and a circulator. The intermediate heat transport loop was assumed to receive $50 \mathrm{MW}$ of thermal power (ANLW 2004). Estimations of the required separation distance between the nuclear and hydrogen process plant vary considerable. For example, Sochet et al. [2004] recommended $500 \mathrm{~m}$ for the High-Temperature Reactor while Smith et al. [2005] recommended a separation distance of from 60 to $120 \mathrm{~m}$ for the VHTR and the hydrogen production plant. For this analysis, a nominal value of $90 \mathrm{~m}$ was used. The working fluid in the loop is assumed to be helium.

In this analysis two configurations were used for the placement of the intermediate heat transport loop. The first configuration was used in the baseline cycle models and assumed one IHX between the primary and secondary side. The flow on the cold side of the IHX was divided with most of the flow going towards the PCU and the rest going towards heat exchanger for the intermediate heat transport loop. For convenience the heat exchanger between the VHTR and the intermediate heat transport loop will be referred to as the heat transport loop heat exchanger (HTLHX). The reheat option did not allow for this configuration so a new configuration was develop in which the HTLHX is in parallel with the intermediate heat exchangers in primary loop before and provides heat to the intermediate heat transport loop.

The VHTR was assumed to produce $600 \mathrm{MW}$ of thermal power with a $900{ }^{\circ} \mathrm{C}$ outlet temperature and use helium coolant on the primary side. The nominal rise in fluid temperature across the core was assumed to be $400{ }^{\circ} \mathrm{C}$, based on the point design (MacDonald et al. 2003). However for the reheat option this value was not used and a smaller temperature rise was calculated and applied to take advantage of the cycle.

The nominal reactor pressure was assumed to be $7 \mathrm{MPa}$ [Davis et al, 2005]. The cycle working pressure was assumed to be $7 \mathrm{MPa}$. The pressure drop across the hot-side of the IHX was assumed to be $0.05 \mathrm{MPa}$. From the component sizing calculations the cold side pressure drop was then calculated. For the HTLHX the nominal cold side pressure drop was taken to be .139 MPa from the report by Davis et. al. Again using the component sizing calculations the pressure drop on the hot side was calculated. The recuperator was assumed to have a hot side pressure drop of .1 $\mathrm{MPa}$. The precoolers and intercoolers, in the three shaft and reheated cycles, were assumed to have a $.05 \mathrm{MPa}$ pressure drop.

\section{Subtask 2-4-2. Methods}

This section describes the methods that were used in determining the efficiency, component sizes and cycle sensitivity to varying working conditions. The different design configurations that were studied are described in Section 2-4-3. The working fluids selection process is explained in the section of working fluids below. The optimization process that was used to determine maximum cycle efficiency is illustrated in Section 2-4-4. Finally the parametric studies were performed on the various PCU configurations and are described in Section 2-4-5. 


\section{Subtask 2-4-3. Design Configurations}

The design of the VHTR power conversion unit is demonstrated using three-shaft, combined and reheated cycle designs to better understand the consequences of various cycle configurations. The primary side of the plant was kept constant for the three-shaft and combined cycles. The primary side working conditions for the VHTR are summarized in 3-11.

Table 3-11. Summary of Primary working conditions for three-shaft and combined cycles.

\begin{tabular}{|l|l|}
\hline \multicolumn{1}{|c|}{ Parameter } & \multicolumn{1}{c|}{ Nominal Value } \\
\hline Power, MW & 600 \\
\hline Inlet temperature, ${ }^{\circ} \mathrm{C}$ & 500 \\
\hline Inlet Pressure, $\mathrm{MPa}$ & 7.05 \\
\hline Outlet temperature, ${ }^{\circ} \mathrm{C}$ & 900 \\
\hline Outlet pressure, $\mathrm{MPa}$ & 7 \\
\hline IHX pressure drop, $\mathrm{MPa}$ & 0.05 \\
\hline Mass Flow, kg/s & 289 \\
\hline Working fluid & $\mathrm{He}$ \\
\hline
\end{tabular}

In the reheated cycle the primary side was altered to produce a more realistic model of the cycle. The reactor inlet temperature must be raised to take advantage of the reheat option. This was done by raising the mass flow through the primary side. The additional intermediate heat exchangers need for the reheat cycle make the use of helium in the primary side infeasible. The additional pressure drop incurred by the heat exchangers offsets the benefits of reheating. Therefore to take advantage of reheat a molten salt was used as the primary working fluid, which has a very small pressure drop relative to helium, making the use of reheating feasible. Flibe which is composed of $66 \% \mathrm{LiF}$ and $42 \% \mathrm{BeF}_{2}$, by weight, was used for this study. Flibe is an incompressible liquid and the pressure drop for this fluid is very low and was assumed to be negligible. The primary side working conditions for the reheat cycle are summarized in Table 3-12.

Table 3-12. Summary of Primary working conditions for reheated cycle.

\begin{tabular}{|l|l|}
\hline \multicolumn{1}{|c|}{ Parameter } & \multicolumn{1}{|c|}{ Nominal Value } \\
\hline Power, MW & 600 \\
\hline Pressure, $\mathrm{MPa}$ & 0.1013 \\
\hline Reactor outlet temperature, ${ }^{\circ} \mathrm{C}$ & 900 \\
\hline IHX pressure drop, $\mathrm{MPa}$ & 0 \\
\hline
\end{tabular}

The VHTR is envisioned to be a demonstration plant for hydrogen production and electrical generation. In order for hydrogen production to be possible process heat from the reactor must be transported to the hydrogen production plant. To accomplish this, an intermediate heat transport loop added to the VHTR design. This loop is coupled to the VHTR by means of the HTLHX. The loop that is used in this document was developed in a paper by Davis et. al. [2005]. The working conditions in that loop are summarized in 3-13. 
Table 3-13. Working conditions in the intermediate heat transport loop.

\begin{tabular}{|l|l|}
\hline \multicolumn{1}{|c|}{ Parameter } & \multicolumn{1}{c|}{ Nominal Value } \\
\hline Power, MW & 50 \\
\hline Heat Loss, MW & 1.79 \\
\hline Outlet temperature of HTLHX, ${ }^{\circ} \mathrm{C}$ & 875.1 \\
\hline HTLHX pressure drop, MPa & 0.139 \\
\hline Pressure, MPa & 2 \\
\hline Mass Flow, $\mathrm{kg} / \mathrm{s}$ & 27.5 \\
\hline
\end{tabular}

The HTLHX is placed in the secondary side in parallel with the PCU for the 3 shaft and combined cycles. In this configuration, the IHX cold-side outlet fluid is split, with most going towards the PCU and the remainder going towards the hydrogen production plant. A small circulator is required to compensate for the pressure loss across the HTLHX and allow the fluid streams to mix downstream of the PCU [Oh, et al., 2006].

The combined cycle, illustrated in Figure 3-21, an indirect cycle with a combined power conversion unit (PCU) configuration and an intermediate heat transport loop for hydrogen production. The primary side of the loop consists of a high temperature nuclear reactor, intermediate heat exchanger (IHX), and a circulator. The conditions for this loop are summarized in Table 3-14. The intermediate heat transfer loop for delivering process heat to hydrogen production was developed at INL and summarized in INL/EXT-05-00453. The PCU configuration, illustrated in Figure 3-21, consists of; (1) a primary loop (2) an intermediate heat transport loop in parallel with (3) the PCU with a Brayton top cycle consisting of a gas turbine, compressor and coupled to a Rankine bottoming cycle through a steam generator. The Rankine cycle consists of a steam turbine, condenser and a pump. This cycle was simulated using helium as the working fluid in the primary and intermediate heat transport loop. Helium, $\mathrm{CO}_{2}$ and the $\mathrm{N}_{2}-\mathrm{He}$ mixture were simulated in the PCU while water was used in Rankine cycle.

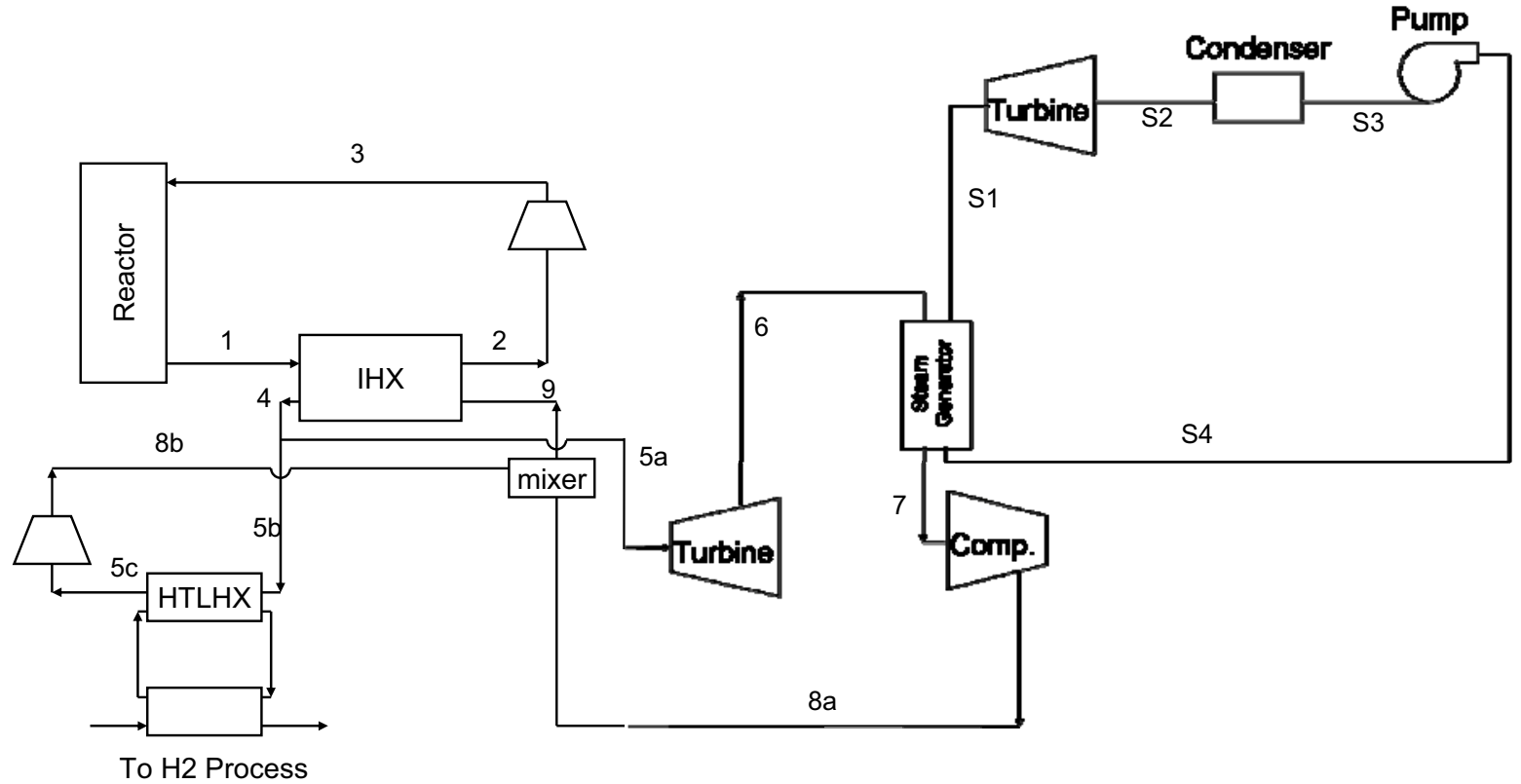

Figure 3-21. Schematic of the combined cycle. 
Table 3-14. Summary of Primary working conditions for the combined cycle.

\begin{tabular}{|l|l|}
\hline \multicolumn{1}{|c|}{ Parameter } & \multicolumn{1}{c|}{ Nominal Value } \\
\hline Power, MW & 600 \\
\hline Inlet temperature, ${ }^{\circ} \mathrm{C}$ & 500 \\
\hline Inlet Pressure, $\mathrm{MPa}$ & 7.05 \\
\hline Outlet temperature, ${ }^{\circ} \mathrm{C}$ & 900 \\
\hline Outlet pressure, $\mathrm{MPa}$ & 7 \\
\hline IHX pressure drop, $\mathrm{MPa}$ & 0.05 \\
\hline Mass Flow, $\mathrm{kg} / \mathrm{s}$ & 289 \\
\hline Working fluid & $\mathrm{He}$ \\
\hline
\end{tabular}

The same Rankine bottoming cycle was used for all three working fluids. This cycle gets heat from the Brayton cycle through a steam generator located between the gas turbine and compressor. The steam turbine inlet temperature was set at $575^{\circ} \mathrm{C}$ to take advantage of the superheat option and keep the turbine outlet quality at $85 \%$.

Comparing the working fluids in this cycle it can be seen that the $\mathrm{CO}_{2}$ working fluid produces the highest efficiency and smallest component sizes. Helium and the $\mathrm{N}_{2}$-He mixture produced similar component sizes; however, helium had a slightly higher efficiency.

Subtask 2-4-4 Efficiency optimization

Using the conditions established in Table 3-14, the cycles were modeled and optimized in HYSYS. To calculate the efficiency the spreadsheet function of HYSYS was used. The overall efficiency of the VHTR was calculated as follows [Oh, et al., 2006]:

$\eta_{\text {overall }}=\frac{\Sigma \mathrm{W}_{\mathrm{T}}-\Sigma \mathrm{W}_{\mathrm{C}}-\Sigma \mathrm{W}_{\mathrm{CIR}}+0.5 * \mathrm{Q}_{\mathrm{H} 2}}{\mathrm{Q}_{\mathrm{th}}}$.

Where $\Sigma \mathrm{W}_{\mathrm{T}}$ is the total turbine workload, $\Sigma \mathrm{W}_{\mathrm{C}}$ is the total compressor workload, $\Sigma \mathrm{W}_{\mathrm{CIR}}$ is the circulator workload in the primary, secondary and, intermediate heat transport loops, $\mathrm{Q}_{\text {th }}$ is the reactor thermal power, and $\mathrm{Q}_{\mathrm{H} 2}$ is the power supplied to the hydrogen generating plant. The efficiency of the hydrogen generation plant was assumed to be $50 \%$.

A model to solve for the effectiveness $\varepsilon$ of a heat exchanger is not defined in HYSYS and had to be developed. The effectiveness of a heat exchanger is defined as the ratio of the actual heat transfer rate to the maximum heat transfer rate. The spreadsheet function was used and the following equations were input:

$$
\begin{aligned}
& \varepsilon=\frac{q}{q_{\max }} \\
& q_{\max }=C_{\text {mim }}\left(T_{h, i}-T_{c, i}\right)
\end{aligned}
$$


Where $\mathrm{C}_{\min }$ refers to the smaller of $\mathrm{C}_{\text {hot }}$ or $\mathrm{C}_{\text {cold }}$.

$$
C_{h o t}=c_{p, h o t} \dot{m}_{h o t}
$$

$C_{\text {cold }}=c_{p, \text { cold }} \dot{m}_{\text {cold }}$

The log mean temperature difference (LMTD) and the minimum approach were calculated by HYSYS and used to determine heat exchanger performance. The effectiveness, LMTD, and minimum approach served as limits to the allowable working conditions within the cycle. An acceptable effectiveness, LMTD and minimum approach for each heat exchanger were determined and the working conditions were set to take advantage of these limits in order to maximize efficiency. The limits imposed on the cycles are summarized in 3-15 through Table 3-17.

The polytropic efficiency of the turbomachinery was used for efficiency calculation rather than the isentropic efficiency. The polytropic efficiencies for the turbines and the compressors were assumed to be $92 \%$ and $90 \%$, respectively. These values are representative of expected efficiency that will be available for the VHTR project.

Once the working conditions and limits were set the cycle pressure ratios were optimized. For the combined cycle the mass split between the PCU and HTLHX was also optimized.

Table 3-15. Cycle conditions for three-shaft configuration.

\begin{tabular}{|l|l|}
\hline Parameter & Nominal Value \\
\hline IHX cold-side outlet temp, ${ }^{\circ} \mathrm{C}$ & 885 \\
\hline IHX effectiveness limit & $<97 \%$ \\
\hline IHX temperature pinch limit, ${ }^{\circ} \mathrm{C}$ & 5 \\
\hline IHX LMTD, ${ }^{\circ} \mathrm{C}$ & 15 \\
\hline Compressor outlet pressure, $\mathrm{MPa}$ & 7.05 \\
\hline Precooler outlet temperature, ${ }^{\circ} \mathrm{C}$ & 30 \\
\hline Recuperator effectiveness & $95 \%$ \\
\hline HTLHX effectiveness limit & $<97 \%$ \\
\hline HTLHX temperature pinch limit, ${ }^{\circ} \mathrm{C}$ & 5 \\
\hline HTLHX LMTD, ${ }^{\circ} \mathrm{C}$ & 27 \\
\hline
\end{tabular}


Table 3-16. Cycle conditions for combined configuration.

\begin{tabular}{|l|l|}
\hline Parameter & Nominal Value \\
\hline IHX cold-side outlet temp, ${ }^{\circ} \mathrm{C}$ & 885 \\
\hline IHX effectiveness limit & $<97 \%$ \\
\hline IHX temperature pinch limit, ${ }^{\circ} \mathrm{C}$ & 5 \\
\hline IHX LMTD, ${ }^{\circ} \mathrm{C}$ & 15 \\
\hline Compressor outlet pressure, $\mathrm{MPa}$ & 7.05 \\
\hline Precooler outlet temperature, ${ }^{\circ} \mathrm{C}$ & 30 \\
\hline Recuperator effectiveness & $95 \%$ \\
\hline HTLHX effectiveness limit & $<97 \%$ \\
\hline HTLHX temperature pinch limit, ${ }^{\circ} \mathrm{C}$ & 5 \\
\hline HTLHX LMTD, ${ }^{\circ} \mathrm{C}$ & 27 \\
\hline steam generator temperature pinch, ${ }^{\circ} \mathrm{C}$ & 5 \\
\hline Steam turbine outlet quality & $>85 \%$ \\
\hline Steam turbine outlet pressure, $\mathrm{kPa}$ & 20 \\
\hline Pump outlet pressure, $\mathrm{MPa}$ & 15 \\
\hline
\end{tabular}

Table 3-17. Cycle conditions for the reheated configuration.

\begin{tabular}{|l|l|}
\hline Parameter & Nominal Value \\
\hline IHX cold-side outlet temp, ${ }^{\circ} \mathrm{C}$ & 885 \\
\hline IHX effectiveness limit & $<97 \%$ \\
\hline IHX temperature pinch limit, ${ }^{\circ} \mathrm{C}$ & 5 \\
\hline IHX LMTD, ${ }^{\circ} \mathrm{C}$ & 15 \\
\hline Compressor outlet pressure, MPa & 7.05 \\
\hline Precooler outlet temperature, ${ }^{\circ} \mathrm{C}$ & 30 \\
\hline Recuperator effectiveness & $95 \%$ \\
\hline HTLHX effectiveness limit & $<97 \%$ \\
\hline HTLHX temperature pinch limit, ${ }^{\circ} \mathrm{C}$ & 5 \\
\hline HTLHX LMTD, ${ }^{\circ} \mathrm{C}$ & 27 \\
\hline
\end{tabular}

Subtask 2-4-5 Working Fluids and Parametric Studies

We examined a number of various working fluids in this study.

\section{Helium Working Fluid}

The helium working fluid was optimized for the combined cycle with a pressure ratio of 2.287 and an efficiency of $47.76 \%$. The secondary mass flow rate was optimized at $289 \mathrm{~kg} / \mathrm{s}$. The total heat exchanger volume was $412.9 \mathrm{~m}^{3}$ and the total cycle work was $718.8 \mathrm{MW}$. Table 3-18 lists the individual component sizing results for the cycle. 
Table 3-18. Component sizing data fro combined cycle with helium working fluid.

\begin{tabular}{|l|l|}
\hline \multicolumn{1}{|c|}{ Component } & \multicolumn{1}{c|}{ Value } \\
\hline Gas Turbine work (MW) & 314.6 \\
\hline Steam Turbine work (MW) & 174.3 \\
\hline Compressor work (MW) & 200.0 \\
\hline Pump work (MW) & 2.4 \\
\hline Circulator work (MW) & 27.5 \\
\hline IHX volume $\left(\mathrm{m}^{3}\right)$ & 80.4 \\
\hline HTLHX volume $\left(\mathrm{m}^{3}\right)$ & 1.7 \\
\hline Steam generator volume $\left(\mathrm{m}^{3}\right)$ & 330.8 \\
\hline
\end{tabular}

\section{CO2 Working Fluid}

The $\mathrm{CO}_{2}$ working fluid was optimized for the combined cycle with a pressure ratio of 7.72 and an efficiency of $48.76 \%$. The secondary mass flow rate was optimized at $1113 \mathrm{~kg} / \mathrm{s}$. The HYSYS simulation is illustrated in Figure 3-22, the T-S diagram is shown in Figure 3-24 and the state points are summarized in Table 3-19. The total heat exchanger volume was $366.9 \mathrm{~m}^{3}$ and the total cycle work was $662.2 \mathrm{MW}$. Table 3-20 lists the individual component sizing results for the cycle.

Parametric studies away from the baseline values of the systems were performed on the three-shaft and combined cycles to determine the effect of varying conditions in the cycle. This gives some insight into the sensitivity of these cycles to various operating. The parametric studies were carried out by isolating and varying a single working condition. Once the working condition was changed the cycle was optimized using the methods discussed in Section 2-4-4.

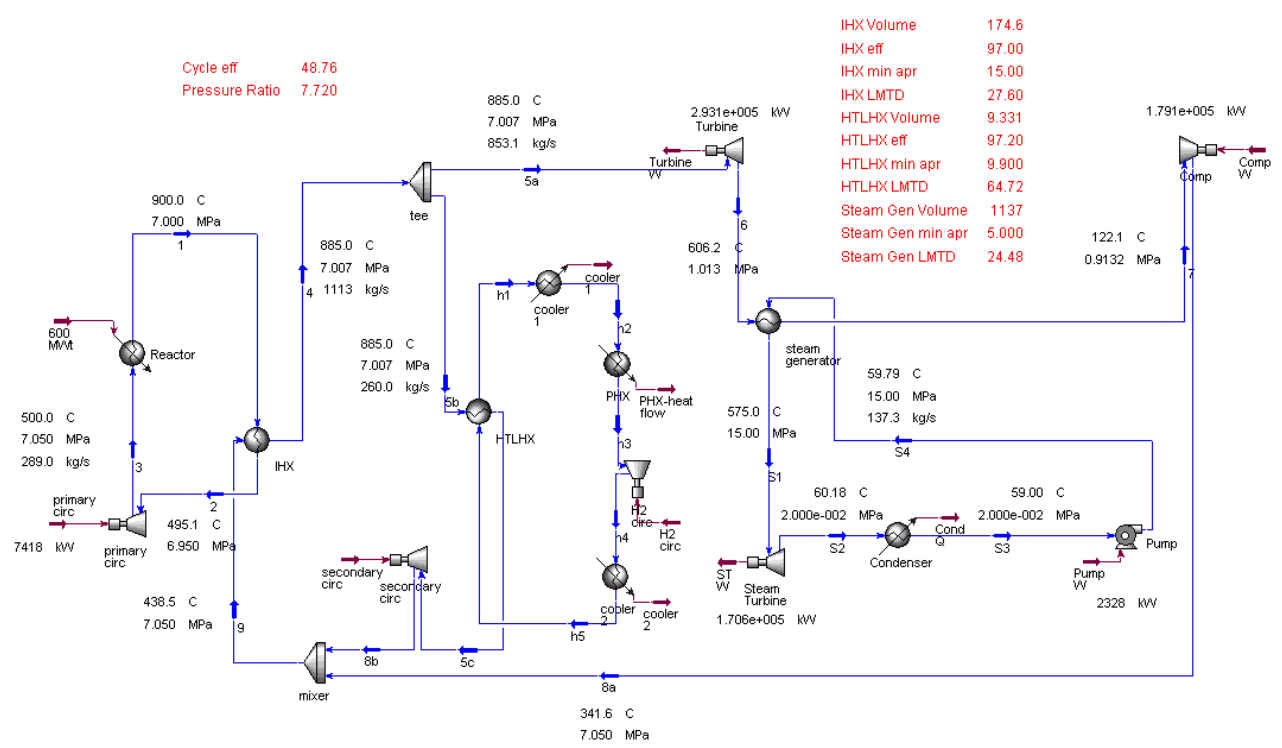

Figure 3-22. HYSYS diagram of Brayton top cycle with $\mathrm{CO}_{2}$ working fluid. 


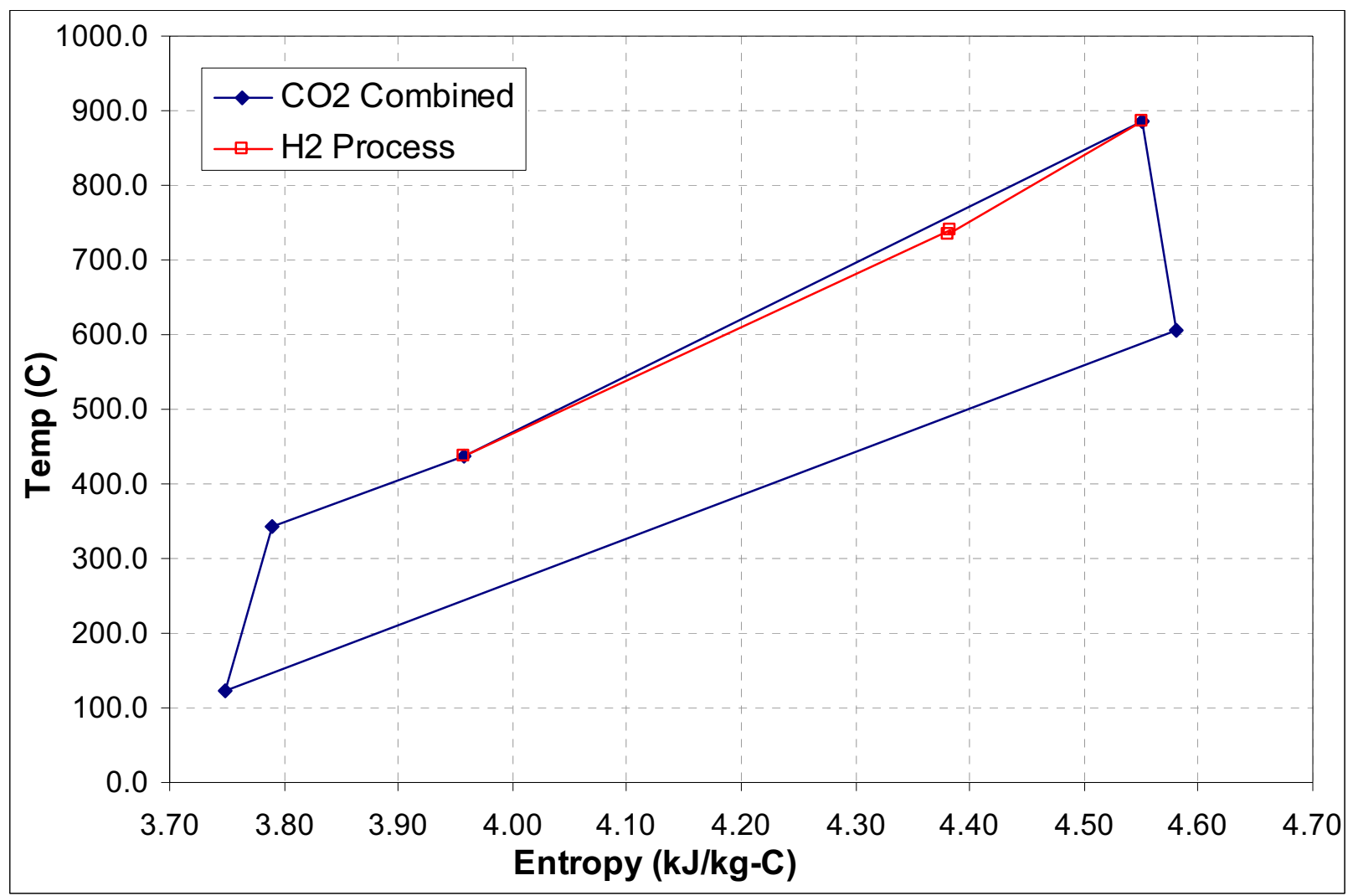

Figure 3-23. T-S diagram of Brayton top cycle with $\mathrm{CO}_{2}$ working fluid.

Table 3-19. State points for Brayton top cycle with $\mathrm{CO}_{2}$ working fluid.

\begin{tabular}{|l|c|c|c|c|}
\hline Point & $\begin{array}{c}\text { Temp } \\
\left({ }^{\circ} \mathrm{C}\right)\end{array}$ & $\begin{array}{c}\text { Pressure } \\
(\mathrm{MPa})\end{array}$ & $\begin{array}{c}\text { Entropy } \\
(\mathrm{kJ} / \mathrm{kg}-\mathrm{K})\end{array}$ & Enthalpy $(\mathrm{kJ} / \mathrm{kg})$ \\
\hline 1 & 900.0 & 7.00 & 19.33 & 4561.1 \\
\hline 2 & 495.1 & 6.95 & 17.15 & 2459.0 \\
\hline 3 & 500.0 & 7.05 & 17.16 & 2484.7 \\
\hline $4,5(\mathrm{a}, \mathrm{b})$ & 885.0 & 7.01 & 4.55 & -7999.0 \\
\hline $5 \mathrm{c}$ & 734.8 & 6.81 & 4.38 & -8188.7 \\
\hline 6 & 606.2 & 1.01 & 4.58 & -8342.5 \\
\hline 7 & 122.1 & 0.91 & 3.75 & -8865.5 \\
\hline $8 \mathrm{a}$ & 341.6 & 7.05 & 3.79 & -8655.5 \\
\hline $8 \mathrm{~b}$ & 741.0 & 7.05 & 4.38 & -8181.1 \\
\hline 9 & 438.5 & 7.05 & 3.96 & -8544.7 \\
\hline
\end{tabular}


Table 3-20. Component sizing data for combined cycle with $\mathrm{CO}_{2}$ working fluid.

\begin{tabular}{|l|l|}
\hline \multicolumn{1}{|c|}{ Component } & \multicolumn{1}{c|}{ Value } \\
\hline Gas Turbine work (MW) & 293.1 \\
\hline Steam Turbine work (MW) & 170.6 \\
\hline Compressor work (MW) & 179.1 \\
\hline Pump work (MW) & 2.3 \\
\hline Circulator work (MW) & 17.1 \\
\hline IHX volume $\left(\mathrm{m}^{3}\right)$ & 48.5 \\
\hline HTLHX volume $\left(\mathrm{m}^{3}\right)$ & 2.6 \\
\hline Steam generator volume $\left(\mathrm{m}^{3}\right)$ & 315.8 \\
\hline
\end{tabular}

Nitrogen-Helium Working Fluid

The $\mathrm{N}_{2}-\mathrm{He}$ mixture was optimized for the combined cycle with a pressure ratio of 2.712 and an efficiency of $47.24 \%$. The secondary mass flow rate was optimized at $759 \mathrm{~kg} / \mathrm{s}$. The total heat exchanger volume was $405.7 \mathrm{~m}^{3}$ and the total cycle work was $727.4 \mathrm{MW}$. Table 3-21 lists the individual component sizing results for the cycle.

Table 3-21. Component sizing data for combined cycle with a nitrogen-helium mixture.

\begin{tabular}{|l|l|}
\hline \multicolumn{1}{|c|}{ Component } & \multicolumn{1}{c|}{ Value } \\
\hline Gas Turbine work (MW) & 315.4 \\
\hline Steam Turbine work (MW) & 176.3 \\
\hline Compressor work (MW) & 201.8 \\
\hline Pump work (MW) & 2.4 \\
\hline Circulator work (MW) & 31.5 \\
\hline IHX volume $\left(\mathrm{m}^{3}\right)$ & 71.7 \\
\hline HTLHX volume $\left(\mathrm{m}^{3}\right)$ & 1.7 \\
\hline Steam generator volume $\left(\mathrm{m}^{3}\right)$ & 332.3 \\
\hline
\end{tabular}

Parametric studies were performed on the reactor outlet temperature, secondary mass flow rate, pressure, and turbine for the 3 working fluids. The results are summarized in Figure 3-24, Figure 3-25, Figure 3-26 and Table 3-21. All three working fluids behaved similarly under off normal working conditions. However, helium was less affected by pressure that $\mathrm{CO}_{2}$ and the $\mathrm{N}_{2}-\mathrm{He}$ mixture. The effect of turbine cooling on the system was an approximately $0.5 \%$ efficiency decrease for all working fluids. 


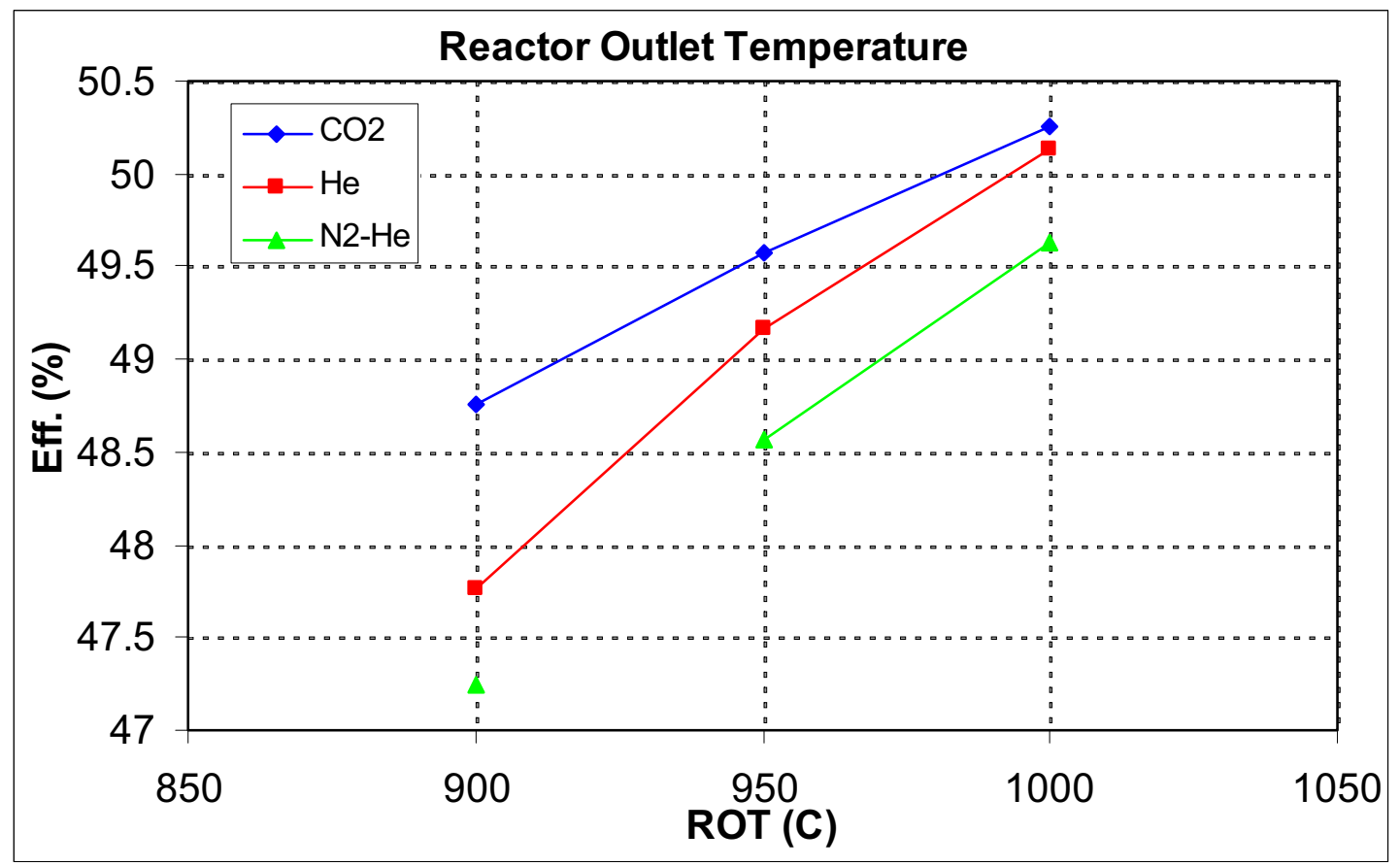

Figure 3-24. Parametric study of the effects of reactor outlet temperature on combined cycle efficiency.

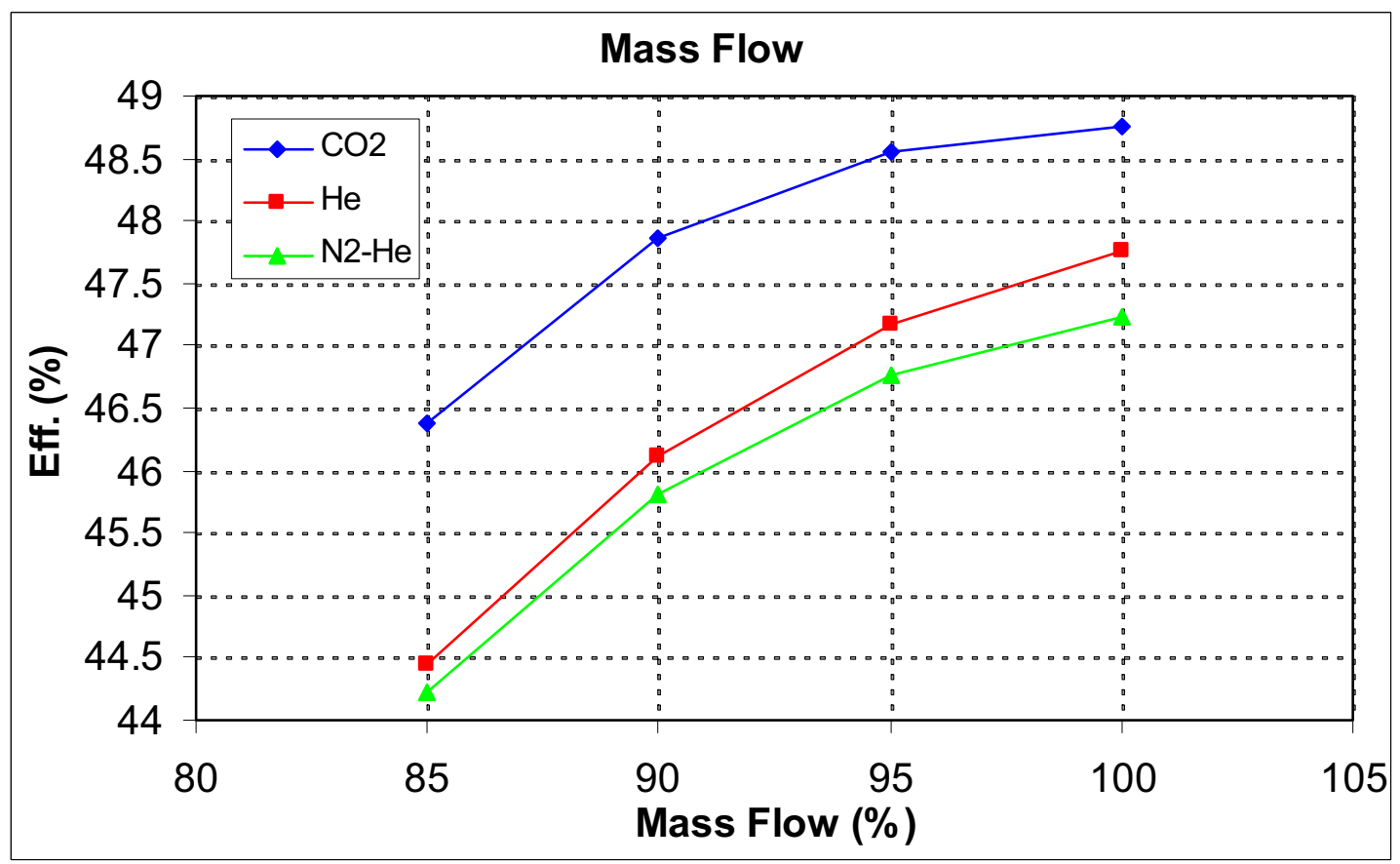

Figure 3-25. Parametric study of the effects of secondary mass flow rate on combined cycle efficiency. 


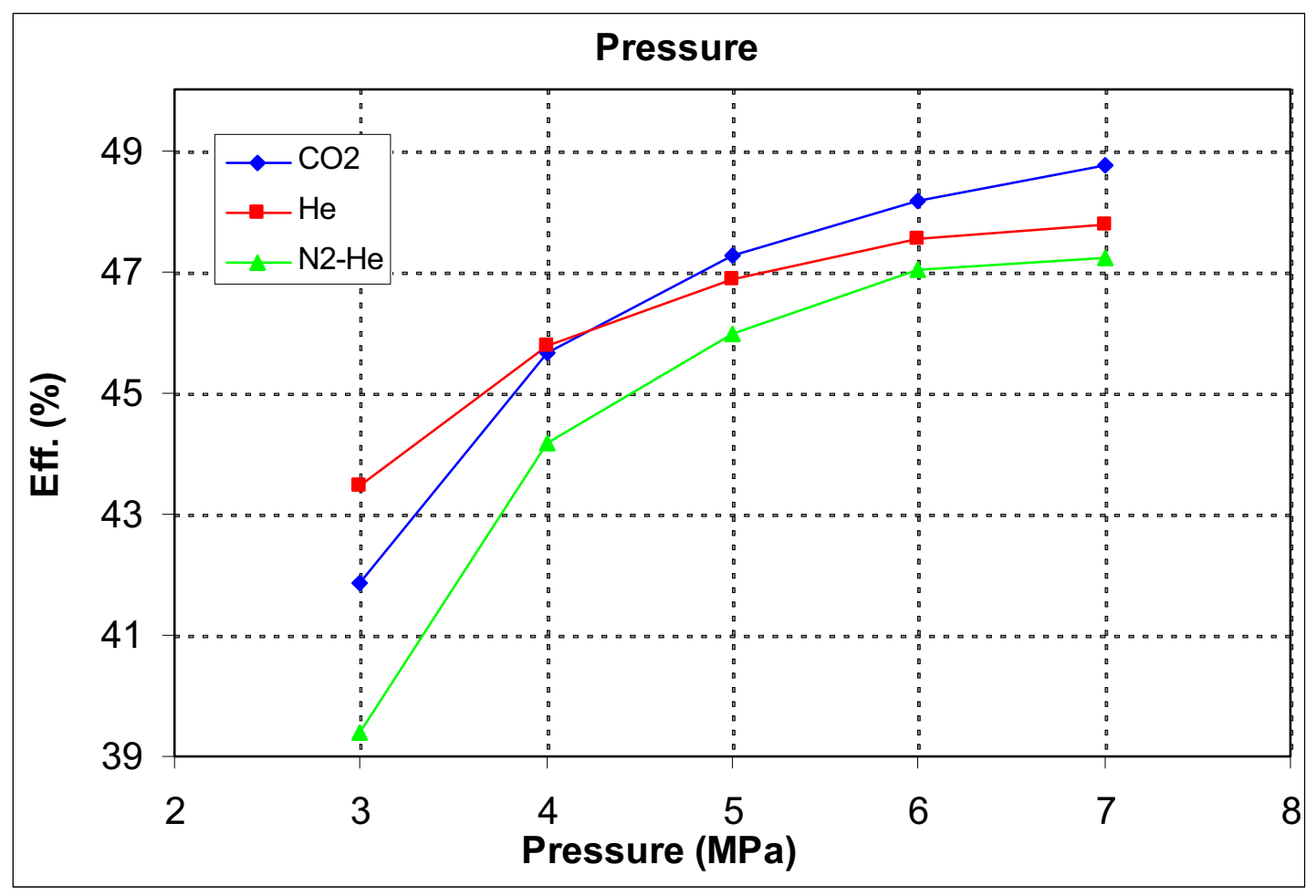

Figure 3-26. Parametric study of the effects of working pressure on combined cycle efficiency.

Table 3-22. Parametric study of the effects of turbine cooling on combined cycle efficiency.

\begin{tabular}{|c|c|c|c|}
\hline \multicolumn{4}{|c|}{ Turbine Cooling } \\
\hline & $\mathrm{CO} 2$ & $\mathrm{He}$ & $\mathrm{N} 2-\mathrm{He}$ \\
\hline None & 50.14 & 48.48 & 48.75 \\
\hline $8 \%$ & 49.63 & 48.06 & 48.38 \\
\hline
\end{tabular}




\section{TASK 3: MATERIAL TESTING}

Identification of materials for a supercritical $\mathrm{CO}_{2}$ Brayton cycle operating at temperatures approaching $1000^{\circ} \mathrm{C}$ remains one of the most troubling issues. Candidate materials must have exceptional high temperature strength and creep resistance as well as exceptional corrosion resistance in order to obtain long component lifetimes ( $>10-20$ years). The material of choice should also be easily fabricated and joined to be cost effective. Normally, metallic alloys would be the material of choice, however, the extremely high operating temperature $\left(\sim 1000^{\circ} \mathrm{C}\right)$ and a pressurized environment, places severe limitations on the number of metallic materials suitable for this application.

One of the candidate, metallic materials for application in the supercritical $\mathrm{CO}_{2}$ Brayton cycle is an oxide dispersion strengthened (ODS) nickel-based alloy designated MA 754. The yttrium oxide dispersion incorporated into this material increases high temperature strength and creep resistance. The nickel-based alloy matrix contains a high amount of chromium $(20 \mathrm{wt} \% \mathrm{Cr})$ that makes it highly corrosion resistant in many environments. The alloy is relatively new and data is lacking in the areas of corrosion behavior in supercritical $\mathrm{CO}_{2}$ and creep rates at various temperature and applied stress combinations. Research was done to evaluate the corrosion resistance and creep behavior in order to determine the suitability of this alloy for long-term applications in the supercritical $\mathrm{CO}_{2}$ Brayton cycle.

Additionally, the alloy I-617 was added to the supercritical $\mathrm{CO}_{2}$ corrosion study. While more mechanical property data at temperatures up to $1000^{\circ} \mathrm{C}$ exists for this alloy (which is currently being evaluated for inclusion in the ASME Boiler and Pressure Vessel code), the corrosion behavior of this alloy in supercritical $\mathrm{CO}_{2}$ is unknown. This is also a nickel based alloy with a slightly higher chromium content (22 wt\% versus $20 \mathrm{wt} \%$ for MA 754) and significant additions of cobalt (12.5 wt \%) and molybdenum ( $9 \mathrm{wt} \%$ ) compared to MA 754 which does not contain these elements. Since the high temperature mechanical properties of this alloy are being evaluated elsewhere, only the corrosion behavior of this alloy was investigated for this particular material.

\section{Task 3-1 Characterization of Creep Deformation of MA 754}

The results of this task have been summarized in two papers - one concerning the coarse-grained (creep resistant) MA 754 material and the other focusing on the fine-grained MA 754. The relevant journal information, where more detailed analysis and explanation of the results can be found, is shown below:

Totemeier, T.C. and Lillo, T.M, "Effect of Orientation on the Tensile and Creep Properties of Coarse-Grained INCONEL Alloy MA754", Metallurgical and Materials Trans. A, vol. 36A, 2005, pp. 785-795.

Totemeier, T.C. Lillo, T.M. and Simpson, J. A, "Elevated Temperature Strength of Fine Grained INCONEL Alloy MA754”, Metallurgical and Materials Trans. A, vol. 36A, 2005, pp. 2552-2555.

Subtask 3-1-1 Characterization of Initial Microstructure - MA 754 can be obtained in either a coarse, elongated grained state or in a relatively fine, equiaxed grained state. The coarse, elongated microstructure is considered to be more creep resistant than the fine, equiaxed microstructure. (The coarse, elongated grain microstructure is produced from the fine equiaxed microstructure by a high temperature heat treatment.) Figure 4-1 shows the initial microstructure of each material as observed in the transmission electron microscope. MA 754 is produced by consolidation of mechanically alloyed powders. Mechanical alloying (MA) is used to incorporate very fine yttrium oxide particles into the nickel/chromium-based powder particles. The mechanically-alloyed powders are then consolidated to full density by extrusion at elevated temperatures to produce a rectangular bar (other shapes can also be 
manufactured). The oxide particles are seen in both microstructures of Figure 4-1 (black, round particles). Also annealing twins, at the white arrows, are observed in the coarse-grained material, Fig. 4-1a, but not in the fine grained material. These grains have a special orientation relationship to the matrix material (related by a $60^{\circ}$ rotation about the $<111>$ crystallographic direction) and have been shown to influence mechanical properties in other materials (see for example Kumar, et. al., 2000 and Flinn, et. al, 2001).
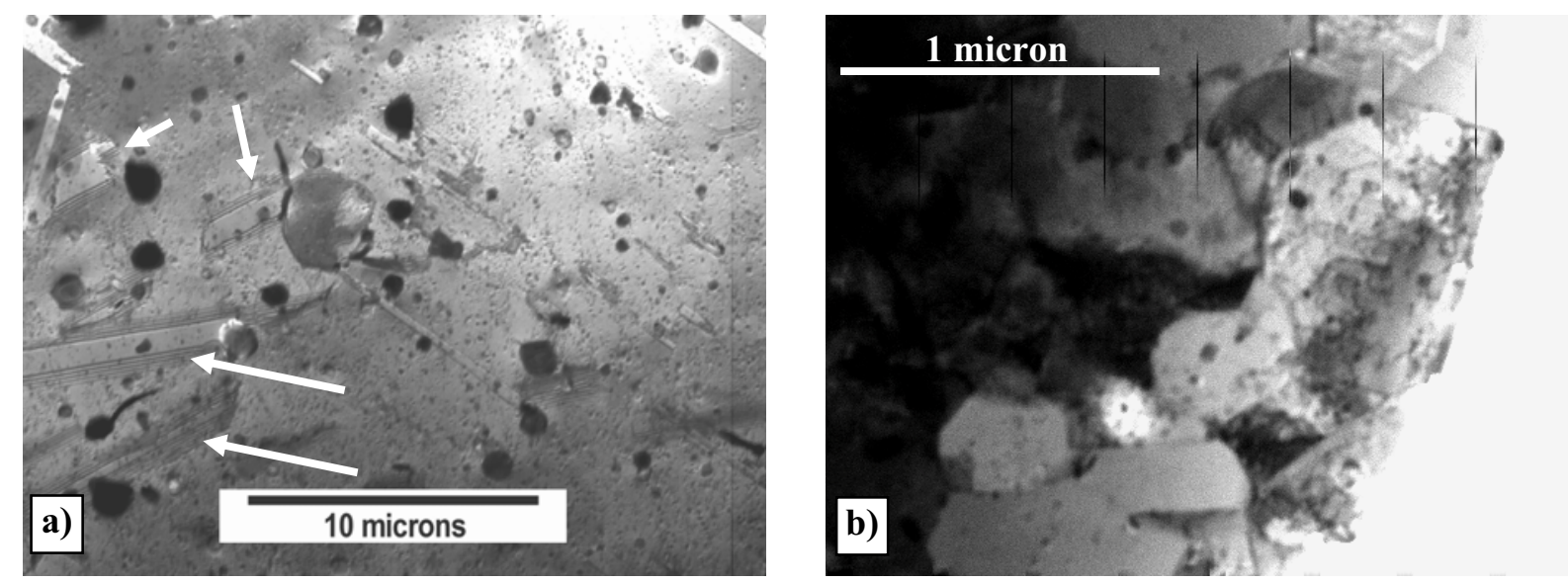

Figure 4-1. Initial microstructures of a) coarse, elongated-grained and b) fine, equiaxed-grained MA 754.

Figure 4-1b shows the fine-grained MA754 to have a grain size on the order of $0.5-1.0 \mu \mathrm{m}$. This is in contrast to the coarse-grained MA754 which exhibited highly elongated grains on the order of millimeters in length. The grain size and morphology of the coarse, elongated grained MA 754 is not shown in Figure 4-1a due to the high magnification of this figure. Figure 4-2 shows representative micrographs of the coarse, elongated microstructure as viewed from various directions in the bar. The grains in this alloy are very large and elongated in the extrusion direction (longitudinal direction), Figs 4$2 \mathrm{a}$ and $4-2 \mathrm{~b}$, while fairly equiaxed in the face perpendicular to the extrusion direction (transverse direction), Fig. 4-2c. The microstructure-dependent mechanical properties are, therefore, expected to vary with orientation within the coarse-grained material. The creep properties are not expected to be as good in the transverse direction as in the longitudinal direction since grain boundaries tend to enhance the creep rate. Figure 4-2 also shows apparent residual porosity, indicated by the arrows. It was determined that the chemicals used to reveal the grain boundaries (the light gray continuous lines in the photomicrographs) exaggerated the porosity and the density of the materials studied actually was greater than $99 \%$ of theoretical density. 


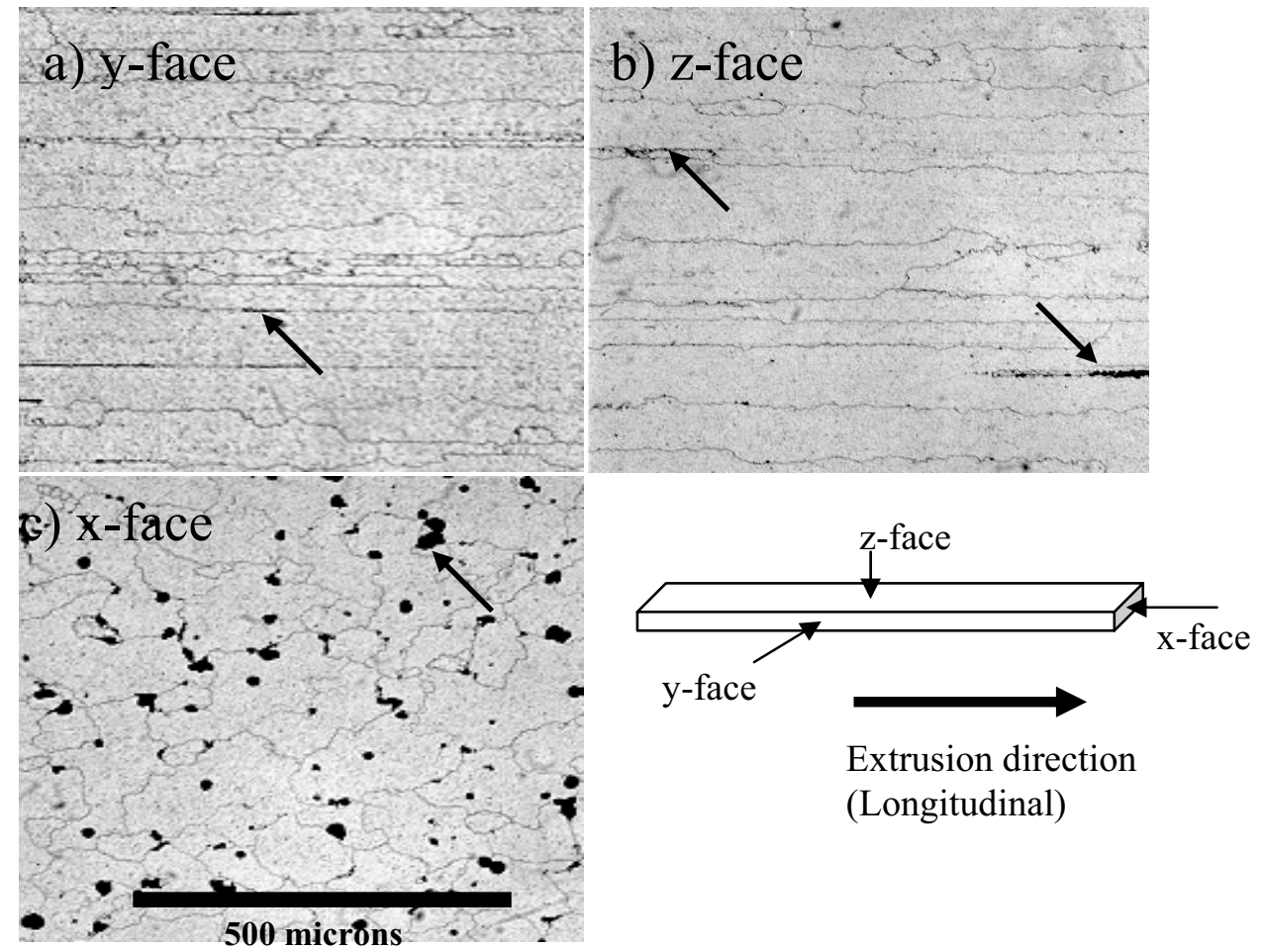

Figure 4-2. Low magnification micrograph of the coarse, elongated microstructure of MA 754 in the as-received condition.

Subtask 3-1-2 High Temperature Mechanical and Creep Properties of Coarse-grained MA 754 The tensile properties (strain rate $\sim 1 \times 10^{-3}$ /second) of coarse-grained MA 754 were determined for temperatures expected to be present in the proposed supercritical $\mathrm{CO}_{2}$ Brayton cycle and are shown in Figure 4-3 for both the longitudinal and transverse directions. These values are significantly greater than those of Inconel 617 at similar temperatures [Special Metals Corporation, 2005]. At $1000^{\circ} \mathrm{C}$, the yield and ultimate tensile stress of MA 754, regardless of orientation, are more than 2 times that of I-617. In this regard, the use of MA 754 represents a significant advantage, allowing components with thinner walls (and less material) to be designed and fabricated. However, the ductility at $1000^{\circ} \mathrm{C}$ for MA 754 is only $\sim 17 \%$ in the longitudinal direction and $\sim 10 \%$ in the transverse direction, Fig. $4-3 \mathrm{~b}$, as opposed to $>70 \%$ for I-617 [Special Metals Corporation, 2005]. In this regard, MA 754 may have fabrication issues. In general, fracture surface morphology was determined by the elongated microstructures with tensile samples oriented in the longitudinal direction exhibiting ductile transgranular rupture and transverse samples exhibiting intergranular failure, Fig. 4-4, i.e. fracture along the elongated grain boundaries. 


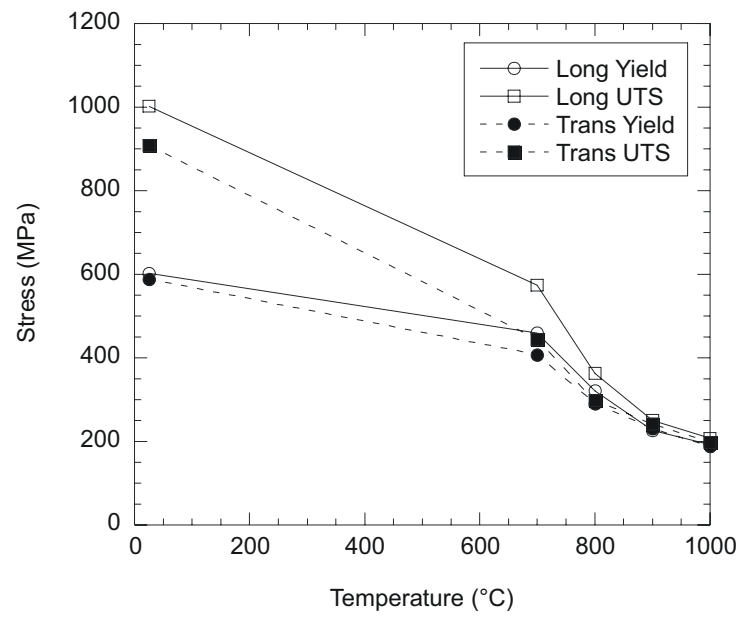

(a)

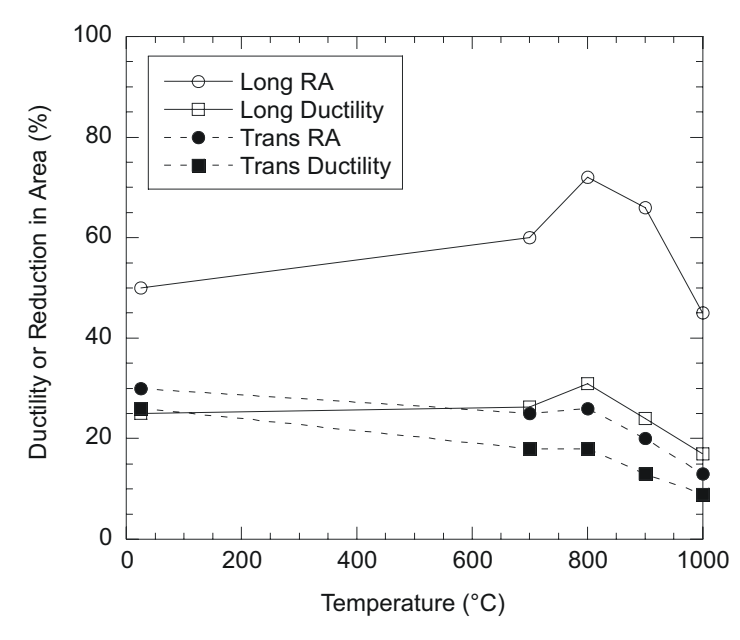

(b)

Figure 4-3. Elevated temperature mechanical properties, a) yield and ultimate stress and b) ductility and reduction in area, of coarse-grained MA 754.

Relatively small differences in the tensile properties are observed in the different directions and are attributed to the elongated grain structure. One notable result not shown in the figures is the anisotropy of the elastic modulus. At room temperature, the modulus in the longitudinal direction is $138 \mathrm{GPa}$, while in the transverse direction it is $200 \mathrm{GPa}$. The anisotropy results from the strong texture that this alloy develops as a result of forming (extrusion) and recrystallization. In comparison, the elastic modulus of I617 at room temperature is approximately $211 \mathrm{GPa}$ and, unlike MA 754, does not vary appreciably with orientation [Special Metals Corporation, 2005]. The strong variation of the elastic modulus in MA 754 also may present design difficulties.
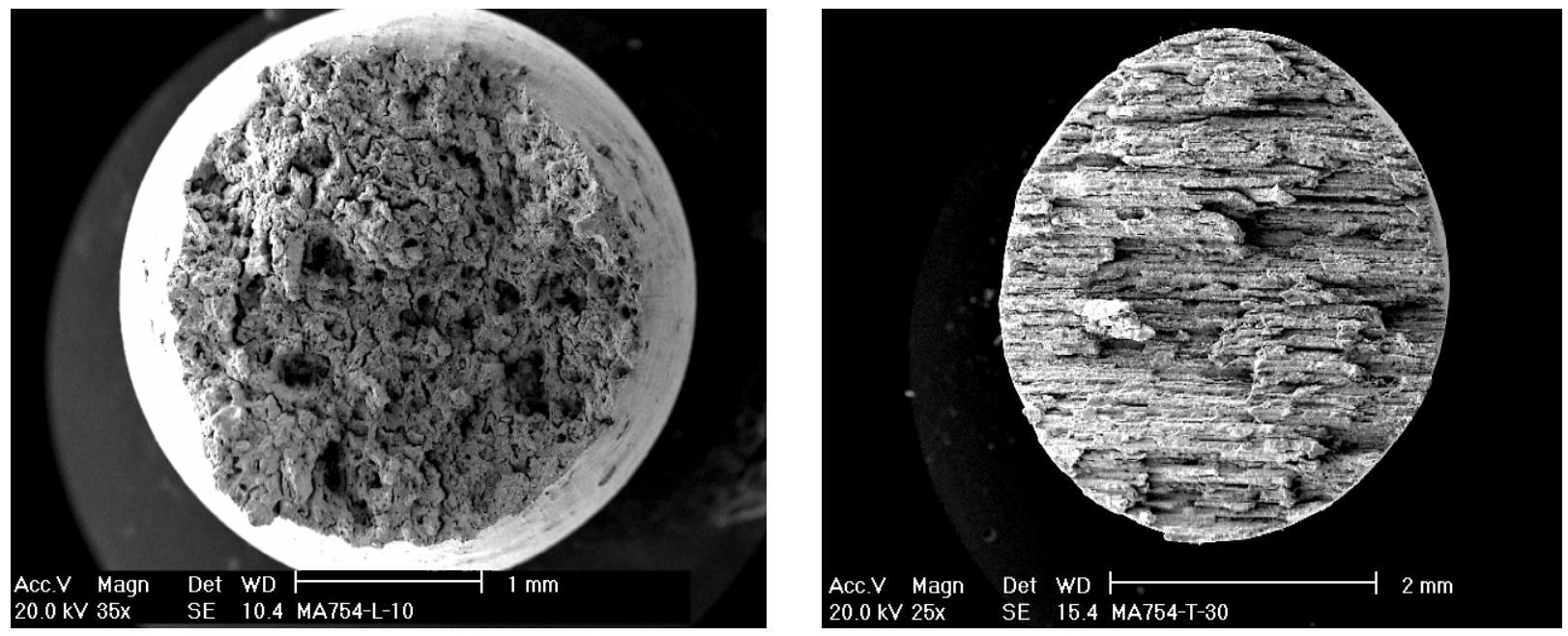

Figure 4-4. Tensile fracture surfaces of MA 754 samples oriented parallel to (left) and perpendicular to (right) the extrusion direction, longitudinal and transverse, respectively. 
Although the above properties are noteworthy, creep behavior probably will play the determining role in deciding whether MA 754 is suitable for the intended application. Again, due to the variation of microstructure with orientation and the complex stress state expected in various components, creep tests were carried out on samples cut from the longitudinal and transverse directions of the original extrusion. Tables 4-1 \& 4-2 present the results of creep testing for the longitudinal and transverse directions, respectively. The data was used to calculate the apparent stress exponent, $n$, in the Norton law [Dieter, 1986],

$$
\dot{\varepsilon}_{\min }=A^{\prime} \sigma_{a}^{n}
$$

while the threshold stress was determined by the method of Artz [Artz, 1994]. (For materials exhibiting a threshold stress the minimum strain rate can be expressed as:)

$$
\dot{\varepsilon}_{\text {min }}=A\left(\frac{\sigma_{\mathrm{a}}-\sigma_{\text {th }}}{\mathrm{E}}\right)^{\mathrm{n}} \exp \left(\frac{-\mathrm{Q}}{\mathrm{RT}}\right)
$$

The apparent stress exponents, $n$, and threshold stresses, $\sigma_{\mathrm{th}}$, as a function of temperature are shown in Table 4-3. The threshold stress for the transverse direction was not calculated due to the large variation in the apparent stress exponent with temperature which implies a change in the relative contribution of dislocation creep, grain boundary deformation and diffusional creep to the observed creep behavior. Therefore a calculation of the threshold stress under these circumstances is not considered meaningful.

The other point to note in Tables 4-1 and 4-2 are the creep elongations at failure. Generally, the longitudinal samples exhibit higher elongation at fracture. However, the values of elongation are quite low, especially in the transverse orientation and at the highest temperature. The fracture is virtually brittle in nature - not a desirable characteristic when employed as a pressure boundary material. Defects will be of a concern in component fabrication.

Finally, the apparent activation energy for creep was calculated for the longitudinal orientation using the equation:

$$
\mathrm{Q}_{\mathrm{app}}=-\mathrm{R}\left(\frac{\partial \ln \dot{\varepsilon}_{\text {min }}}{\partial(1 / \mathrm{T})}\right)_{\sigma}
$$

where $Q_{\text {app }}$ is the apparent activation energy. A value of $640 \mathrm{~kJ} / \mathrm{mol}$ was calculated in this fashion using $\dot{\varepsilon}_{\text {min }}$ data at 800 and $900^{\circ} \mathrm{C}$ and a stress level of $200 \mathrm{MPa}$; a value of $610 \mathrm{~kJ} / \mathrm{mol}$ was calculated using $\dot{\varepsilon}_{\text {min }}$ data at 900 and $1000^{\circ} \mathrm{C}$ and a stress level of $150 \mathrm{MPa}$. The mean of these two values is $630 \mathrm{~kJ} / \mathrm{mol}$. This initial value was refined by accounting for the temperature variation in elastic modulus using equation (4-3) [Malu, et. al., 1975]:

$$
Q_{c}=Q_{a p p}+n R \frac{T^{2}}{E} \frac{d E}{d T}
$$


Table 4-1. Longitudinal Creep Conditions and Results For Coarse-Grained MA 754

\begin{tabular}{|c|c|c|c|c|c|c|}
\hline Specimen ID & Temperature & Stress & Minimum Creep Rate & Time to Rupture & Elongation & RA \\
\hline & $\left({ }^{\circ} \mathrm{C}\right)$ & $(\mathrm{MPa})$ & $(\mathrm{sec}-1)$ & $(\mathrm{hr})$ & $(\%)$ & $(\%)$ \\
\hline L-17 & 800 & 196 & $6.3 \times 10^{-9}$ & 1414 & 9 & 15 \\
\hline L-15 & 800 & 211 & $1.2 \times 10^{-7}$ & 72 & 14 & 36 \\
\hline L-13 & 800 & 224 & $1.2 \times 10^{-6}$ & 11.8 & 23 & 50 \\
\hline L-14 & 800 & 224 & $1.9 \times 10^{-6}$ & 7.3 & 23 & 48 \\
\hline & & & & & & \\
\hline L-19 & 900 & 156 & $3.6 \times 10^{-9}$ & 1553 & 3.9 & 7 \\
\hline L-18 & 900 & 169 & $1.1 \times 10^{-7}$ & 84 & 9 & 19 \\
\hline L-20 & 900 & 200 & $2.7 \times 10^{-6}$ & 3.9 & 9 & 28 \\
\hline L-16 & 900 & 204 & $4.9 \times 10^{-5}$ & 0.3 & 12 & 49 \\
\hline & & & & & & \\
\hline L-24 & 1000 & 126 & $7.0 \times 10^{-10}$ & 747 & 1.4 & 14 \\
\hline L-21 & 1000 & 135 & $5.9 \times 10^{-9}$ & 306 & 1.4 & 4 \\
\hline L-25 & 1000 & 142 & $4.8 \times 10^{-8}$ & 108 & 3.7 & 4 \\
\hline L-22 & 1000 & 150 & $9.5 \times 10^{-8}$ & 49 & 3.6 & 7 \\
\hline
\end{tabular}

where $Q_{\mathrm{c}}$ is the corrected activation energy. A value of $350 \mathrm{~kJ} / \mathrm{mol}$ was calculated at $900^{\circ} \mathrm{C}$ using elastic modulus data for textured MA 754 [Special Metals Corporation, 2002] and an $n$ value of 33.5 (the mean of $n$ values at the three temperatures). The corrected activation energy agrees reasonably well with the activation energy for self-diffusion of $\mathrm{Ni}$ in $\mathrm{Ni}-20 \mathrm{wt} \% \mathrm{Cr}$ alloy, $\sim 285 \mathrm{~kJ} / \mathrm{mol}$.

Table 4-2. Transverse Creep Conditions and Results For Coarse-Grained MA 754

\begin{tabular}{|c|c|c|c|c|c|c|}
\hline Specimen ID & Temperature & Stress & Minimum Creep Rate & Time to Rupture & Elongation & RA \\
\hline & $\left({ }^{\circ} \mathrm{C}\right)$ & $(\mathrm{MPa})$ & $(\mathrm{sec}-1)$ & $(\mathrm{hr})$ & $(\%)$ & $(\%)$ \\
\hline $\mathrm{T}-32$ & 800 & 132 & $3.0 \times 10^{-9}$ & 287 & 0.7 & 0 \\
\hline $\mathrm{T}-46$ & 800 & 160 & $1.4 \times 10^{-9}$ & 760 & 0.4 & 0 \\
\hline $\mathrm{T}-39$ & 800 & 175 & $5.8 \times 10^{-9}$ & 235 & 0.8 & 0 \\
\hline $\mathrm{T}-37$ & 800 & 182 & $6.1 \times 10^{-9}$ & 266 & 0.1 & 0 \\
\hline $\mathrm{T}-41$ & 800 & 183 & $1.2 \times 10^{-8}$ & 124 & 1.3 & 0 \\
\hline $\mathrm{T}-38$ & 800 & 189 & $1.0 \times 10^{-7}$ & 37 & 2.1 & 0 \\
\hline $\mathrm{T}-42$ & 800 & 196 & $8.7 \times 10^{-8}$ & 41 & 2.0 & 0 \\
\hline $\mathrm{T}-44$ & 800 & 206 & $5.7 \times 10^{-7}$ & 11 & 4.6 & 8 \\
\hline & & & & & & \\
\hline $\mathrm{T}-50$ & 900 & 98 & $1.8 \times 10^{-9}$ & 327 & 0.5 & 0 \\
\hline $\mathrm{T}-33$ & 900 & 114 & $6.1 \times 10^{-9}$ & 115 & 0.4 & 0 \\
\hline $\mathrm{T}-36$ & 900 & 121 & $7.7 \times 10^{-9}$ & 98 & 0.4 & 0 \\
\hline $\mathrm{T}-40$ & 900 & 124 & $9.2 \times 10^{-9}$ & 82 & 0.5 & 0 \\
\hline $\mathrm{T}-43$ & 900 & 129 & $2.4 \times 10^{-8}$ & 59 & 0.9 & 0 \\
\hline $\mathrm{T}-45$ & 900 & 136 & $1.7 \times 10^{-8}$ & 46 & 0.6 & 0 \\
\hline $\mathrm{T}-47$ & 900 & 145 & $1.5 \times 10^{-8}$ & 34 & 0.6 & 0 \\
\hline T-48 & 900 & 160 & $8.0 \times 10^{-8}$ & 10 & 0.8 & 0 \\
\hline
\end{tabular}




\begin{tabular}{|c|c|c|c|c|c|c|}
\hline Specimen ID & Temperature & Stress & Minimum Creep Rate & Time to Rupture & Elongation & RA \\
\hline $\mathrm{T}-49$ & 900 & 170 & $7.4 \times 10^{-7}$ & 3 & 1.3 & 5 \\
\hline $\mathrm{T}-61$ & 1000 & 41 & $-{ }^{\mathrm{a}}$ & $>3000$ & $-^{\mathrm{a}}$ & $-^{\mathrm{a}}$ \\
\hline T-60 & 1000 & 51 & $2.2 \times 10^{-10}$ & 1876 & 0.2 & 0 \\
\hline $\mathrm{T}-62$ & 1000 & 51 & $8.9 \times 10^{-10}$ & 294 & 1.8 & 0 \\
\hline $\mathrm{T}-58$ & 1000 & 58 & $3.7 \times 10^{-9}$ & 111 & 0.5 & 0 \\
\hline $\mathrm{T}-59$ & 1000 & 61 & $2.1 \times 10^{-9}$ & 122 & 0.1 & 0 \\
\hline $\mathrm{T}-53$ & 1000 & 68 & $3.4 \times 10^{-9}$ & 142 & 0.3 & 0 \\
\hline $\mathrm{T}-52$ & 1000 & 78 & $-{ }^{\mathrm{b}}$ & 107 & $-{ }^{\mathrm{b}}$ & 0 \\
\hline $\mathrm{T}-51$ & 1000 & 88 & $7.8 \times 10^{-8}$ & 6.7 & 0.5 & 0 \\
\hline $\mathrm{T}-56$ & 1000 & 92 & $2.9 \times 10^{-9}$ & 33 & 0.4 & 0 \\
\hline $\mathrm{T}-34$ & 1000 & 100 & $-{ }^{b}$ & 18 & $-{ }^{\mathrm{b}}$ & 0 \\
\hline $\mathrm{T}-57$ & 1000 & 100 & $1.7 \times 10^{-8}$ & 15.5 & 0.2 & 0 \\
\hline $\mathrm{T}-55$ & 1000 & 107 & $2.6 \times 10^{-8}$ & 8.2 & 0.2 & 0 \\
\hline
\end{tabular}

From a mechanical property standpoint, the following can be concluded concerning the suitability of coarse-grained MA 754 for use in a supercritical $\mathrm{CO}_{2}$ loop.

Table 4-3. Apparent Stress Exponents and Threshold Stresses for High Temperature Creep

\begin{tabular}{|l|c|c|c|}
\hline & $\begin{array}{c}\text { Temperature } \\
{ }^{\circ} \mathrm{C}\end{array}$ & $\begin{array}{c}\text { Apparent Stress } \\
\text { Exponent, } n\end{array}$ & Threshold Stress, MPa \\
\hline Longitudinal & 800 & 41 & 185 \\
\hline & 900 & 30 & 145 \\
\hline & 1000 & 29 & 115 \\
\hline Transverse & & & N/A \\
\hline & 800 & 24 & N/A \\
\hline & 900 & 9.3 & N/A \\
\hline
\end{tabular}

Despite the weakness of the transverse orientation, the stress-rupture behavior of coarse-grained MA 754 still compares favorably with other high-temperature engineering alloys that are being considered for use as tubing or heat exchangers in advanced power plants. Figure 4-5 compares the stressrupture behavior of MA 754 at 800 and $1000^{\circ} \mathrm{C}$ with that of three prototypic wrought high-temperature alloys: a solid solution Ni-base alloy (INCONEL ${ }^{\circledR} 617$ ), a solid-solution Fe-Ni-Cr alloy (INCONEL ${ }^{\circledR}$ $800 \mathrm{H}$ ), and a precipitation-hardened Ni-base superalloy (NIMONIC $\left.{ }^{\circledR} 105\right)$. Even in the weaker transverse orientation, MA 754 is stronger than both solid solution alloys at both 800 and $1000^{\circ} \mathrm{C}$. While the $\gamma^{\prime}$ strengthened alloy NIMONIC ${ }^{\circledR} 105$ is stronger at $800^{\circ} \mathrm{C}$ than MA 754 in both orientations, it is weaker at $1000^{\circ} \mathrm{C}$ for rupture lives greater than $1000 \mathrm{hr}$, reflecting the inherent high-temperature stability of the yttria dispersion with respect to $\gamma^{\prime}$ precipitates. 
The utility of the strength advantage is limited, however, by poor transverse ductility. The extremely creep-brittle nature of MA 754 in the transverse orientation leads to poor defect tolerance in this direction. Ductility and defect tolerance are critical for materials that serve as pressure boundaries, particularly in systems that contain either radioactive or corrosive working fluids. Alignment of grain structures with the primary loading axis (hoop direction) in tubular forms or strengthening of grain boundaries to prevent sliding and cavitation will be critical to the successful application of ODS alloys in tubing or heat exchanger applications. While some progress has been made in the area of grain structure manipulation with Fe-base ODS alloys [Chen, et. al., 2002], considerable work is still required.

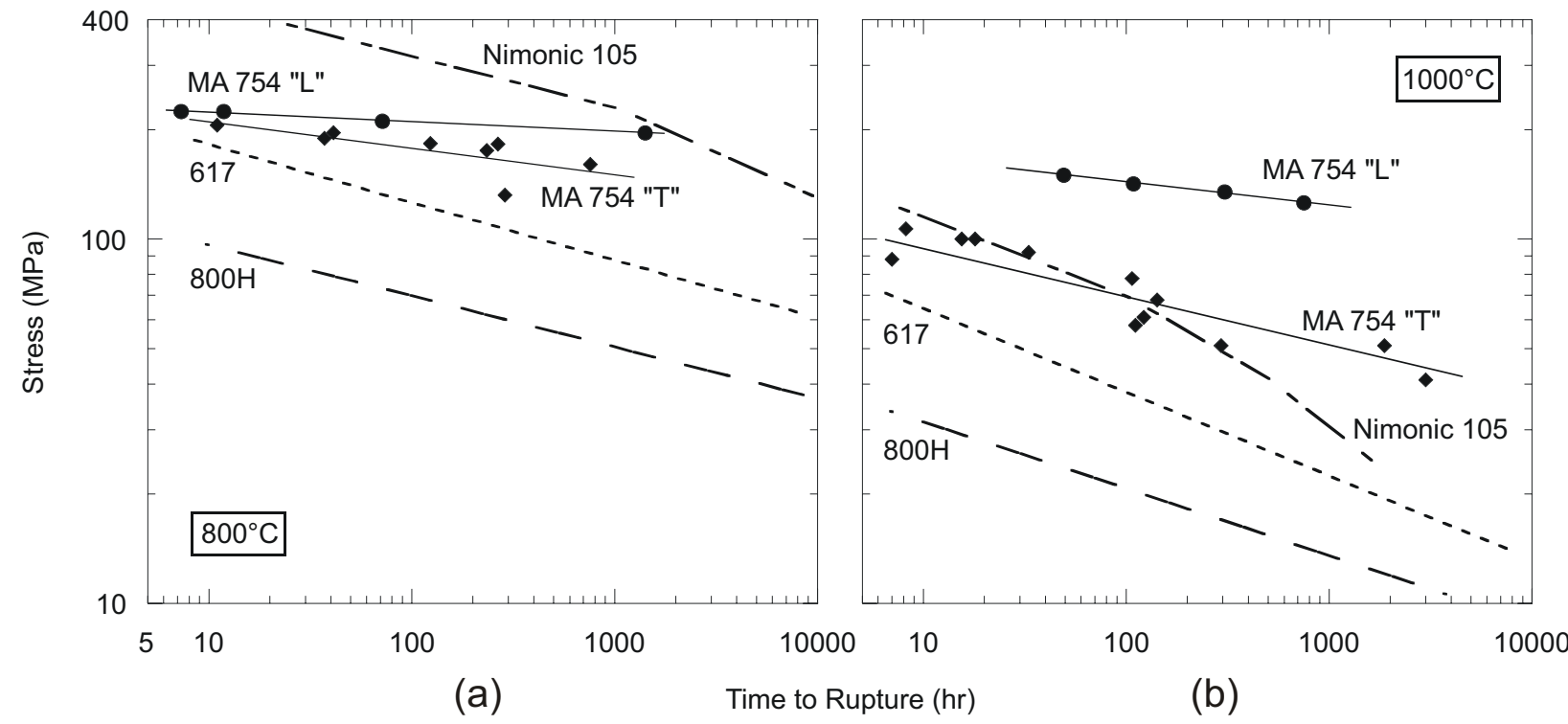

Figure 4-5. Comparison of the stress rupture data for MA 754 with other high temperature alloys.

Subtask 3-1-3 Mechanical and Creep Properties of Fine-grained MA 754 - Gregory, et al., 1985, reported the deformation characteristics of MA 754 in a fine-grained condition, i.e. prior to the final annealing step which produces a coarse, elongated grain structure in MA 754. High elongation to failure was observed in tensile tests at a variety of strain rates at temperatures ranging from 900 to $1100^{\circ} \mathrm{C}$. In consideration of these findings, we performed a series of tensile and creep-rupture tests on MA 754 in a similar fine-grained condition in the hope that increased ductility, especially in the creep regime, would be observed without an unacceptable decrease in strength.

The results of elevated temperature tensile tests (strain rate $\sim 1 \times 10^{-3} /$ second) are shown in Figure 4-6. (Mechanical properties were determined only in the transverse direction since this orientation was expected to have the lowest strength and ductility due to the alignment of the oxide inclusions perpendicular to this orientation. Therefore, mechanical properties in this direction will be design limiting.) The elevated temperature properties of coarse-grained MA 754 have been included as dashed lines in this figure for comparison. The strength of the fine-grained MA 754 quickly drops from relatively high values at room temperature (greater than coarse-grained MA 754) to low values at temperatures above $800^{\circ} \mathrm{C}$ (lower than coarse-grained MA 754). The fine-grained MA 754 exhibits good ductility at elevated temperatures although it does fall off at $1000^{\circ} \mathrm{C}$. 

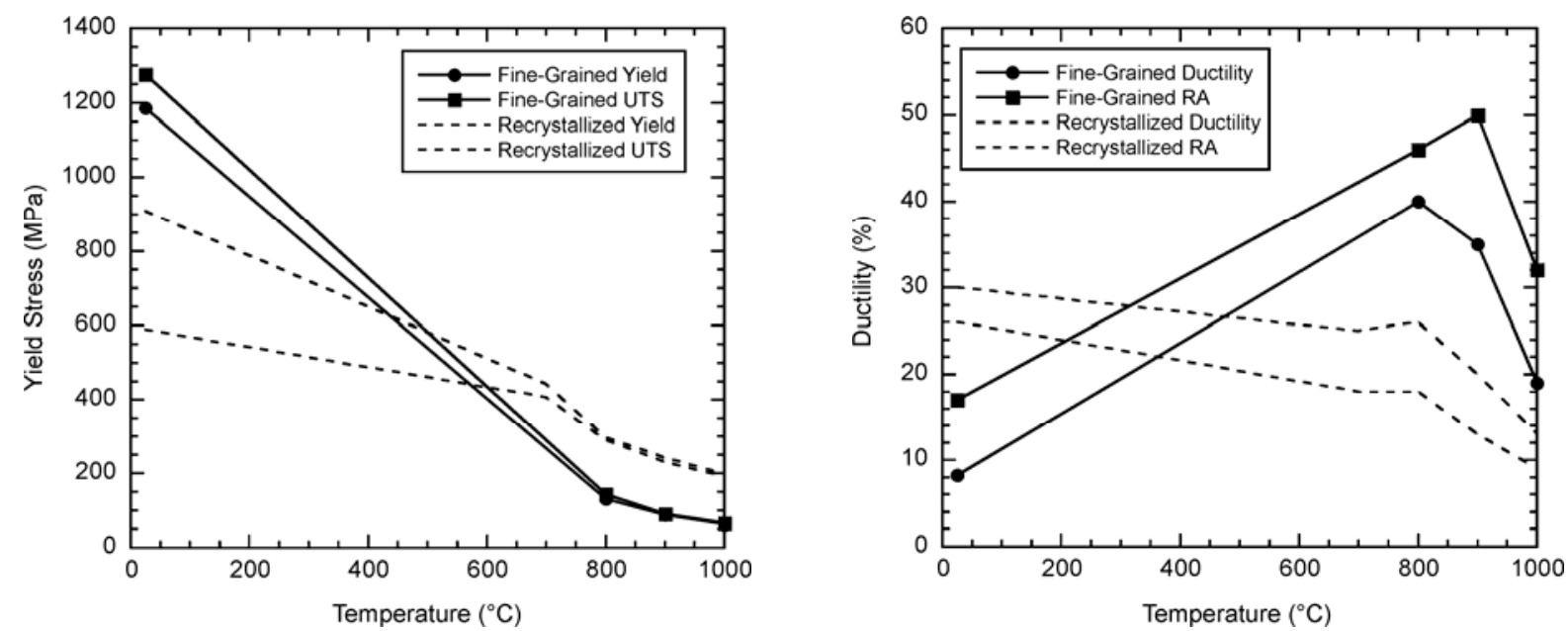

Figure 4-6. Elevated temperature yield and ultimate strength (left) and ductility and reduction in area (right) for fine-grained MA 754. Dashed curves show the elevated temperature properties of coarsegrained MA 754 (Recrystallized).

The test conditions and results for creep-rupture tests are listed in Table 4-4; creep and stressrupture data are plotted in Figures 4-7 and 4-8, respectively. Lines representing coarse-grained data are again shown for comparison. As expected, given the high grain boundary density, the creep and rupture strength of the fine-grained material is markedly lower than the coarse-grained material. These strengths of the fine-grained material are approximately $20 \%$ of the coarse-grained material at all temperatures.

Table 4-4. Creep-Rupture Test Conditions and Results for Fine-Grained MA 754

\begin{tabular}{|l|l|l|l|l|l|l|}
\hline Specimen ID & \multicolumn{1}{|c|}{$\begin{array}{c}\text { Temperature } \\
\left({ }^{\circ} \mathrm{C}\right)\end{array}$} & $\begin{array}{c}\text { Stress } \\
(\mathrm{MPa})\end{array}$ & \multicolumn{1}{|c|}{$\begin{array}{c}\text { Minimum Creep Rate } \\
\left(\mathrm{sec}^{-1}\right)\end{array}$} & $\begin{array}{c}\text { Time to Rupture } \\
(\mathrm{hr})\end{array}$ & $\begin{array}{c}\text { Elongation } \\
(\%)\end{array}$ & $\begin{array}{c}\text { RA } \\
(\%)\end{array}$ \\
\hline F-T-12 & 800 & 45 & $5.4 \times 10^{-9}$ & 268 & 0.7 & 0 \\
\hline F-T-15 & 800 & 60 & $7.3 \times 10^{-8}$ & 35 & 1.5 & 0 \\
\hline F-T-11 & 800 & 74 & $7.9 \times 10^{-7}$ & 6.4 & 3.2 & 0 \\
\hline F-T-12 & 800 & 92 & $--^{\mathrm{a}}$ & 0.9 & 14 & 15 \\
\hline & & & & 1138 & 2.4 & 0 \\
\hline F-T-14 & 900 & 25 & $3.1 \times 10^{-9}$ & 105 & 1.6 & 0 \\
\hline F-T-18 & 900 & 35 & $3.5 \times 10^{-8}$ & 15 & 1.6 & 0 \\
\hline F-T-13 & 900 & 45 & $1.7 \times 10^{-7}$ & 1.1 & 3.2 & 0 \\
\hline F-T-10 & 900 & 64 & $5.5 \times 10^{-6}$ & & & $>24^{\mathrm{b}}$ \\
\hline
\end{tabular}


The creep ductility of MA 754 in the fine-grained condition was low. Elongation to failure was generally less than $5 \%$, with zero reduction in area for all but one test. High elongation, but no area reduction, was observed for the specimen tested at $10 \mathrm{MPa}$ at $1000^{\circ} \mathrm{C}$. Examination of a metallographic cross-section of the failed specimen (Figure 4-9a) showed this apparently anomalous result to be due to extensive cavitation and sub-critical crack growth - apparently the stress was sufficiently low that stable cavity growth was possible. Figure 4-9b shows the cross-section of a specimen tested at $900^{\circ} \mathrm{C}$ which failed at $2.4 \%$ elongation with commensurately lower porosity. Creep deformation in all tests appeared to occur nearly entirely by cavity nucleation and growth, with the exception of test F-T-12, which was conducted at a relatively high stress $(92 \mathrm{MPa})$. The high stress applied to this specimen probably led to more homogeneous deformation by dislocation creep, and therefore higher ductility.

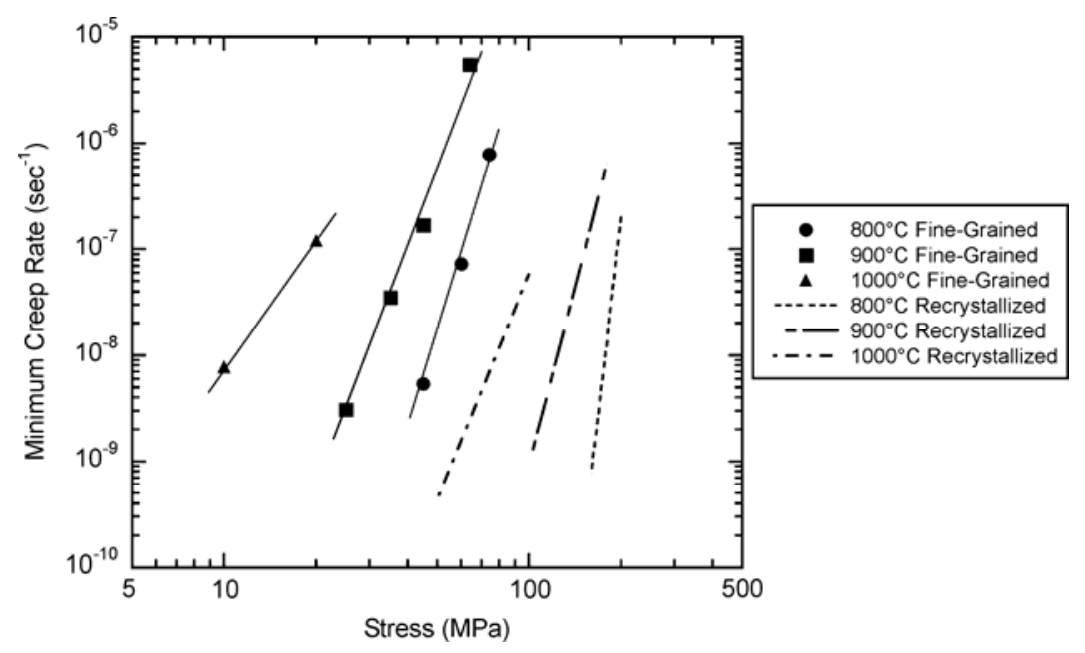

Figure 4-7. Minimum creep rates for fine-grained MA 754 as function of temperature. Lines representing coarse-grained data (Recrystallized) are shown for comparison.

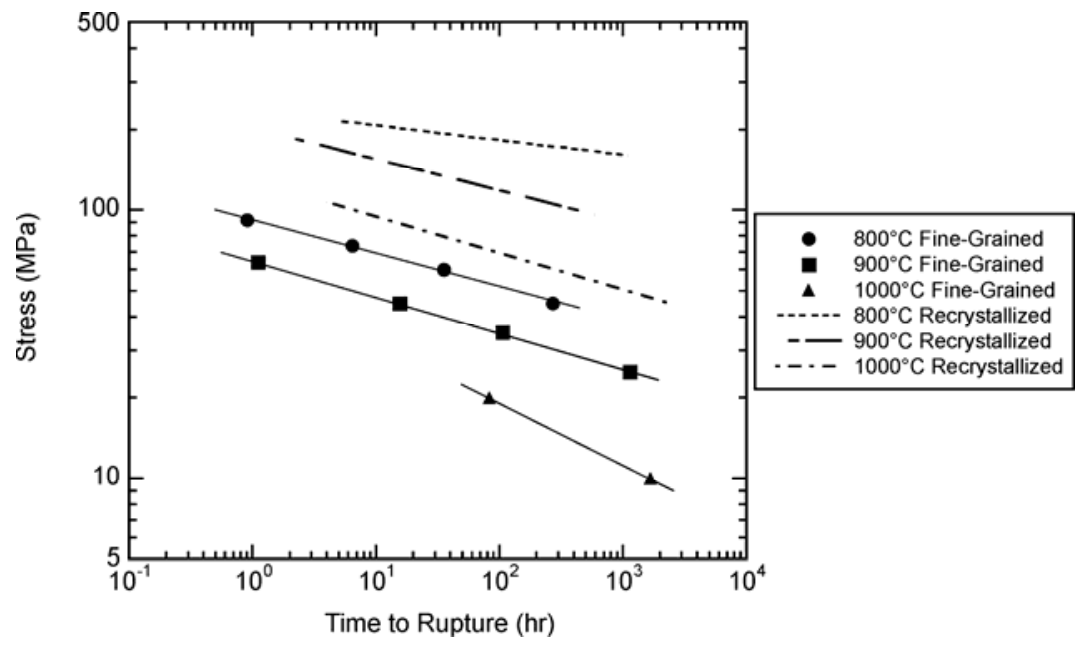

Figure 4-8. Stress-rupture behavior of fine-grained MA 754 as a function of temperature. Lines representing coarse-grained data (Recrystallized) are shown for comparison. 

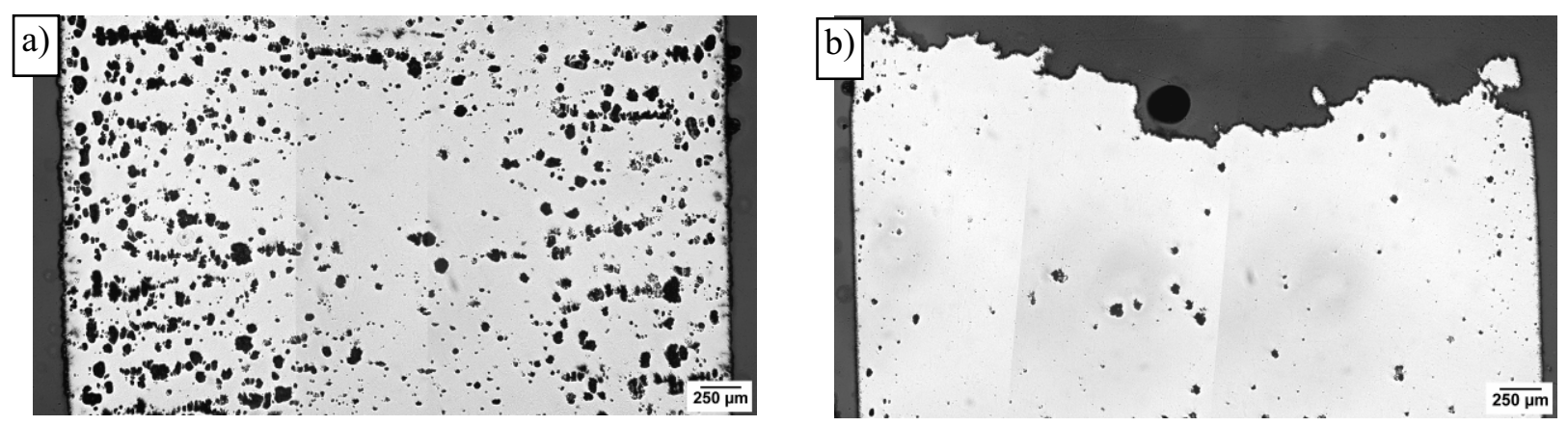

Figure 4-9. Metallographic cross-sections of creep specimens: (a) specimen F-T-19 tested at $1000^{\circ} \mathrm{C}$ and $10 \mathrm{MPa}$, elongation $24 \%$ (prior to failure); (b) specimen F-T-14 tested at $900^{\circ} \mathrm{C}$ and $25 \mathrm{MPa}$, failure elongation $2.4 \%$.

The present results clearly indicate that fine-grained MA 754 offers no advantage over the annealed, coarse-grained condition in creep-limited applications. This is true even for the relatively weaker long transverse orientation. Creep and rupture strengths are approximately a factor of five lower, and the alloy still shows very creep-brittle behavior. As with the coarse grained MA 754, the low ductility and brittle failure mode poses serious problems for the application of this material in a supercritical $\mathrm{CO}_{2}$ Brayton cycle operating at high temperatures.

\section{Task 3-2 Thermogravimetric Analyses}

The other vital aspect of prospective materials for use in a supercritical $\mathrm{CO}_{2}$ Brayton cycle is their corrosion behavior in high temperature, high pressure $\mathrm{CO}_{2}$. Even if the mechanical properties of the material enable, or do not prevent, their use in the system, poor corrosion resistance may ultimately determine their suitability.

Subtask 3-2-1 Design and Construction of Supercritical $\mathrm{CO}_{2}$ Test Loop - High temperature, high pressure $\mathrm{CO}_{2}$ corrosion testing systems were developed as part of this work to explore the corrosion behavior of potential materials. The temperatures and pressure are sufficiently high to prevent the use of commercially-available equipment. New systems had to be designed and fabricated. Two such systems were constructed. Both were of the once-through design with $\mathrm{CO}_{2}$ being compressed, heated, either passed through or over candidate materials and then vented to the atmosphere. The $\mathrm{CO}_{2}$ was not recirculated. One system allowed a large number of samples to be tested simultaneously while the other system tested individual materials in a pipe configuration and contained significant gradients in temperature and stress.

Figure 4-10 shows a schematic representation of the multi-sample system. The test sections are pipes on the order of 1.2 meters in length with approximately $11 \mathrm{~mm}$ internal diameter. These tubes were fabricated from 304 stainless steel. (The wall thickness was sufficient to withstand an internal pressure of $7 \mathrm{MPa}$ at $1000^{\circ} \mathrm{C}$ for 10,000 hours.) The hot zone was on the order of $0.6 \mathrm{~m}$ long, over which the temperature found to vary by less than $+5^{\circ} \mathrm{C}$. Sample coupons were placed inside the 304 stainless steel tubes. The $\mathrm{CO}_{2}$ flow rate was on the order of $5 \mathrm{ml} /$ minute, although higher flow rates were possible. However, turbulent flow conditions are probably not possible with system and the experiment was carried out under laminar flow conditions. The system was automated and only required personnel to occasionally change out the $\mathrm{CO}_{2}$ cylinders.

Figure 4-11 shows a schematic of the other system utilizing a sample in the form of a pipe with the supercritical $\mathrm{CO}_{2}$ flowing through the internal passage. The sample pipe is connected to the high pressure $\mathrm{CO}_{2}$ with water cooled connectors. The ends of the sample are therefore much lower $\left(\sim 200-300^{\circ} \mathrm{C}\right)$ than 
the center of the pipe $\left(\sim 1000^{\circ} \mathrm{C}\right)$ and large temperature gradients exist between the center and ends of the sample pipe. Tests parameters were the same as in the multi-sample system described above.

Both systems operated as intended. However, the multi-sample system suffered from corrosion and subsequent creep of the 304 stainless steel containment tubes while the water cooled connectors on the second system presented problems with water leakage. Future experiments in the multi-sample system would use either I-617 or MA 754 containment tubes to minimize creep and/or corrosion effects that might limit experiment duration. The water-cooled connectors of the system utilizing the sample pipe configuration should be redesigned so that the high pressure gas connections occur well outside the furnace. These issues are considered to be minor and easily fixed prior to future experiments.

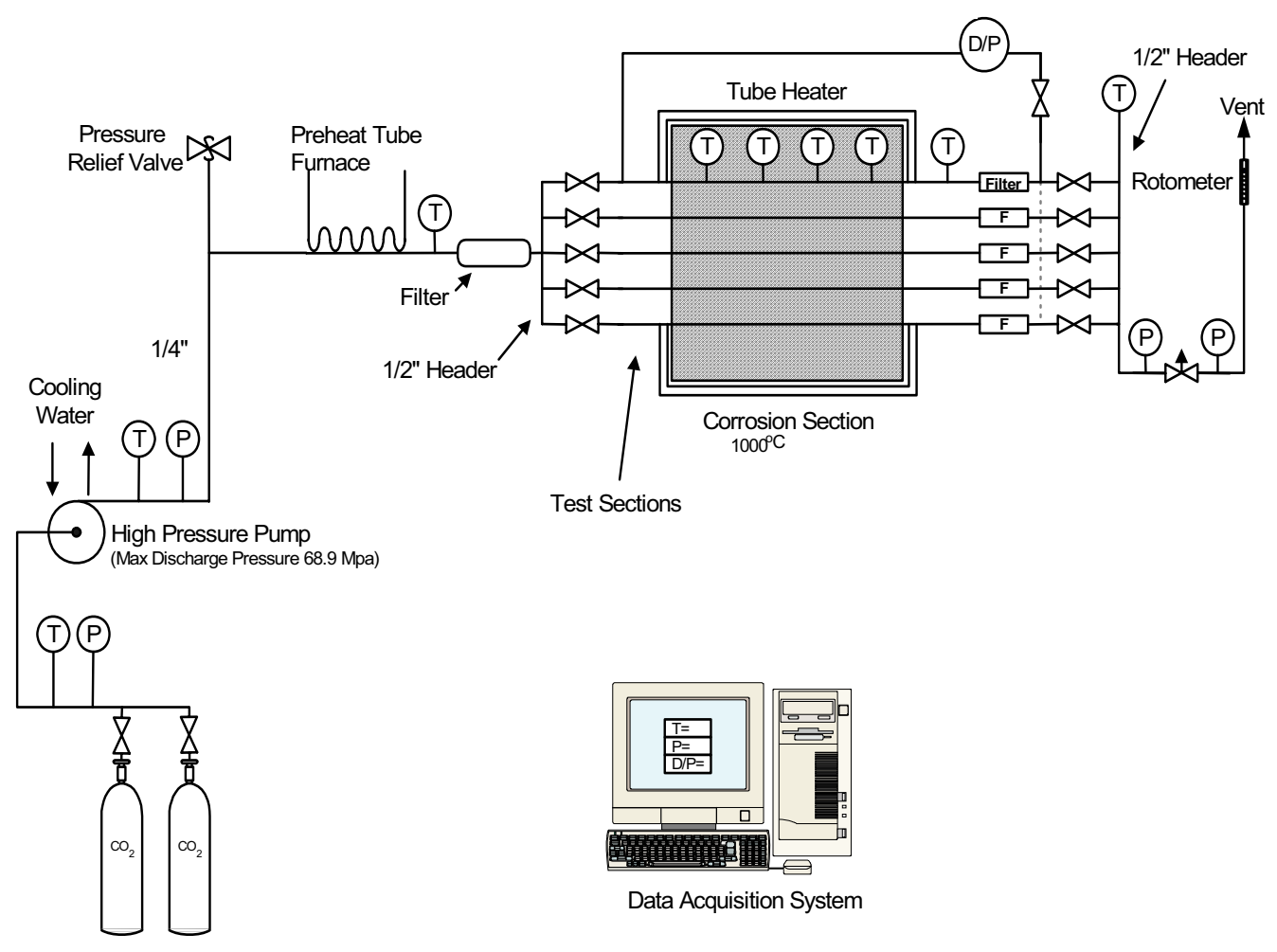

Figure 4-10. Schematic of the multi-sample supercritical $\mathrm{CO}_{2}$ corrosion testing system. 


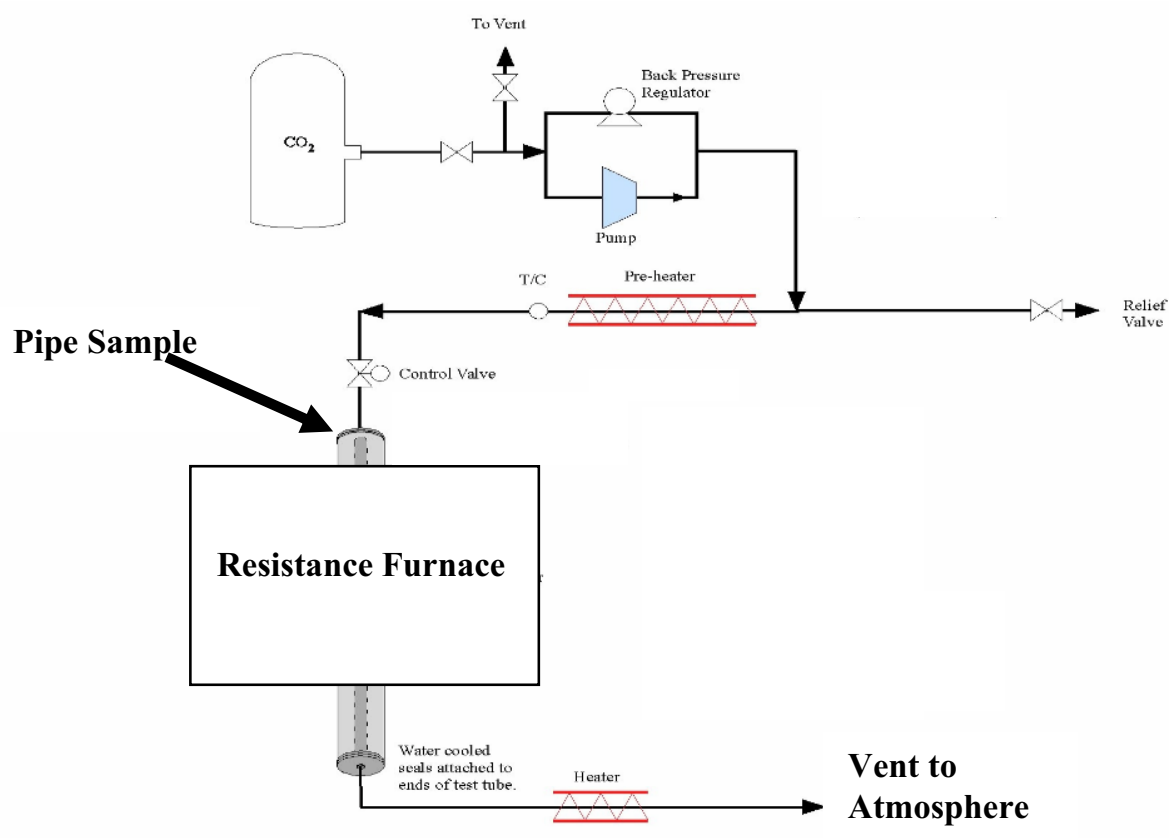

Figure 4-11. Schematic of second $\mathrm{CO}_{2}$ corrosion system utilizing the sample in a form of a pipe. The sample acted as the pressure boundary.

Subtask 3-2-2 Corrosion Testing of MA 754 in Supercritical $\mathrm{CO}_{2}$ - Both coarse-grained and finegrained MA 754 was subjected to corrosion testing in supercritical $\mathrm{CO}_{2}$. Since the coarse-grained material would most likely be the condition used to satisfy the creep requirements, most of the corrosion behavior characterization was focused on the coarse-grained material.

Coarse-grained MA 754 Corrosion Behavior - Corrosion testing of the coarse-grained material was carried out in the system that utilized the sample in the form of a pipe. Unfortunately MA 754 in the form of pipe could not be obtained from a commercial vendor. Therefore, rods of MA 754 were machined from an extrusion of rectangular cross section with the axis of the rod parallel to the extrusion direction. The rods were then drilled through their length to produce a pipe with an OD of approximately $12.5 \mathrm{~mm}$ and an ID of $4.3 \mathrm{~mm}$ for the flowing supercritical $\mathrm{CO}_{2}$. Four samples were exposed to flowing supercritical $\mathrm{CO}_{2}$ for $47,120,335$ and 500 hours at $1000^{\circ} \mathrm{C}$ and $10 \mathrm{MPa}$.

After exposure, samples were cut from the tube at $25 \mathrm{~mm}$ intervals along the tube length. The cross-sections were cut longitudinally to expose the inner corroded surface. The samples were then mounted, polished, and analyzed utilizing a SEM. Higher corrosion rates were observed in the sample taken from between 50 and $75 \mathrm{~mm}$ compared that observed in the sample taken between 0 and $25 \mathrm{~mm}(75$ $\mathrm{mm}$ is the mid point of the tube). This was expected since the first $50 \mathrm{~mm}$ are housed in a water-cooled, high pressure gas connector and the temperature was much less than $1000^{\circ} \mathrm{C}$. Conversely, the section of pipe between 50 and $75 \mathrm{~mm}$ experienced a temperature close to $1000^{\circ} \mathrm{C}$, i.e. a steep temperature gradient existed from the water-cooled connector to the mid point of the tube.

Figure 4-12 plots the measured corrosion rate of the coarse grained MA 754 as a function of exposure time. (Corrosion layer thickness measurements for calculation of the corrosion rate were always recorded at the midpoint of the tube.) At short exposure times the corrosion rate is quite high but as the exposure time increases the time-averaged corrosion rate quickly decreases to relatively low values. It 
appears that at exposure times less than 500 hours the material is still in a transient corrosion mode where corrosion layers are being developed that ultimately provide protection from further corrosion. After 500 hours the corrosion rate is less than about $0.2 \mathrm{~mm} /$ year. Longer exposures may yield even lower corrosion rates, although spalling (not observed in this study) may occur, resulting in an increase in the corrosion rate. Exposure times greater than 1000 hours need to be performed to ensure the corrosion rate remains low and that other mechanisms like spalling or dusting do not lead to unsuitable corrosion behavior.

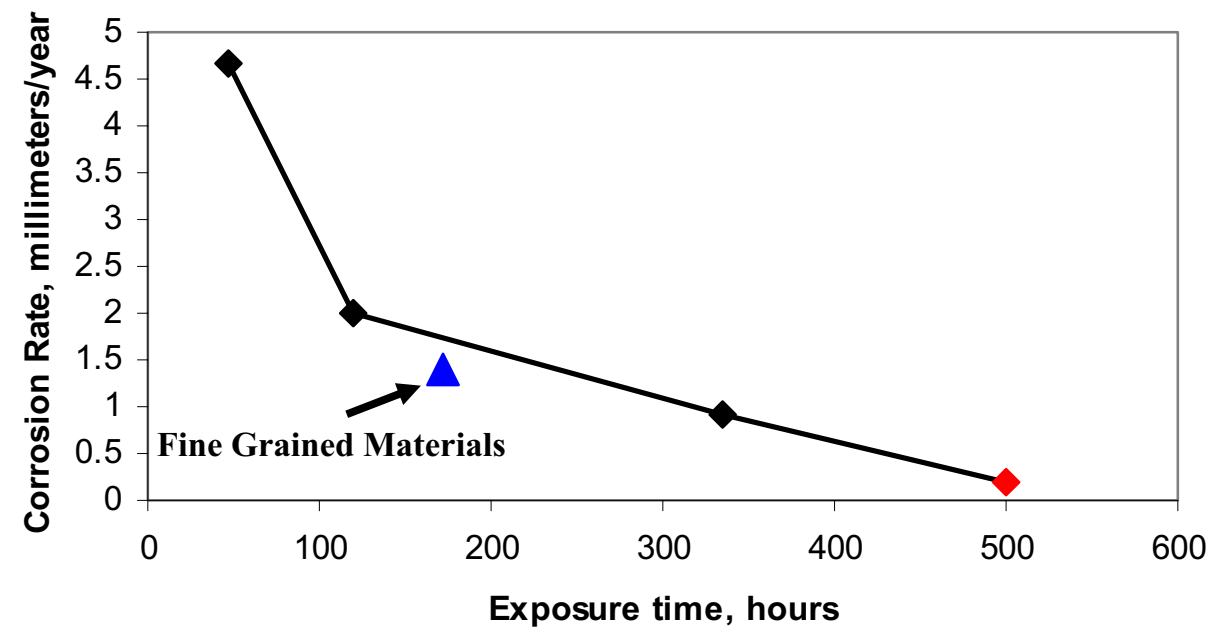

Figure 4-12. Corrosion rates of coarse-grained MA 754 in supercritical $\mathrm{CO}_{2}$ at $1000^{\circ} \mathrm{C}$ and $10 \mathrm{MPa}$ as a function of exposure time. The corrosion rate for fine grained MA 754 is shown as a blue triangle.

Metallographic samples were observed in the SEM. Photomicrographs representative of three locations along the pipe are shown in Figure 4-13, from the water-cooled connection, Fig. 4-13a, to the pipe center, Fig. 4-13c. Corrosion is more evident as one approaches the midpoint of the tube where the temperature was the greatest $\left(1000^{\circ} \mathrm{C}\right)$. Close to the water-cooled ends, Figure 4-13a, the corrosion products appear to adhere to the base metal quite well while the corrosion products near the mid-point of the tube, Figure 4-13c, exhibit considerable porosity. The base metal also shows the development of porosity under the corrosion layer. Elemental analysis of the corrosion products was conducted on the 50$75 \mathrm{~mm}$ length sample. Five different spots, Figure 4-14, were selected and analyzed by EDS analysis to qualitatively determine the elemental species present in the corrosion product. From the analysis it was evident that chromium was being preferentially oxidized during the exposure to supercritical $\mathrm{CO}_{2}$. The outer 


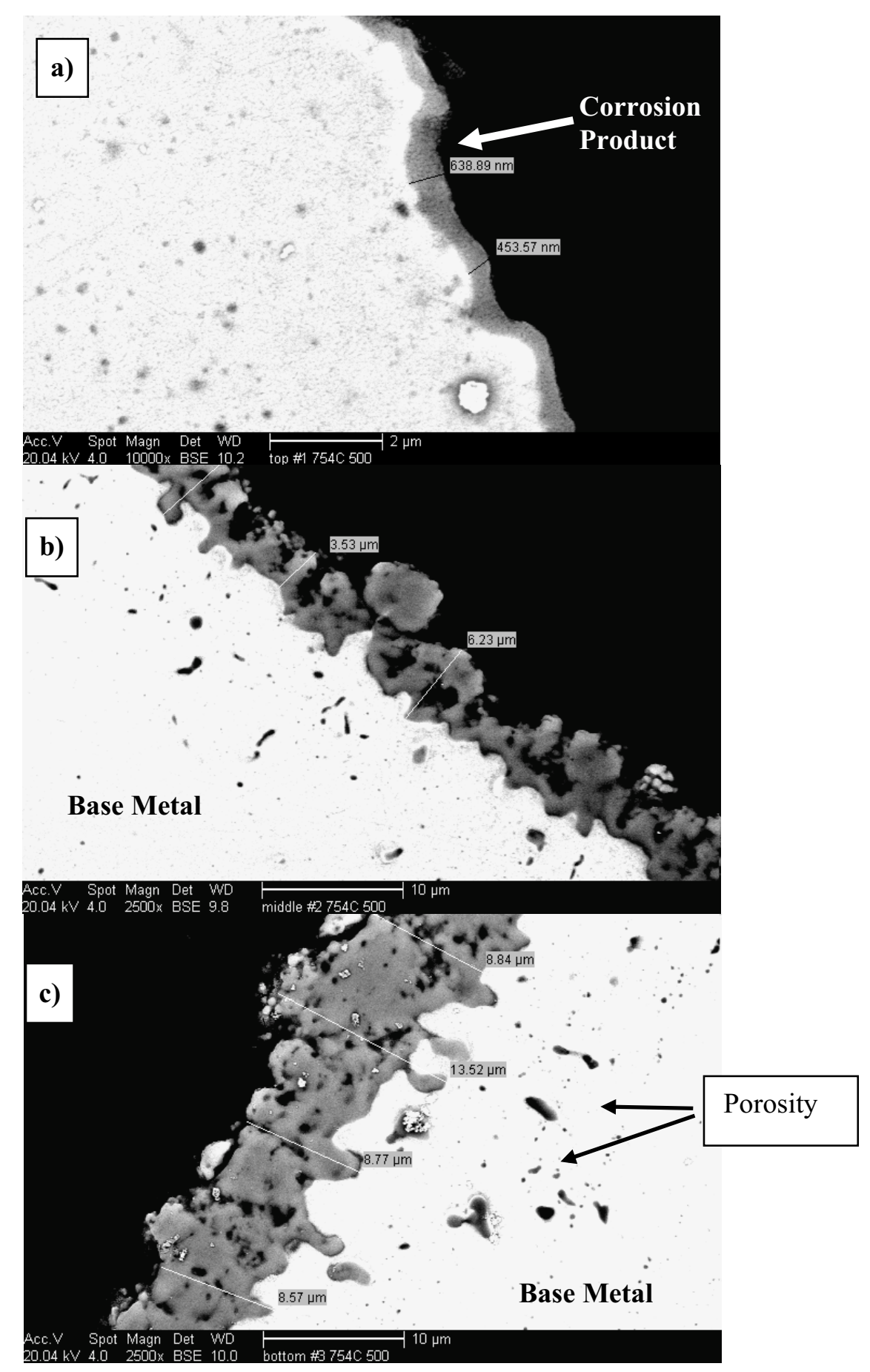

Figure 4-13. SEM photographs of each section of the tube sample after 500 hours of exposure. Samples were taken from the a) 0-25 $\mathrm{mm}$, b) $25-50 \mathrm{~mm}$ and c) $50-75 \mathrm{~mm}$ sections of the tube.

most analysis area, spot \#2 in Fig. 4-14, is almost exclusively chromium oxide, Figure 4-15. This is not surprising since the Gibbs free energy of $\mathrm{Cr}_{2} \mathrm{O}_{3}$ is significantly lower than that of $\mathrm{CO}_{2}$ at $1000^{\circ} \mathrm{C}$, resulting in the decomposition of $\mathrm{CO}_{2}$ to $\mathrm{CO}$ and oxygen with the subsequent oxidation of chromium at the base metal surface. (The free energy of $\mathrm{NiO}$ is higher than $\mathrm{CO}_{2}$ at $1000^{\circ} \mathrm{C}$ and one would, therefore, not expect to find $\mathrm{NiO}$ in the corrosion products.) The corrosion rate limiting process, therefore, appears 
to be the diffusion of chromium through the corrosion layer. The corrosion rate is expected to decrease with increasing exposure time since it take longer for chromium atoms to diffuse through the base metal and the growing corrosion layer. This would also explain the presence of porosity in the base metal, i.e. the chromium is being depleted in the near surface of the base metal, leaving behind porosity.

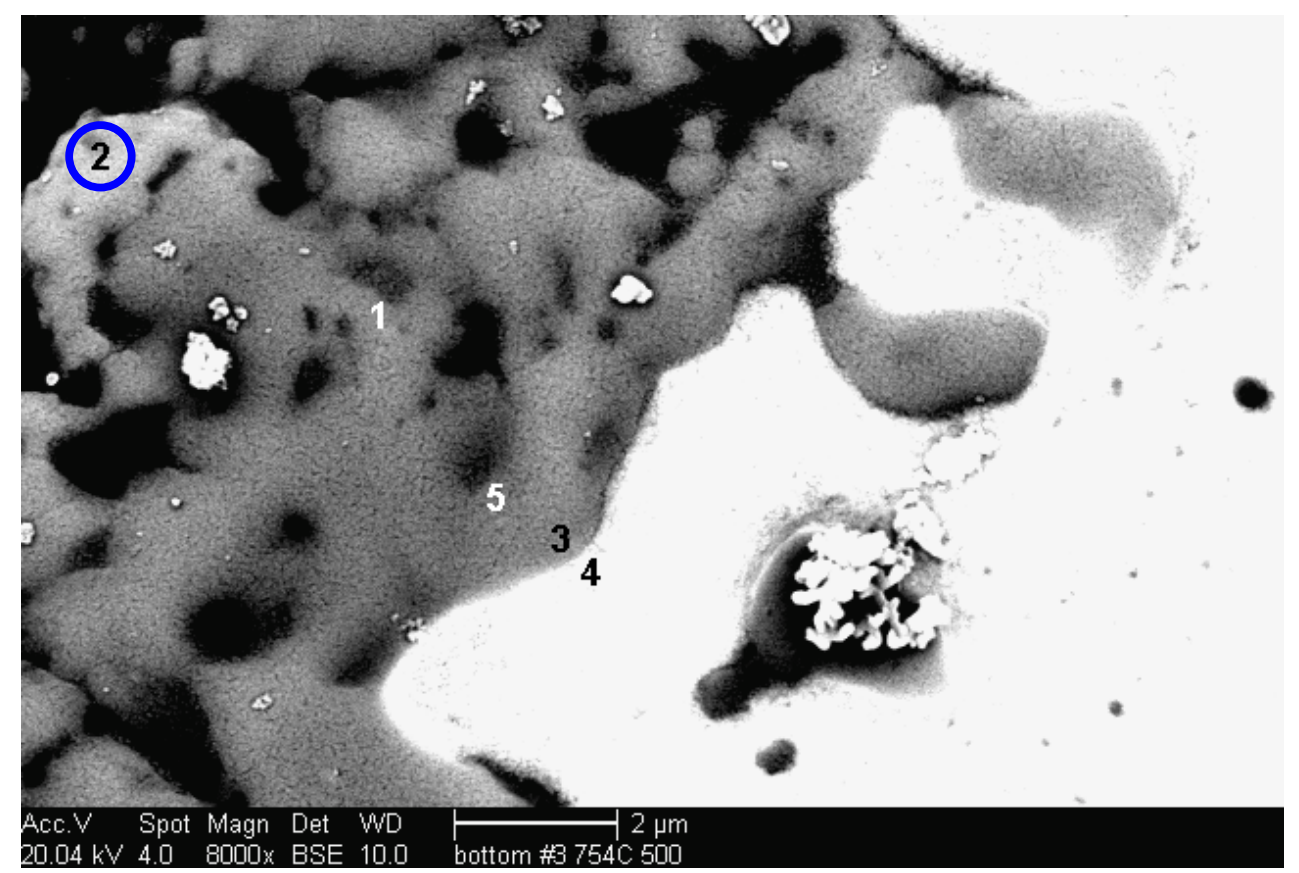

Figure 4-14. (BSE) Corrosion (dark) in the 50-75 $\mathrm{mm}$ length (i.e. the pipe center) showing EDS analysis locations.

In the unetched condition, there also appeared to be occasional intrusions of corrosion products into the base metal, Figure 4-16a. The sample was etched to determine if the intrusion followed grain boundaries, which would indicate intergranular corrosion. The etch revealed that the base metal had recrystallized, producing a fine grained microstructure very near the surface of the base metal, Fig. 4-16b. It is not known at this time why this inner surface recrystallized. It is possible that drilling of this inner diameter to form the pipe may have produced significant strain in the near surface, causing recrystallization when exposed to $1000^{\circ} \mathrm{C}$ during the corrosion test. Therefore, the corrosion rates determined from these experiments, Fig. 4-12, may well represent that for fine grained MA 754 as opposed to that for coarse grained material. In the future if pipe samples are fabricated in this manner, they need be subjected to a high temperature recrystallization heat treatment to ensure the inner surface is, indeed, large-grained. (The corrosion rate may be different for large and fine grained materials if grain boundary processes are important in the corrosion process.) 


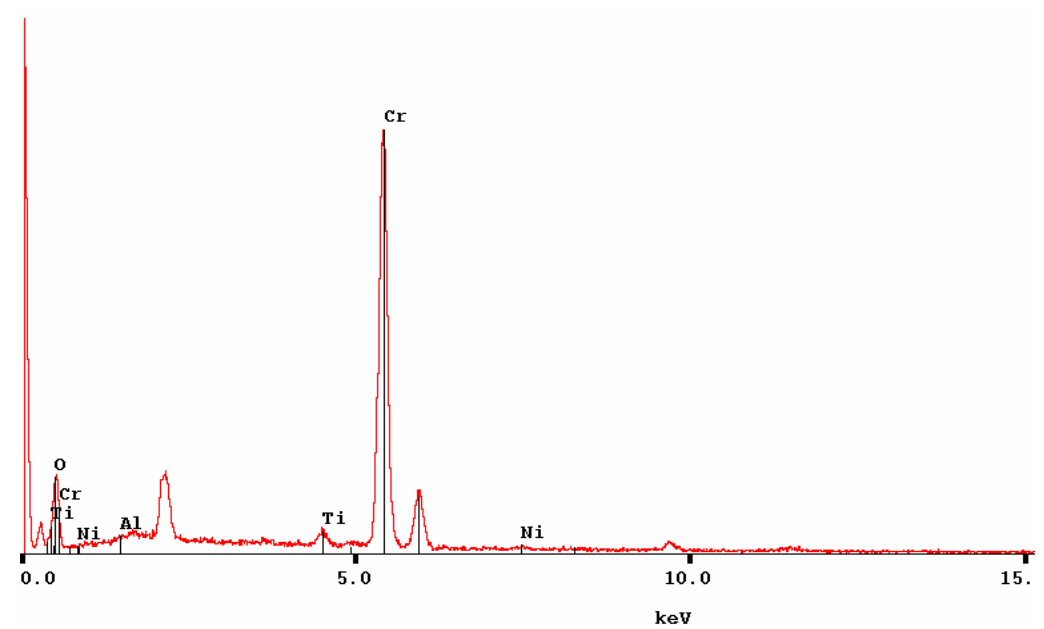

Figure 4-15. Elemental analysis by EDS showing the corrosion product at the outermost \#2 location (Figure 4-14 in blue circle) is almost exclusively chromium oxide. (The unidentified peaks are from a conductive gold coating applied after exposure.)

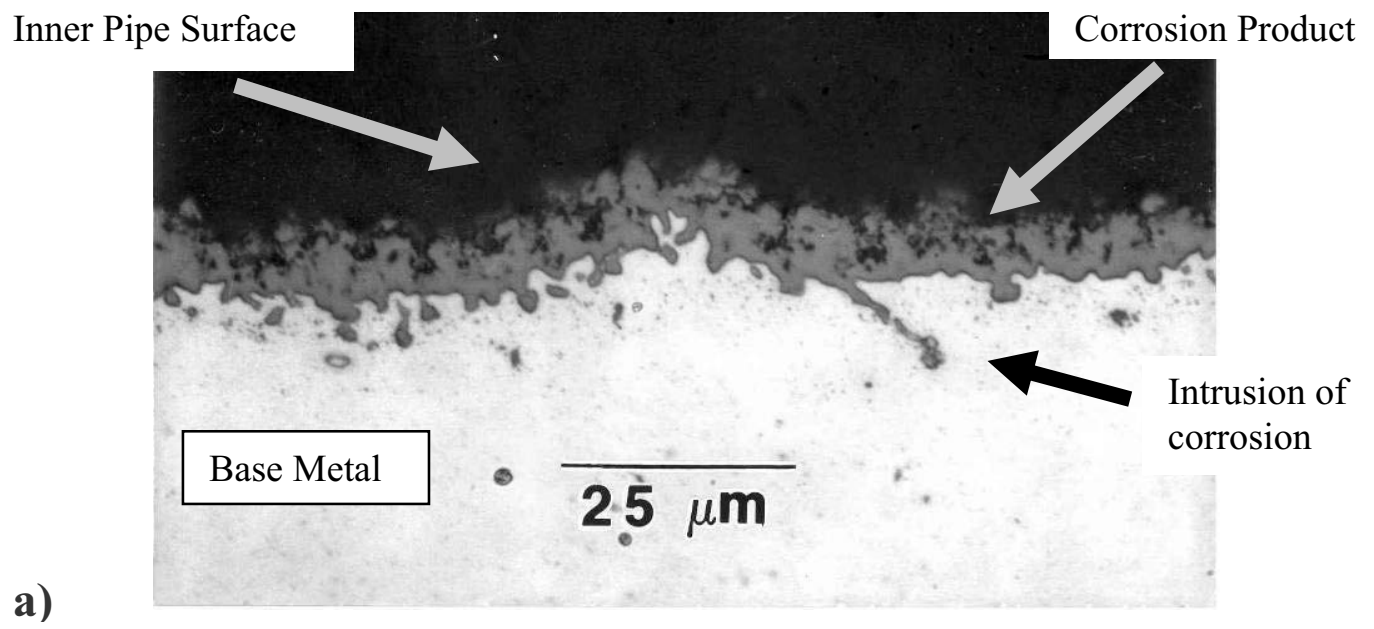

b)

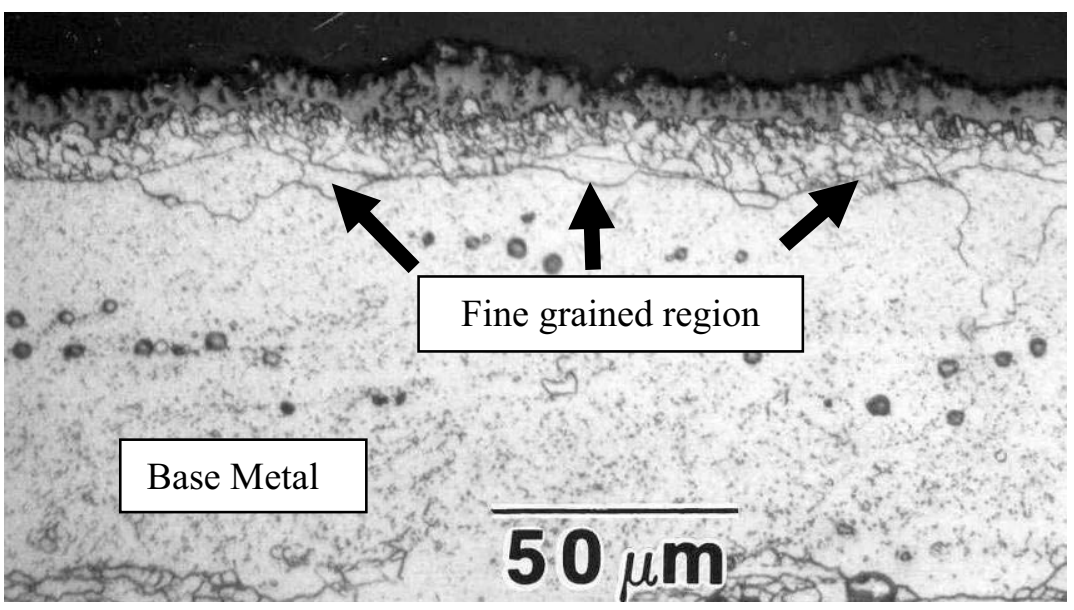

Figure 4-16. The intrusion of corrosion into the base metal, a), may be due to corrosion along the grain boundaries of the fine grain material near the inner surface of the sample, $b$ ). 
Fine-grained MA 754 Corrosion Behavior -The corrosion behavior of fine-grained material was investigated in the multi-sample system, Figure 4-10. A single experiment was performed on this material at $1000^{\circ} \mathrm{C}$ at $7 \mathrm{MPa}$ for approximately 175 hours. (This system did not become fully operational until late in the project and only one, relatively short experiment could be performed.) The samples developed a black corrosion layer that was dissolved using Ox-Out 536 (ChemClean Corp.), a commercial descaling agent for nickel-based alloys. This allowed an accurate determination of the weight change due to corrosion and calculation of the corrosion rate, Table 4-5. The samples correspond to various surface finishes, i.e. 7A - 60 grit, 7B - 120 grit, 7D - 320 grit, 7E - 800 grit and 7F - as-received. As seen in Table 4-5, little variation in corrosion rate with surface finish is observed and the average corrosion rate for these five samples is $1.4 \mathrm{~mm} /$ year. This value for an exposure time of 175 hours has been plotted in Figure 4-12, as the blue triangle. This value is consistent with the large grained corrosion results for similar exposure times. This would imply that observed corrosion behavior is still in the transient region and that longer exposure times are needed to determine the steady-state corrosion rate to ultimately determine the suitability of this material for use in the high temperature Brayton cycle.

Table 4-5. Corrosion Rate for Fine Grained MA 754

\begin{tabular}{|c|c|c|c|c|c|c|c|}
\hline $\begin{array}{c}\text { Sample } \\
\text { ID }\end{array}$ & $\begin{array}{c}\text { Initial } \\
\mathrm{Wt}, \mathrm{g}\end{array}$ & $\begin{array}{c}\text { Final } \\
\mathrm{Wt}, \mathrm{g}\end{array}$ & Change, $\mathrm{g}$ & $\begin{array}{c}\text { Length, } \\
\mathrm{mm}\end{array}$ & $\begin{array}{c}\text { Width, } \\
\mathrm{mm}\end{array}$ & $\begin{array}{c}\text { Thickness, } \\
\mathrm{mm}\end{array}$ & $\begin{array}{c}\text { Apparent } \\
\text { Corrosion Rate*, } \\
\mathrm{mm} / \mathrm{yr}\end{array}$ \\
\hline 7A & 1.2991 & 1.2398 & 0.0593 & 13.26 & 7.89 & 1.49 & 1.32 \\
\hline 7B & 1.3165 & 1.2600 & 0.0565 & 13.34 & 7.91 & 1.49 & 1.24 \\
\hline 7D & 1.2763 & 1.2197 & 0.0566 & 13.27 & 7.86 & 1.47 & 1.27 \\
\hline 7E & 1.2007 & 1.1430 & 0.0577 & 13.27 & 7.87 & 1.38 & 1.31 \\
\hline 7F & 1.4647 & 1.3773 & 0.0874 & 13.32 & 7.85 & 1.68 & 1.89 \\
\hline * Exposure time = 175 hours \\
\hline \multicolumn{7}{|l}{} \\
\hline
\end{tabular}

Summary and Conclusions on the Corrosion Behavior of MA 754 in Supercritical CO $\mathrm{O}_{2}$ - Two viable supercritical $\mathrm{CO}_{2}$ corrosion testing system were designed, fabricated and operated. One system allows the testing of a large number of samples $(>200)$ during a single test while the other system consists of configuration closely resembling that expected in an operating system, e.g. a pipe configuration with gradients in temperature and stress imposed on the sample. During tests in these systems, MA 754 showed transient corrosion behavior even in the longest exposure time ( $\sim 500$ hours $)$ used in this study. It appears the steady state corrosion rate will drop below $\sim 0.2 \mathrm{~mm} /$ year at long exposure times which is approaching a level acceptable to the commercial sector. However, longer term experiments are required to ensure that other corrosion processes, such as spalling or metal dusting, do not eventually become the dominate corrosion process. The corrosion product is chromium oxide, the thermodynamically stable compound at $1000^{\circ} \mathrm{C}$ in the presence of $\mathrm{CO}_{2}$. No discernable difference in corrosion behavior between coarse-grained and fine-grained MA 754 in supercritical $\mathrm{CO}_{2}$ at $1000^{\circ} \mathrm{C}$ was observed.

\section{Task 3-3 Corrosion Behavior of I-617 in Supercritical $\mathrm{CO}_{2}$}

Inconel 617 is a high temperature alloy with potential application to numerous high temperature components in the Next Generation Nuclear Plant (NGNP). This alloy possesses some of the best high temperature creep properties of the available metallic alloys. However, very little is known concerning the corrosion behavior of this alloy in high temperature, supercritical $\mathrm{CO}_{2}$. Therefore, this alloy was added to the corrosion investigation.

Subtask 3-3-1 Corrosion rate Determination - Samples with different surface finishes were obtained and exposed to supercritical $\mathrm{CO}_{2}$ at $1000^{\circ} \mathrm{C}$ and $7 \mathrm{MPa}$ for 175 hours. These samples were run in 
the same test as the fine grained MA 754 (results described under subtask 3-2-2), in the multi-sample test system, Fig. 4-10. The two materials were in separate containment tubes and cross contamination should have been minimal, i.e. the two materials were run in parallel test lines. The samples, again, had various surface finishes, i.e. $6 \mathrm{~A}-60$ grit, $6 \mathrm{~B}-120$ grit, $6 \mathrm{D}-320$ grit, $6 \mathrm{E}-800$ grit and $6 \mathrm{~F}-$ as-received.

These samples were black after exposure to high temperature, supercritical $\mathrm{CO}_{2}$ and appeared similar to the MA 754 samples. Table 4-6 records the corrosion behavior of this alloy. During cleaning, the corrosion layer was found to be much more adherent than the corrosion layer on the MA 754. In fact, some samples could not be cleaned completely in a reasonable amount of time, i.e. sample $6 \mathrm{E}$ and $6 \mathrm{~F}$ in Table 4-6. The average corrosion rate, excluding samples $6 \mathrm{E}$ and $6 \mathrm{~F}$, is $0.25 \mathrm{~mm} /$ year. This is significantly lower than the corrosion rate for either fine- or coarse-grained MA 754 for a similar exposure time, Fig. 4-12 and Table 4-5. However, it should be kept in mind that the exposure time was relatively short and the long term corrosion rate may be significantly different, especially is spalling or metal dusting occurs at longer exposure times.

Table 4-6. Alloy I-617

\begin{tabular}{|c|c|c|c|c|c|c|c|}
\hline $\begin{array}{c}\text { Sample } \\
\text { ID }\end{array}$ & $\begin{array}{c}\text { Initial } \\
\text { Wt, g }\end{array}$ & $\begin{array}{c}\text { Final } \\
\text { Wt, g }\end{array}$ & Change, g & $\begin{array}{c}\text { Length, } \\
\mathrm{mm}\end{array}$ & $\begin{array}{c}\text { Width, } \\
\mathrm{mm}\end{array}$ & $\begin{array}{c}\text { Thickness, } \\
\mathrm{mm}\end{array}$ & $\begin{array}{c}\text { Apparent } \\
\text { Corrosion Rate, } \\
\mathrm{mm} / \mathrm{yr}\end{array}$ \\
\hline 6A & 1.2568 & 1.2542 & 0.0026 & 13.26 & 7.85 & 1.45 & 0.25 \\
\hline 6B & 1.2632 & 1.2591 & 0.0042 & 13.28 & 7.92 & 1.44 & 0.28 \\
\hline 6D & 1.2741 & 1.2738 & 0.0003 & 13.25 & 7.91 & 1.46 & 0.22 \\
\hline 6E & 1.2910 & 1.2909 & 0.0001 & 13.25 & 7.82 & 1.50 & $0.16^{* *}$ \\
\hline 6F & 1.3718 & 1.3681 & 0.0037 & 13.28 & 7.94 & 1.57 & $0.20^{* *}$ \\
\hline
\end{tabular}

Metallography samples also were prepared and the corrosion layer analyzed. Figure 4-17a shows a high magnification photograph of the I-617 sample surface. Significant corrosion following the grain boundaries is observed, suggesting intergranular corrosion. This is in contrast to MA 754 which appears to corrode more uniformly over the entire surface, Figure 4-17b, although short intrusion were found, Fig. 4-16a. Intergranular corrosion can lead to relatively high corrosion rates. Intergranular corrosion has already penetrated $\sim 22$ microns into the base metal in just 175 hours. Further intergranular corrosion may cause large pieces of base metal to fall out, resulting in a sudden increase in the corrosion rate. Therefore, it is extremely important to perform long term exposures on this material to fully elucidate the long term corrosion behavior of I-617. 
a)

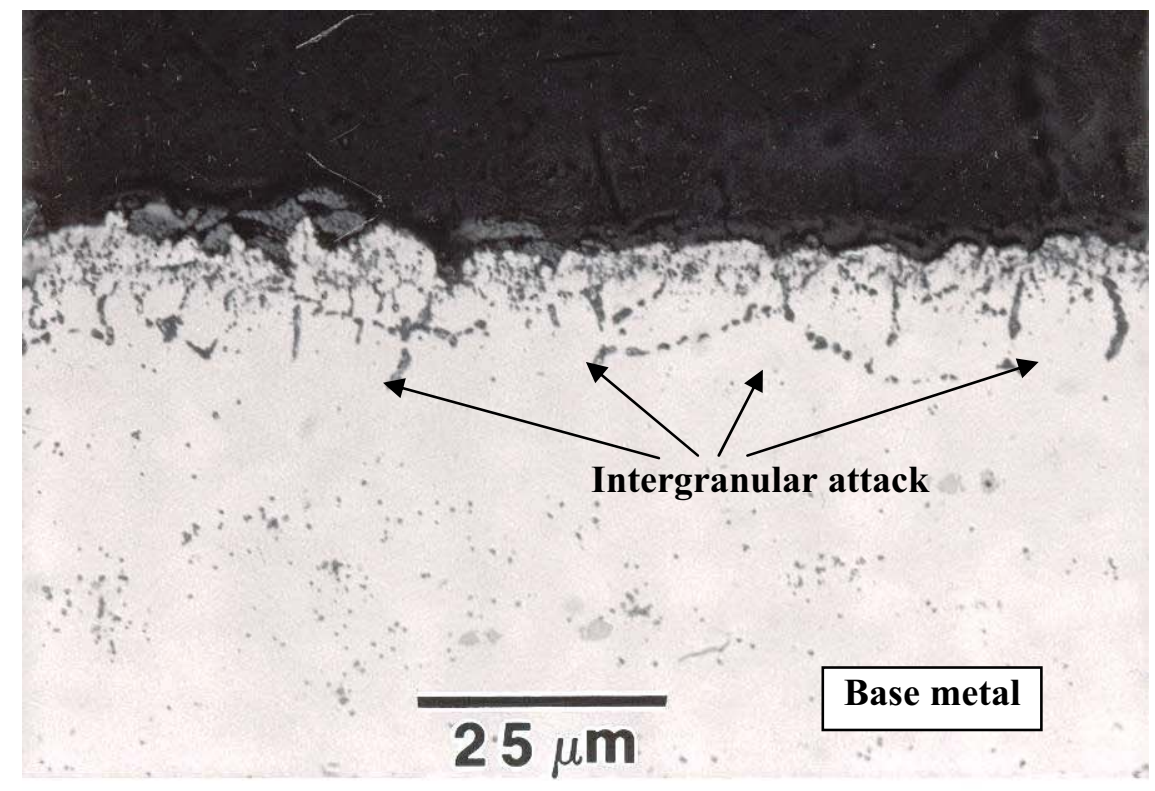

b)

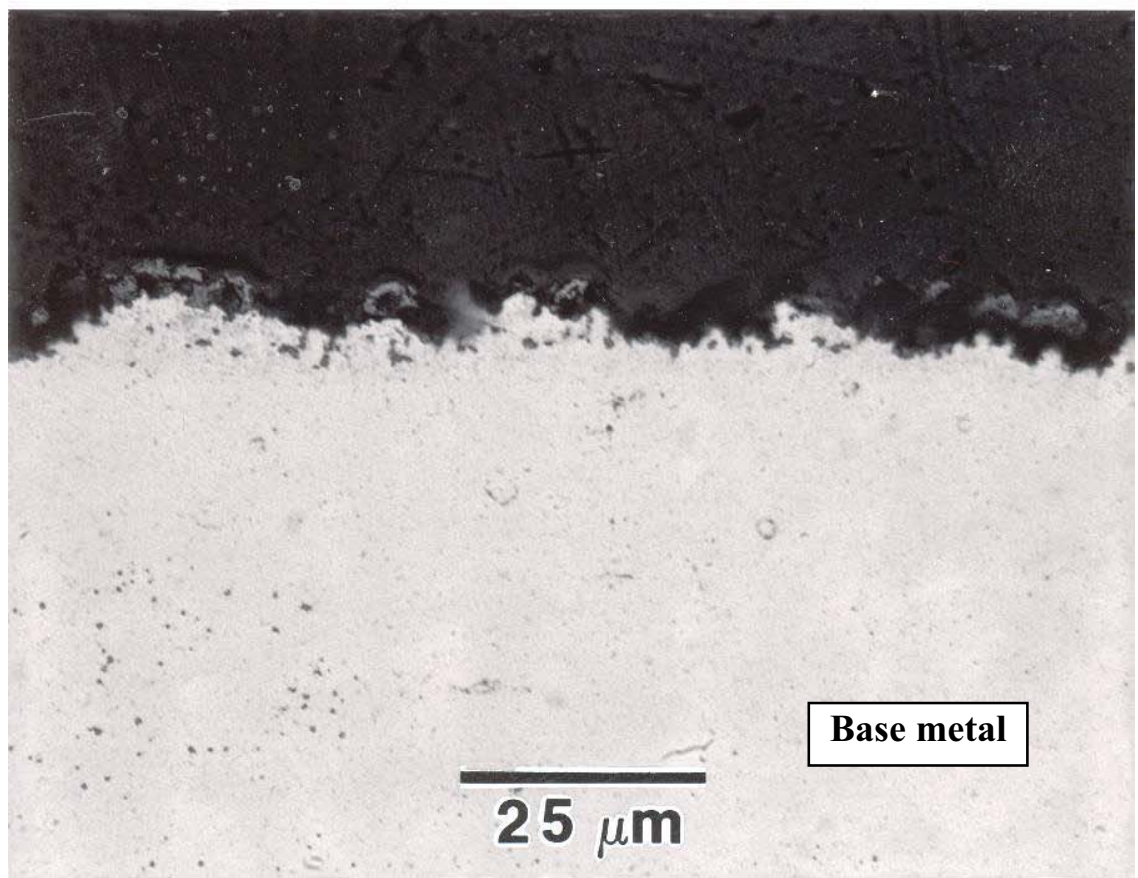

Figure 4-17. Cross section through samples, a) I-617 and b) MA 754, exposed to supercritical $\mathrm{CO}_{2}$ at $1000^{\circ} \mathrm{C}$ for 175 hours. I-617 shows intergranular attack which is absent from the MA 754 sample. 


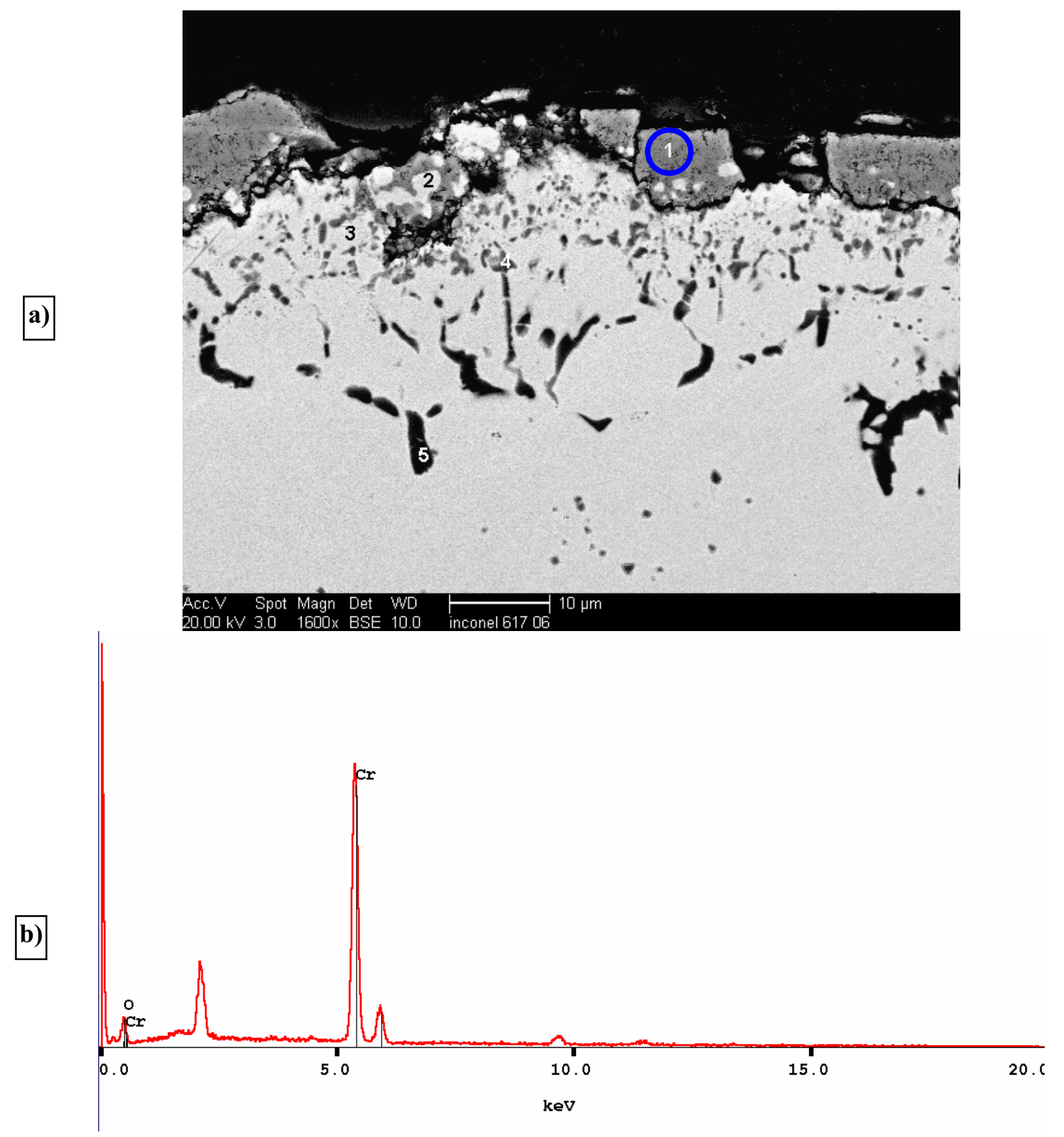

Figure 4-18. The corrosion product at spot 1 (blue circle in a)) that forms on I-617 in supercritical $\mathrm{CO}_{2}$ at $1000^{\circ} \mathrm{C}$ is composed mainly of chromium oxide as shown by the EDS spectra in b). (The unidentified peaks are from a conductive gold coating applied after exposure.)

EDS chemical analysis was used to get a qualitative composition of the corrosion products in Figure 4-17a. Chemical analysis of the corroded intergranular areas was performed on the SEM. Figures 4-18a \& 4-18b shows the areas of analysis and the EDS spectra obtained from spot 1, respectively. It is evident from Fig. $4-18 \mathrm{~b}$ that the corrosion product is composed exclusively of chromium oxide. (The rather large unidentified peaks correspond to gold which was used to coat the sample to make the corrosion products more conductive and enable SEM to be performed.) Again, chromium oxide is the only thermodynamically stable corrosion product at $1000^{\circ} \mathrm{C}$. (It should be pointed out that many forms of 
molybdenum oxide exist but most are either liquid or gaseous at $1000^{\circ} \mathrm{C}$, allowing their migration to cooler regions of the containment tube. They, therefore, may not be present in this sample which was in the hot zone of the furnace.)

Summary and Conclusions on the Corrosion Behavior of I-617 in Supercritical $\mathrm{CO}_{2}-$ At short exposure times I-617 exhibits a corrosion rate lower than that of either coarse- or fine-grained MA 754. The tightly adhering corrosion product appears to be composed mainly of chromium oxide which is thermodynamically stable at $1000^{\circ} \mathrm{C}$ in the presence of $\mathrm{CO}_{2}$. However, unlike MA 754, significant intergranular corrosion is observed in I-617 even at relatively short exposure times. Longer exposures may result in large pieces falling out of the surface and a breakdown in the protective aspect of the corrosion layer, allowing rapid corrosion. Although nothing in this study would suggest that this alloy is unfit for service in a supercritical $\mathrm{CO}_{2}$ Brayton cycle, it is imperative that long term corrosion studies be carried out to fully document the corrosion behavior of I-617 in supercritical $\mathrm{CO}_{2}$ at temperatures approaching $1000^{\circ} \mathrm{C}$. 


\section{SUMMARY AND CONCLUSIONS}

Key accomplishments from this three year program are highlighted in this section. Note that these accomplishments include items required to meet task objectives outlined in the original proposal for this project and items that meet the overall NERI objectives. As indicated in the Executive Summary we performed extra task which was not included in the original proposal, that is Power Conversion Unit of VHTR Coupled to Hydrogen Plant in Section 2.4.

Task 1: The objective of this task involves the development of $\mathrm{S}-\mathrm{CO}_{2}$ Brayton cycle. Five sub-tasks involve the mathematical derivation of the turbine and compressor efficiency for real expansion and compression, check of S- $\mathrm{CO}_{2}$ thermal and transport properties with NIST database and a number of equations of state, the selection of the optimization computer code, the optimized $\mathrm{S}-\mathrm{CO}_{2}$ cycle, and performance of the baseline calculations.

The task summaries are :

- $\quad$ The Soave equation of state in HYSYS in Aspen Plus gives good agreement of thermal properties compared with NIST database.

- $\quad$ We used both HYSYS and Aspen Plus cods to simulate the PBR reference design and the results are close with a small difference. HYSYS was selected for this project because HYSYS has the capability to model polytropic expansion and compression as opposed to Aspen Plus which is limited to isentropic expansion and compression.

- The HYSYS $\mathrm{CO}_{2}$ Brayton cycle model gives a 51\% plant efficiency, which is an improvement over the $47 \%$ for the helium Brayton cycle using the same BOP layout. The improvement in efficiency is attributed to the reduced volumetric flow of $\mathrm{CO}_{2}$ over that of helium, which results in less compression work.

Task 2: The objective of this task is to determine and improve the overall cycle efficiency. In order to accomplish this task, we investigated the parametric study of the effect of each parameter on the overall cycle efficiency.

- We checked the discharge temperature at the exit of a polytropic expansion and compression using pressure-enthalpy data of $\mathrm{S}-\mathrm{CO}_{2}$ from the NIST database and compared with that from HYSYS calculation. They agree well.

- $\quad$ As part of validation and verification, we used the GHTH 300 reference design to compare results from HYSYS. They agree well.

- $\quad$ For the task 2-4, $\mathrm{CO}_{2}$ proved to be the best working fluid in terms of efficiency, with an efficiency of $48.76 \%$. Helium had an efficiency of $47.76 \%$ and the nitrogen-helium mixture had an efficiency of $47.24 \%$.

- $\quad$ For the task 2-4, the turbomachinery work using $\mathrm{CO}_{2}$ was approximately $8.5 \%$ lower than the work when using helium and the mixture. $\mathrm{CO}_{2}$ also produced the smallest total heat exchanger volume which was $10 \%$ lower than the volume when using the nitrogen-helium mixture and $11 \%$ lower than the volume when using helium.

- $\quad$ For the task 2-4, parametric studies demonstrated that the working fluids were equally affected by the working conditions within the cycle, except helium was less affected by pressure. The pressure study also highlighted that the combined cycle was not greatly effected by the pressure. Therefore, lower pressures could be used in the system to decrease component sizes with a small decrease in efficiency. The cycle was also the least affected as compared to the three-shaft and reheated cycles. 
Task 3: The objective of this task was to explore the high temperature creep and corrosion behaviors of high temperature alloys under conditions expected in the supercritical $\mathrm{CO}_{2}$ Brayton cycle. Alloys MA 754, an oxide dispersion strengthened nickel-based alloy, and I-617, a solid solution nickelbase alloy, were chosen for evaluation. The following was found:

- $\quad$ Coarse-grained MA 754 possesses superior high temperature strength and creep resistance $(\sim 2 \mathrm{x})$ compared to other high temperature alloys such as I-617

- $\quad$ Fine-grained MA 754 exhibits better ductility but lower yield strength than coarse-grained MA 754 at temperature above $800^{\circ} \mathrm{C}$.

- $\quad$ Both fine- and coarse-grained MA 754 exhibit very low ductility in creep, generally less than 5\%, in the transverse orientation.

- $\quad$ Use of MA 754 as a pressure boundary material at high temperatures is desirable from a strength point-of-view, however, it is not from a fracture point-of-view due to the low creep ductility.

- A corrosion rate of $0.2 \mathrm{~mm} /$ year was measured for coarse-grained MA 754 after an exposure of 500 hours in supercritical $\mathrm{CO}_{2}$ at $1000^{\circ} \mathrm{C}$ and $7 \mathrm{MPa}$. This appears to still be a transient value and longer exposures are required to establish the steady-state corrosion rate and evaluate the potential for spalling and metal dusting.

- $\quad$ The corrosion product that forms on MA 754 in high temperature, supercritical $\mathrm{CO}_{2}$ is predominately chromium oxide.

- Alloy I-617 exhibits a corrosion rate approximately 5 times lower than MA 754 in supercritical $\mathrm{CO}_{2}$ at $1000^{\circ} \mathrm{C}$ and $7 \mathrm{MPa}$ at short exposure time ( 175 hours). However, I-617 exhibits intergranular corrosion, while MA 754 does not, which may lead to very high corrosion rates at long exposure times.

- $\quad$ Long term ( $\geq 1000$ hours) supercritical $\mathrm{CO}_{2}$ exposures at $1000^{\circ} \mathrm{C}$ and $7 \mathrm{MPa}$ will be required to fully characterize the corrosion behaviors of MA 754 and I-617. 


\section{REFERENCES}

Artz, E., 1994, in Mechanical Properties of Metallic Composites, S. Ochiai, editor, Marcel Dekker, New York, NY, pp. 205-223.

Aspen Plus User's Manual, 2001, Aspentech Company.

Chen, Y.L., Jones, A.R., Pond, R.C., Miller, U., 2002, "The Microstructure and Recrystallization of Flow-Formed Oxide Dispersion Strengthened Ferritic Alloy: Part II. Recrystallization Behavior", Metallurgical and Materials Transactions A, vol. 33A, pp. 3787-3794

Copsey, B. et al., 2004, "The Framatome ANP Indirect-Cycle Very High Temperature Reactor," Proceedings of ICAPP'04, Pittsburgh, PA, June 13-17, 2004.

Davis, C., C.H. Oh, R. Barner, S. Sherman and D. Wilson, 2005, Thermal-Hydraulic Analyses of Heat Transfer Fluid Requirements and Characteristics for Coupling A Hydrogen Production Plant to a High-Temperature Nuclear Reactor, INL/EXT-05-00453, June 2005.

Dieter, G.E., 1986, Mechanical Metallurgy, $3^{\text {rd }}$ Edition, McGraw-Hill, New York, NY

Dostal, V, M.J. Driscoll, P. Hejzlar, 2004,A Supercritical Carbon Dioxide Cycle for Next Generation Nuclear Reactors, March 10, 2004, MIT-ANP-TR-100.

Flinn, J.E., Field, D.P., Korth, G.E., Lillo, T.M., Macheret, J., 2001, “The Flow Stress Behavior of OFHC Polycrystalline Copper", Acta Mater., 49, pp. 2065-2074

Gregory, J.K., Gibeling, J.C., Nix, W.D., 1985, Metallurgical and Materials Transactions A, vol. 16A, pp. $777-787$

Forsberg, C.W, P.F. Peterson, and L. Ott, 2004, "The Advanced High-Temperature Reactor for Producing Hydrogen to Manufacture Liquid Fuels," ANES Paper, Miami Beach, FL., 2004.

GPSA Data Book, 2003, $11^{\text {th }}$ Edition GPSA Engineering Data Book, Section 13.

Generation IV Roadmap, 2001, Description and Evaluation of Candidate gas-Cooled reactor Systems, TWG-2, Summary Prt XR01-03, December 19, 2001.

Gilli, R., K. Krueger, and W. Dering, 1975, "The AVR-reactor-a contribution to the development of the HTR, Transactions of the American Nuclear Society, Vol. 20.

Hu, S. et al., 2004, "Power Operation Commissioning Tests of HTR-10, Proceedings of the Conference on High Temperature Reactors, Beijing, China, September 22-24, 2004.

HYSYS User's Manual V.2.2.2, 2001, Aspentech Company.

IAEA, 1984, Status of and Prospects for gas-Cooled Reactors, Technical Reports series No. 235.

Idaho National Engineering and Environmental Laboratory and Massachusetts Institute of Technology, 1999, Strategic Nuclear Research Collaboration: FY-99 Annual Report, INEEL/EXT-99-00649, July 1999. 
INEEL, 2005, Design Features and Technology Uncertainties for the Next generation Nuclear Plant, INEEL/EXT-04-01816, June 30, 2004.

INEEL, 2005, RELAP5-3D ${ }^{\odot}$ Code Manual, INEEL-EXT-98-00834, Revision 2.3, April 2005.

Ingersoll, D et. al., "Status of Preconceptual design of the Advanced High-Temperature Reactor", ORNL/TM-2004/104, May, 2004.

Knapp H., 1989, Vapor-Liquid Equilibria for Mixtures of Low Boiling Substances, Chemistry Data Series, Vol. VI, DECHEMA.

Kumar, M.A, King, W.E., Schwarz, A.J., 2000, "Modifications to the Microstructural Topology in F.C.C. Materials Through Thermomechanical Processing", Acta Mater., 48, pp. 2081-2091

Malu, M., Tien, J.K., 1975, “The Elastic Modulus Correction Term in Creep Activation Energies: Applied to Oxide Dispersion Strengthened Superalloy", Scripta Metallurgica, 9, pp. 1117-1120

Nicholls, D., 2001, “The Modular Pebble Bed Reactor,” Nuclear News, September 2001, pp.35-40, September 2001.

NIST, 2002, NIST Reference Fluid Thermodynamic and Transport Properties

Database(REFPROP):Version 7.0.

Oh, C.H. and R. Moore, 2003, "Enhancement of the Thermal Efficiency for High Temperature GasCooled Reactors," the $10^{\text {th }}$ International Topical Meeting on Nuclear Reactor Thermal Hydraulics (NURETH-10), Seoul, Korea, October 5-9, 2003.

Oh, C.H. and R. Moore, 2004, "Parametric Investigation of Brayton Cycle for High Temperature GasCooled Reactors," Proceedings of 2004 ASME Heat Transfer/Fluids Engineering Summer Conference, Charlotte, North Carolina, July 11-15, 2004.

Oh, C.H., R. Moore, and C. Davis, 2005, "Power Conversion Study for High Temperature Gas-Cooled Reactors," Proceedings of ICAPP '05, Seoul, Korea, May 15-19, 2005.

Oh, C.H., R. Barner, C. Davis, and S. Sherman, 2006, "Evaluation of Working Fluids in an Indirect Combined Cycle in a Very High Temperature Gas-Cooled Reactor," submitted and accepted at Nuclear Technology, 2006.

Oh, C.H, C. Davis, S. Sherman, and R. Barner, "Thermal Hydraulic Analysis of HTGR Coupled with Hydrogen Plant," submitted and accepted at ANS National Meeting, Reno, June, 2006.

Oh, C.H. and R. Barner, "Effects of Interstage Cooling on Brayton Cycle Efficiency," submitted and accepted at ANS National Meeting, Reno, June, 2006.

Oh, C.H, R. Barner, C. Davis, S. Sherman, and P. Pickard, 2006, "Thermal Hydraulic Analysis for Coupling High Temperature Gas-Cooled Reactor to Hydrogen Plant," submitted and accepted at International Heat Transfer Conference in Sydney, Australia, August, 2006.

Peng, D.Y and D.B. Robison, 1976, “A Two Constant Equation of State,” I.E.C. Fundamentals, 15, 1976, pp.59-64. 
Perry, R., D. Green, and J. Maloney, 1984, Perry's Chemical Engineer's Handbook, Sixth Edition, McGraw-Hill.

Peterson, P.F., 2003, "Multiple-Reheat Brayton Cycles for Nuclear Power Conversion with Molten Salt," Nuclear Technology, vol. 144, December 2003.

Reid, R.C., J.M. Prausnitz, and T.K. Sherwood, 1977, The Properties of Gases and Liquids, Fourth Edition, McGraw-Hill Book Company, New York.

Reid, R.C., J.M. Prausnitz, and B.E. Poling, 1987, The Properties of Gases and Liquids, Third Edition, McGraw-Hill Book Company, New York.

Rivken, S.L, 1988, Thermodynamic Properties of Gases, Fourth Edition (Revised), Hemisphere Publishing Corporation.

Schleifenheimer, K., 1970, "Steady-state, transient and start-up properties of the AVR experimental power station," Proceedings of a symposium on the performance of nuclear power reactor components. HMSO, London, UK.

Smith, C., S. Beck, and B. Galyean, 2005, An Engineering Analysis for Separation Requirements of a Hydrogen Production Plant and High-Temperature Nuclear Reactor, INL/EXT-05-00137 Rev 0, March.

Sochet, I., J. L. Rouyer, and P. Hemmerich, 2004, "Safe Hydrogen Generation by Nuclear HTR, Paper 4261,” Proceedings of ICAPP '04, Pittsburgh, PA, USA, June 13-17.

Special Metals Corporation, 2005, Technical Datasheet: Inconel Alloy 617, SMC - 029

Special Metals Corporation, 2002, Technical Datasheet: $M A$ 754, SMC - 040

Totemeier, T.C. and Lillo, T.M, 2005, "Effect of Orientation on the Tensile and Creep Properties of Coarse-Grained INCONEL Alloy MA754”, Metallurgical and Materials Trans. A, vol. 36A, pp. 785-795.

Totemeier, T.C. Lillo, T.M. and Simpson, J. A, 2005, "Elevated Temperature Strength of Fine Grained INCONEL Alloy MA754”, Metallurgical and Materials Trans. A, vol. 36A, pp. 2552-2555.

Wang, C., 2003, Design, Analysis and Optimization of the Power Conversion System for the Modular Pebble Bed Reactor System, MIT Ph.D. Thesis.

Yan et al., 2003, "Cost and Performance Design Approach for GTHTR300 Power Conversion System," Nuclear Eng. \& Des., 226, pp.351-373.

Zierman, E., "The AVR nuclear power facility-progress report, Nuclear Engineering \& Design, Vol.78, No.2, 1984. 